Florida International University

FIU Digital Commons

5-6-2019

\title{
The Relationship of a Novel Marker of Inflammation (Neutrophil- to-Lymphocyte Ratio) to Nutritional Status, Diet and Clinical Outcomes in Hemodialysis Patients
}

Janet Diaz Martinez

jmart556@fiu.edu

Follow this and additional works at: https://digitalcommons.fiu.edu/etd

Part of the Human and Clinical Nutrition Commons, Nutritional Epidemiology Commons, and the Other Nutrition Commons

\section{Recommended Citation}

Diaz Martinez, Janet, "The Relationship of a Novel Marker of Inflammation (Neutrophil-to-Lymphocyte Ratio) to Nutritional Status, Diet and Clinical Outcomes in Hemodialysis Patients" (2019). FIU Electronic Theses and Dissertations. 4276.

https://digitalcommons.fiu.edu/etd/4276

This work is brought to you for free and open access by the University Graduate School at FIU Digital Commons. It has been accepted for inclusion in FIU Electronic Theses and Dissertations by an authorized administrator of FIU Digital Commons. For more information, please contact dcc@fiu.edu. 


\section{FLORIDA INTERNATIONAL UNIVERSITY}

Miami, Florida

THE RELATIONSHIP OF A NOVEL MARKER OF INFLAMMATION

(NEUTROPHIL-TO-LYMPHOCYTE RATIO) TO NUTRITIONAL STATUS, DIET

AND CLINICAL OUTCOMES IN HEMODIALYSIS PATIENTS

A dissertation submitted in partial fulfillment of

the requirements for the degree of

DOCTOR OF PHILOSOPHY

in

DIETETICS AND NUTRITON

by

Janet Diaz Martinez 
To: Dean Tomas Guilarte

R. Stempel College of Public Health and Social Work

This dissertation, written by Janet Diaz Martinez, and entitled The Relationship of a Novel Marker of Inflammation (Neutrophil-to-Lymphocyte Ratio) to Nutritional Status, Diet and Clinical Outcomes in Hemodialysis Patients, having been approved in respect to style and intellectual content, is referred to you for judgment.

We have read this dissertation and recommend that it be approved

$\begin{array}{r}\hline \text { Marianna K. Baum } \\ \hline \text { Fatma G. Huffman } \\ \hline \text { Florence George } \\ \hline \text { Adriana Campa, Major Professor }\end{array}$

Date of Defense: May 6, 2019

The dissertation by Janet Diaz Martinez is approved.

Dean Tomás Guilarte R. Stempel College of Public Health and Social Work

Andrés G. Gil Vice President for Research and Economic Development and Dean of the University Graduate School

Florida International University, 2019 


\section{DEDICATION}

First I recognize my children, the essence of my life, for their constant support, patience and love: Ana Karla, Janet, Carlos and Ana Sofia. I hope to inspire them to always believe in the power of knowledge.

To my roots: my parents and grandmother, Eucaris, Carlos and Lucy, whose unconditional love and sacrifice fed my life and career.

And to my husband, Friedman, whose support makes me feel valued and respected. 


\section{ACKNOWLEDGMENTS}

This dissertation would not have been possible without the active participation of my professors: Dr. Marianna Baum, her brilliant and sagacious ideas have illuminated this research since the very beginning; Dr. Fatma Huffman, her career commitment to her students and to the art of teaching nourished this project to completion; Dr. Florence George, who is the friendliest statistics expert wanted by any Ph.D. student, her frequent advice was key to translating numbers into findings. In addition, I am very grateful to Dr. Ivan Delgado-Enciso of the University of Colima, Mexico for his collaboration, advice and research partnership.

My gratitude and acknowledgement for my Major Professor, my mentor, my inspiration, my role model, Dr. Adriana Campa, is infinite. She laid the foundations for my career development and gave me her support since I entered our Department of Dietetics and Nutrition with the dream of becoming a dietitian. She was inspiring and in everything she did she showed integrity, commitment and greatness. She unselfishly invested time and energy in this ambitious project, leaving an indelible footprint in my life, and wherever I may go from here, I shall forever be her proud pupil.

Special thanks to Julia Gonzalez, who has a magic touch for student guidance. She was always gracious, timely, and never stopped smiling, even on the busiest days, and to Laurie Holmes, whose logistic and coordination efforts make a difference in all our academic events. I am also very grateful to the Caridad Clinic Center, and especially to Jetsabel Maisonet for connecting me to the community served by the Clinic. 
I need to especially recognize all my DaVita Tamarac dialysis patients for their encouragement and trust, and for allowing me to be their dietitian; as well as to my all dear teammates, for being patient and supportive.

I am grateful to my fellow doctoral student friends, for bringing laughs and joy to my life. Finally, I would like to extend my acknowledgment to the CV Start Scholarship awards for providing funding to complete my research study and expanding my connections with my Hispanic community, which I am committed to serve until the end of my career. 
ABSTRACT OF THE DISSERTATION

THE RELATIONSHIP OF A NOVEL MARKER OF INFLAMMATION

(NEUTROPHIL-TO-LYMPHOCYTE RATIO) TO NUTRITIONAL STATUS, DIET

AND CLINICAL OUTCOMES IN HEMODIALYSIS PATIENTS

by

Janet Diaz Martinez

Florida International University, 2019

Miami, Florida

Professor Adriana Campa, Major Professor

The aim of this dissertation was to examine prospectively the relationship of a novel marker of inflammation (neutrophil-to-lymphocyte ratio) with nutrition markers, diet and clinical outcomes in a cohort study that included 77 patients from one hemodialysis (HD) center located in South Florida. Demographics and clinical parameters were obtained from patients' medical charts. Nutritional status was determined at baseline, six and 12 months using the Malnutrition Inflammation Score (MIS) and the 7-point Subjective Global Assessment (SGA) scale consisting of two categories: medical history and physical examination. Dietary assessments were performed, and 24-hour diet recalls were collected at each assessment visit.

Neutrophil-to-Lymphocyte Ratio (NLR) at baseline was associated with nutritional markers (albumin and body mass index) and was a predictor of hospitalizations only for diabetics $(\mathrm{HR}=0.27,95 \% \mathrm{CI} 0.07-0.96, \mathrm{P}=0.044)$. Participants with moderate-to-severe malnutrition based on SGA had a 2.67 higher risk for hospitalization events. MIS $>5$ was associated with hospitalization $(\mathrm{HR}=2.11,95 \%$ 
$\mathrm{CI}: 1.12-3.97, \mathrm{P}=0.019)$ and with mortality $(\mathrm{HR}=13.87,95 \% \mathrm{CI}: 1.56-123.045, \mathrm{P}=0.018)$ even after adjustments.

Meeting energy recommendations reduced the chances of hospitalization by $59 \%$ $(\mathrm{HR}=0.4195 \% \mathrm{CI}: 0.21-0.79, \mathrm{P}=0.008)$, and mortality was reduced by $81 \%(\mathrm{HR}=0.19$, 95\% CI:0.03-0.98, $\mathrm{P}=0.049)$. The intake of two or more fruit servings per day was associated with lowering mortality risk by $75 \%(\mathrm{HR}=0.246,95 \% \mathrm{CI}: 0.069-0.880$, $\mathrm{P}=0.031$ ); and intake of at least 7 grams of cereal fiber per day lowered mortality risk by $81 \%(\mathrm{HR}=0.187 ; 95.0 \% \mathrm{CI}: 0.05-0.693, \mathrm{P}=0.012)$

Our findings support the use of NLR, an inexpensive and convenient inflammation marker, as strong predictor of outcomes in hemodialysis patients, and provide preliminary data on the protective effect that a low NLR might have on the risk of hospitalizations in HD patients. Our study also provided observational evidence for nutrition interventions that aim at improving nutrition-inflammation status and promoting adequate energy, protein and fiber intakes in patients living with hemodialysis. 


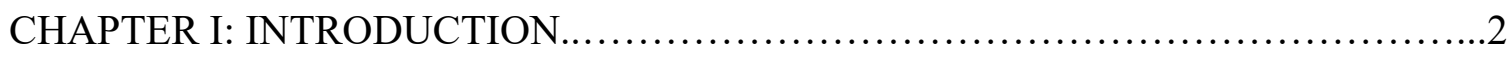

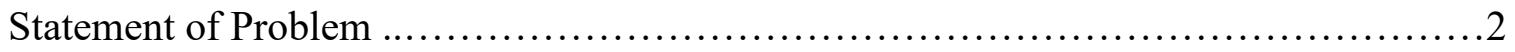

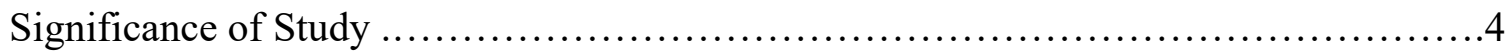

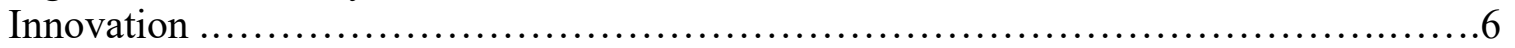

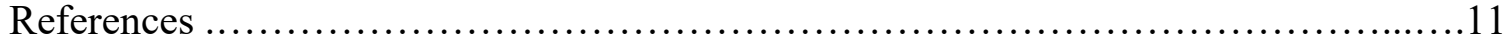

CHAPTER II: LITERATURE REVIEW .........................................13

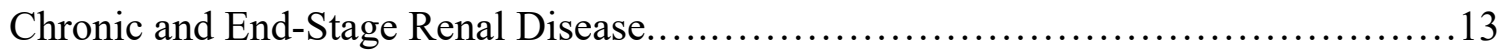

Nutritional status of patients living with CKD and ESRD ...........................14

Assessment of nutritional status in hemodialysis patients............................15

The impact of inadequate nutritional status of patients with CKD-ESRD on morbidity

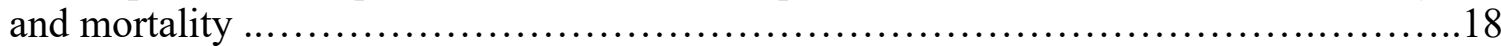

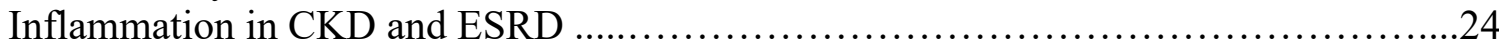

Neutrophil-to-lymphocyte ratio (NLR) as a useful marker of inflammation and

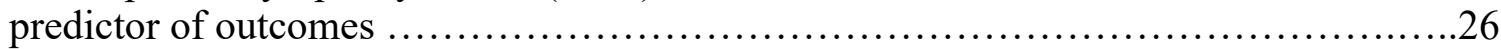

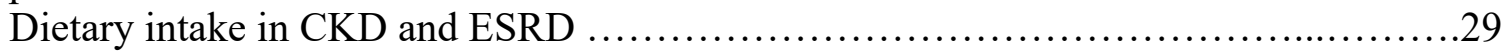

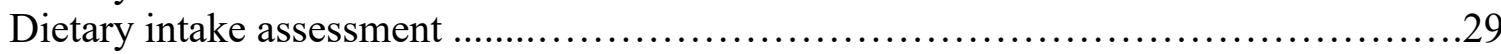

Impact of quantitative nutrition deficiencies in outcomes of CKD-ESRD patients ........32

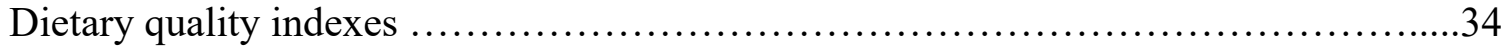

The Alternative Healthy Eating Index (AHEI) .....................................35 Consequences of qualitative deficiencies in nutritional intake in CKD-ESRD patients.. 36

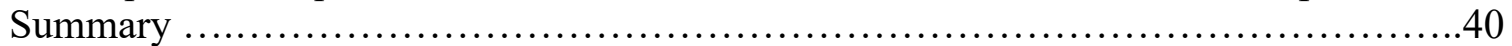

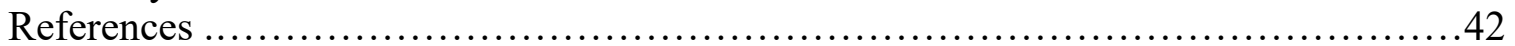

CHAPTER III: ASSOCIATION BETWEEN NEUTROPHIL-TO-LYMPHOCYTE RATIO, NUTRITION PARAMETERS AND HEALTH OUTCOMES IN HEMODIALYSIS PATIENTS .................................................. 51

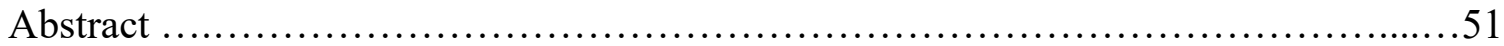

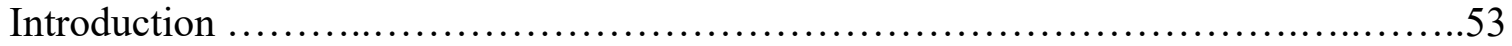

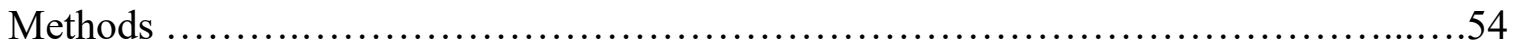

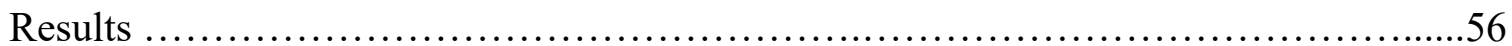

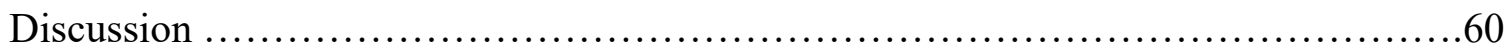

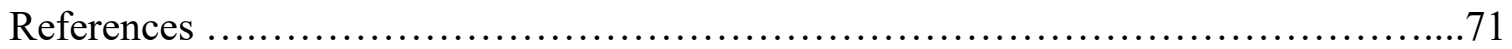

CHAPTER IV: NUTRITIONAL STATUS AND DIETARY INTAKE AS PREDICTORS OF POOR OUTCOMES IN HEMODIALYSIS PATIENT ...............74

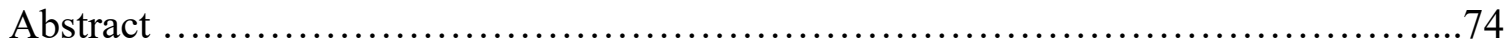

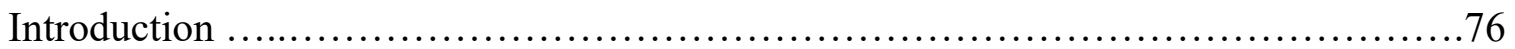

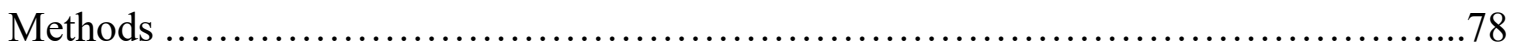

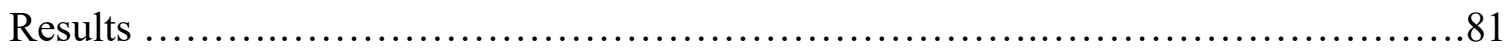

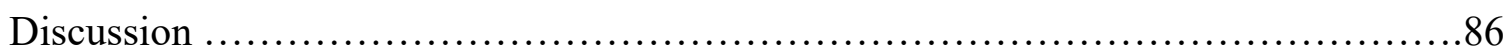

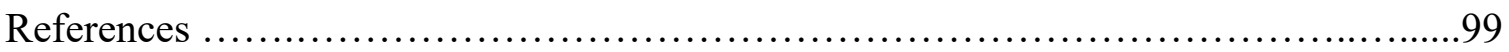


CHAPTER V: DIET QUALITY AS A PREDICTOR OF POOR OUTCOMES IN HEMODIALYSIS PATIENTS AND ITS RELATIONSHIP WITH

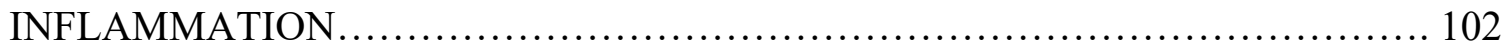

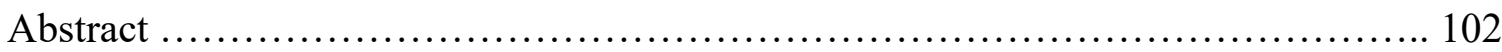

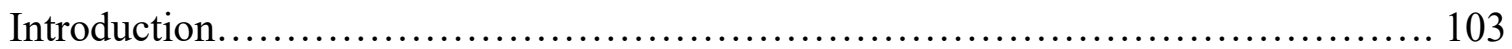

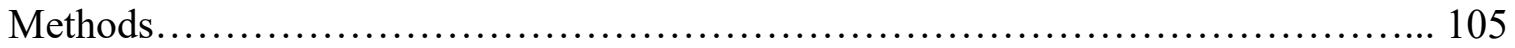

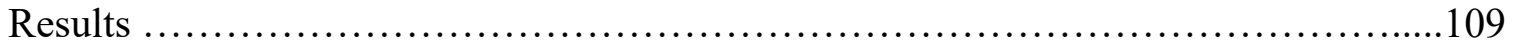

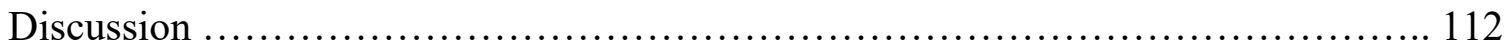

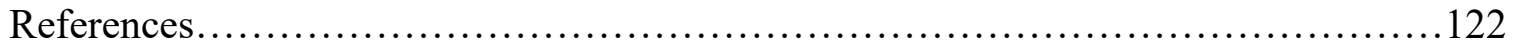

CHAPTER VI: SUMMARY OF CONCLUSIONS AND IMPACT ON PRACTICE...125

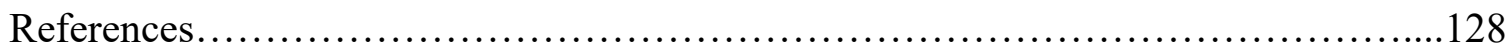

CHAPTER VII: STRENGTHS AND LIMITATIONS...........................130

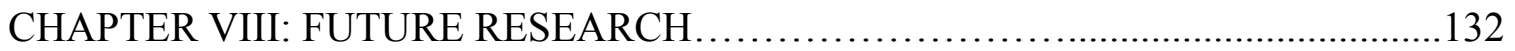

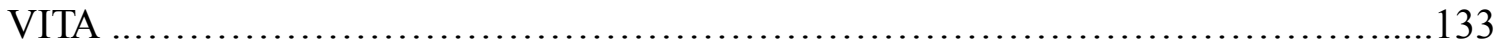




\section{LIST OF THE TABLES}

TABLES

PAGE

CHAPTER I

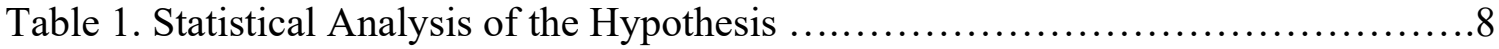

CHAPTER III

Table 1. Baseline characteristics of the overall participants and comparing participants grouped into NLR quartiles

Table 2. Table of characteristic comparing not hospitalized versus hospitalized.

Table 3. Multivariate Cox regression model for all-cause of hospitalization in all participants .68

Table 4. Multivariate Cox regression model for all-cause of hospitalization in diabetic and non-diabetic patients.

CHAPTER IV

Table 1. Classification of participants in well-nourished and moderate-to-severe malnourished (year average) by nutrition assessment tools.

Table 2. Table of characteristic comparing not hospitalized versus hospitalized and survivors versus non-survivors .................................................92

Table 3. Multivariate Cox regression models analyzing SGA (year-average) for mortality and hospitalizations.

Table 4. Multivariate Cox regression models analyzing MIS (year-average) for mortality and hospitalizations.

Table 5. Multivariate Cox regression models analyzing participants that met

KDOQI/energy recommendations for mortality and hospitalizations....

Table 6. Multivariate Cox regression models analyzing participants that met

$\mathrm{KDOQI} /$ protein recommendations for mortality and hospitalizations

\section{CHAPTER V}

Table 1. Cohort's demographics characteristics and 12 month-endpoints.

Table 2. Comparing diet components between survivors versus non-survivors and hospitalized versus non-hospitalized.

Table 3. Multivariate Cox regression model analyzing Fruit intake for mortality and hospitalizations

Table 4. Multivariable Cox regression analysis analyzing Cereal-fiber intake for mortality and hospitalizations

Table 5. Comparing AHEI total score and its components between hospitalized versus not-hospitalized and survivors versus non-survivors.

Table 6. Total AHEI score, sub-scores and diet components by comparing participants grouped into NLR quartiles.

Table 7. Total AHEI score, sub-scores and diet components by comparing participants in the lowest quartile of inflammation versus the rest. 


\section{LIST OF FIGURES}

FIGURES

PAGE

CHAPTER III

Figure A. Kaplan-Meier estimates of mortality for overall participants.................70

Figure B. Kaplan-Meier estimates of hospitalization for overall participants................70

Figure C. Kaplan-Meier estimates of hospitalization for participants

with diabetes.................................................................... 71

\section{CHAPTER IV}

Figure A. Kaplan-Meier curve for Mortality and SGA (year average).................97

Figure B. Kaplan-Meier curve for Hospitalization and SGA (year average)..............97

Figure C. Kaplan-Meier curve for Mortality and MIS (year average) ..................98

Figure D. Kaplan-Meier curve for Hospitalization and MIS (year average).............98

Figure E. Kaplan-Meier curve for Mortality and energy intake.........................99

Figure F. Kaplan-Meier curve for Hospitalization and energy intake....................99 
THE RELATIONSHIP OF A NOVEL MARKER OF INFLAMMATION (NEUTROPHIL-TO-LYMPHOCYTE RATIO) TO NUTRITIONAL STATUS, DIET AND CLINICAL OUTCOMES IN HEMODIALYSIS PATIENTS 


\section{CHAPTER I: INTRODUCTION}

\section{Statement of Problem}

The United States Renal Data System (USRDS) reported in its 2018 Annual Data Report that in 2016 there were more than 720,000 patients afflicted by end stage renal disease (ESRD) in the country and the number of prevalent cases rises by about 20,000 per year. ${ }^{1}$ Over two-thirds of patients with ESRD who are receiving dialysis have been hospitalized annually, experiencing an average of nearly two hospital admissions and a $20-25 \%$ mortality rate per year, ${ }^{1}$ and a 5 -year survival rate of $35 \%$. For these patients, cardiovascular and infective diseases account for approximately $50 \%$ and $20 \%$ of deaths respectively. ${ }^{1}$

Malnutrition also bestows a considerable socioeconomic challenge in today's U.S. hemodialysis healthcare settings, with an estimated prevalence from approximately $20 \%$ to over $90 \%$, depending on the assessment tool been used. ${ }^{2}$ Large epidemiological studies have evidently demonstrated a significant relationship between malnutrition and mortality in patients with renal failure ${ }^{3-5}$ For example, the Netherlands Cooperative Study on Chronic Kidney Disease ${ }^{4}$ and the Dialysis Outcome and Practice Study (DOPPS $)^{5}$ both revealed that malnourished patients had higher mortality risk when compared to those who had adequate nutrition status. ${ }^{4,5}$ Furthermore, nutrition parameters from anthropometrics, biochemical measurements, and daily dietary intake can strongly predict mortality. ${ }^{6,7}$

Patients receiving hemodialysis suffer from lack of appetite and energy, gastrointestinal impairment, fatigue, nutrient imbalances, emotional stress and other multiple comorbidities, which all can lead to malnutrition. ${ }^{7,8}$ These factors, however, 
cannot completely explain the signs of malnutrition seen in this population, and additional mechanisms have been studied to better understand the etiology of this phenomenon, including nutrient deficiencies, diet patterns and inflammation. ${ }^{8-10,14 .}$

The impact of inflammation, as a risk factor for malnutrition, has been recently recognized. ${ }^{11}$ Multiple markers of inflammation have been shown to be strongly associated with adverse clinical outcomes and nutrition parameters in the hemodialysis population. ${ }^{12-14}$ Therefore, chronic inflammation may be a crucial factor that causally links malnutrition to increased morbidity and mortality among dialysis patients. ${ }^{14}$ Although there are many studies that have investigated specific nutrient intakes of hemodialysis patients, ${ }^{15-17}$ there is limited information evaluating overall diet quality using diet quality indices and correlating them with outcomes in hemodialysis patients, including inflammation. This potential relationship warrants further investigation, as the acting mechanisms are not clearly delineated.

This study proposes to examine major contributors to adequate nutritional status in hemodialysis patients by examining their dietary quantitative and qualitative intake and the relationships with a novel marker of inflammation and with dialysis outcomes. If a relationship is uncovered, it will provide new tools for medical professionals to alleviate and prevent the damage that chronic inflammation inflicts on these patients, and that may be linked to malnutrition, mortality and hospitalizations. To the best of our knowledge, this is the first prospective study to examine the association between a novel biomarker of inflammation (NLR) with diet quality, diet quantity and dialysis outcomes in patients receiving maintenance hemodialysis. 
Moreover, promoting and facilitating healthy diet patterns that increase the overall nutritional quality of the diet could be an effective intervention to reduce hospitalizations and mortality and improve the well- being of people living with ESRD.

\section{Significance of Study}

Currently, over 400,000 patients are receiving hemodialysis in the United States and Medicare has been spending nearly $\$ 90,000$ per patient per year. ${ }^{1}$ The ultimate goal of receiving hemodialysis is to reverse the uremia associated with CKD stage 5, while minimizing complications and improving length and quality of life for these patients. Unfortunately, two-thirds of hemodialysis patients are hospitalized annually, experiencing an average of nearly two hospital admissions per year, ${ }^{1}$ which represents a significant financial burden for society and accounts for approximately $40 \%$ of total Medicare expenditures for dialysis patients. ${ }^{1}$ Compared to the general population, the mortality rate of these patients continues to be very high. ${ }^{1}$ Although malnutrition and proinflammatory states are very common among ESRD patients and are considered risk factors for mortality, they cannot totally explain the high rates of mortality and hospitalization of hemodialysis patients. The relationship between nutrition-inflammation status and hemodialysis patient's diet (quantity and quality) and their associations with mortality and hospitalization are not fully understood. If a relationship is indicated, it will provide new tools for medical professionals to identify, alleviate and prevent the damage that chronic inflammation inflicts on these patients, and that may be linked to adverse dialysis outcomes. 
The evidence from the literature generates to the following questions:

- Does the neutrophil-to lymphocyte ratio (NLR), as a marker of inflammation, has a prognostic value for hospitalization and mortality in hemodialysis patients? What are the NLR 's threshold levels that optimally distinguish non-inflamed versus inflamed patients?

- Which available assessment tool for HD patients, the Subjective Global Assessment (SGA) or the Malnutrition-Inflammation Score (MIS), is a more marker to detect protein energy wasting (PEW), and more strongly associated with dietary intake and dialysis outcomes?

- Are diet quality indices associated with the number of hospitalizations and deaths in this population?

- Is there a relationship between the components of the diet, NLR as a marker of inflammation and dialysis outcomes?

This study's aims were to examining major contributors to adequate nutritional status in hemodialysis patients by examining their inflammation status using a novel marker of inflammation NLR, an index of diet quality (AHEI) and quantity (food records), malnutrition scores (SGA and MIS) and the relationship of these markers with clinical outcomes (hospitalization events and mortality). 


\section{Innovation}

To the best of our knowledge, this is the first prospective study to examine the association of inflammation status, measured by NLR a novel marker of inflammation, with nutritional status, quality and quantity of dietary intake, hospitalization and mortality in patients receiving hemodialysis. A new immunological-based marker, NLR, constructed from accessible and inexpensive blood counts used for cancer patients and other conditions, is used for the first time in a cohort of hemodialysis participants to test its relationship with diet and nutrition status and its potential as a predictor of hospitalization and mortality.

\section{Specific Aims and Hypothesis}

\section{CHAPTER III: ASSOCIATION BETWEEN NEUTROPHIL-TO-LYMPHOCYTE RATIO, NUTRITION PARAMETERS AND HEALTH OUTCOMES IN HEMODIALYSIS PATIENTS}

Specific Aim 1: To investigate the relationship of inflammation with measures of nutritional status and health outcomes in patients undergoing hemodialysis over a oneyear period.

Hypothesis 1a: In patients undergoing hemodialysis, the presence of proinflammatory status (increased neutrophil-to-lymphocyte ratio) is associated with higher number of hospitalizations and deaths over a oneyear period.

Hypothesis $1 \boldsymbol{b}$ : In patients undergoing hemodialysis, the presence of proinflammatory status (increased neutrophil-to-lymphocyte ratio) is associated with poorer measures of nutritional status indicated by BMI, albumin, net protein catabolic rate, cross-sectionally and over a one-year period. 


\section{CHAPTER IV: NUTRITIONAL STATUS AND DIETARY INTAKE AS PREDICTORS OF POOR OUTCOMES IN HEMODIALYSIS PATIENTS}

Specific Aim 2: To assess the nutritional status by the Subjective Global Assessment (SGA) and malnutrition-inflammation score (MIS), dietary intake and to examine the relationship of these variables with health outcomes in patients undergoing hemodialysis over a one-year period.

Hypothesis 2a: In patients undergoing hemodialysis, the presence of malnutrition determined by MIS and SGA scores are associated with higher number of hospitalizations and deaths over a one-year period.

Hypothesis $2 \boldsymbol{b}$ : In patients undergoing hemodialysis, those meeting the renal dietary guidelines for protein and energy intake have lower number of hospitalizations and deaths over a one-year period compared with those who are not meeting renal dietary guidelines.

\section{CHAPTER V: DIET QUALITY AS PREDICTOR OF POOR OUTCOMES IN HEMODIALYSIS PATIENTS AND ITS RELATIONSHIP TO INFLAMMATION}

Specific Aim 3: To investigate the relationship of diet quality (AHEI) with inflammation and health outcomes in patients undergoing hemodialysis over a one-year period.

Hypothesis 3a: In patients undergoing hemodialysis, higher AHEI score are associated with lower number of hospitalizations and deaths over a one-year period when compared with those with lower AHEI score.

Hypothesis $3 \boldsymbol{b}$ : In patients undergoing hemodialysis, those with higher AHEI score will be have lower inflammation (lower neutrophillymphocyte ratio) when compared with those with lower AHEI score.

\section{Sample Size}

The study recruited a convenience sample of 77 participants from one single dialysis units of DaVita Kidney Care in the State of Florida. DaVita International serves 10 countries, including the United States and approximately 1.7 million patients. ${ }^{18}$

\section{Statistical Analyses}

Table 1 describes the dependent and independent variables tested in each chapter for each hypothesis and the statistical analyses used for each of the hypotheses. 
Table 1: Statistical Analysis of the Hypotheses

\begin{tabular}{|c|c|c|c|}
\hline Hypotheses & Dependent Variable & Independent Variable & Statistical Analysis \\
\hline $\begin{array}{l}\text { Chapter III } \\
\text { Hypothesis } \\
\text { 1a }\end{array}$ & $\begin{array}{l}\text { Mortality: } \\
\text { Dichotomous } \\
\text { variables Y/N } \\
\text { Hospitalization: } \\
\text { Dichotomous } \\
\text { variables Y/N } \\
\text { *Obtained from } \\
\text { Medical chart }\end{array}$ & $\begin{array}{l}\text { NLR and NLR } \\
\text { quartiles } \\
\text { Continuous and } \\
\text { ordinal variable } \\
\text { *Obtained from } \\
\text { Neutrophil\% and } \\
\text { Lymphocyte \% in } \\
\text { blood }\end{array}$ & $\begin{array}{l}\text { Multivariate and } \\
\text { stepwise cox regression } \\
\text { analysis to identify } \\
\text { outcome's predictors. } \\
\text { Proportional Hazard } \\
\text { Survival Models were } \\
\text { performed to compare } \\
\text { hazard ratios on time to } \\
\text { event (death and } \\
\text { hospitalizations for } \\
\text { NLR. Survival and } \\
\text { hospitalization curves } \\
\text { for NLR were estimated } \\
\text { by Kaplan-Meier } \\
\text { analysis. One-way } \\
\text { Anova, student's t tests, } \\
\text { chi-square tests, or } \\
\text { Mann-Whitney tests } \\
\text { were used to compare } \\
\text { variables between } \\
\text { hospitalized and not } \\
\text { hospitalized; survivors } \\
\text { and non-survivors, and } \\
\text { inflammation quartiles, } \\
\text { as appropriate. }\end{array}$ \\
\hline $\begin{array}{l}\text { Chapter III } \\
\text { Hypothesis } \\
1 \mathrm{~b}\end{array}$ & $\begin{array}{l}\text { NLR and NLR } \\
\text { quartiles } \\
\text { Continuous and } \\
\text { ordinal variable } \\
\text { *Obtained from } \\
\text { Neutrophil\% and } \\
\text { Lymphocyte \% in } \\
\text { blood }\end{array}$ & $\begin{array}{l}\text { BMI } \\
\text { Continuous variable } \\
\text { measured as weight in } \\
\mathrm{kg} / \text { height in meters } \\
\text { squared } \\
\text { Albumin } \\
\text { Continuous variable } \\
\text { nPCR } \\
\text { Continuous variable } \\
\text { TIBC } \\
\text { Continuous variable } \\
\text { *The three values } \\
\text { obtained from blood }\end{array}$ & $\begin{array}{l}\text { Pearson and Spearman } \\
\text { correlations, as deemed } \\
\text { appropriate were } \\
\text { performed to evaluate } \\
\text { the relationship between } \\
\text { NLR and BMI, } \\
\text { Albumin, nPCR and } \\
\text { TIBC. }\end{array}$ \\
\hline $\begin{array}{l}\text { Chapter IV } \\
\text { Hypothesis } \\
\text { 2a }\end{array}$ & $\begin{array}{l}\text { Mortality: } \\
\text { Dichotomous } \\
\text { variables Y/N }\end{array}$ & $\begin{array}{l}\text { SGA, MIS } \\
\text { Dichotomous } \\
\text { variables: } \\
\text { 0-wellnourished }\end{array}$ & $\begin{array}{l}\text { Proportional Hazard } \\
\text { Survival Models were } \\
\text { performed to compare } \\
\text { hazard ratios on time to }\end{array}$ \\
\hline
\end{tabular}




\begin{tabular}{|c|c|c|c|}
\hline & $\begin{array}{l}\text { Hospitalization: } \\
\text { Dichotomous } \\
\text { variables Y/N } \\
\text { *Obtained from } \\
\text { Medical chart }\end{array}$ & $\begin{array}{l}\text { 1-malnourished } \\
\text { *From nutrition } \\
\text { assessment by RD }\end{array}$ & $\begin{array}{l}\text { event death and } \\
\text { hospitalizations for SGA } \\
\text { and MIS. Survival and } \\
\text { hospitalization curves } \\
\text { for MIS and SGA were } \\
\text { estimated by Kaplan- } \\
\text { Meier analysis. } \\
\text { Student's t tests, chi- } \\
\text { square tests, or Mann- } \\
\text { Whitney tests were used } \\
\text { to compare variables } \\
\text { between malnourished } \\
\text { and well-nourished as } \\
\text { appropriate, }\end{array}$ \\
\hline $\begin{array}{l}\text { Chapter IV } \\
\text { Hypothesis } \\
2 \text { b }\end{array}$ & $\begin{array}{l}\text { Mortality: } \\
\text { Dichotomous } \\
\text { variables Y/N } \\
\text { Hospitalization: } \\
\text { Dichotomous } \\
\text { variables Y/N } \\
\text { *Obtained from } \\
\text { Medical chart }\end{array}$ & $\begin{array}{l}\text { Energy and protein } \\
\text { intake } \\
\text { Dichotomous } \\
\text { variables: } \\
\text { 0-did not meet } \\
\text { recommendations } \\
\text { 1-meet } \\
\text { recommendations } \\
\text { *Obtained from } 24- \\
\text { hour recall by RD }\end{array}$ & $\begin{array}{l}\text { Proportional Hazard } \\
\text { Survival Models were } \\
\text { performed to compare } \\
\text { hazard ratios on time to } \\
\text { event (death and } \\
\text { hospitalizations for Met } \\
\text { recommendations or not } \\
\text { Student's t tests, chi- } \\
\text { square tests, or Mann- } \\
\text { Whitney tests were used } \\
\text { to compare variables } \\
\text { between patients that } \\
\text { meet nutrition } \\
\text { recommendations and } \\
\text { not, Survival and } \\
\text { hospitalization curves } \\
\text { for energy } \\
\text { recommendations were } \\
\text { estimated by Kaplan- } \\
\text { Meier analysis }\end{array}$ \\
\hline $\begin{array}{l}\text { Chapter V } \\
\text { Hypothesis } \\
\text { 3a }\end{array}$ & $\begin{array}{l}\text { Mortality: } \\
\text { Dichotomous } \\
\text { variables Y/N } \\
\text { Hospitalization: } \\
\text { Dichotomous } \\
\text { variables Y/N } \\
\text { *Obtained from } \\
\text { Medical chart }\end{array}$ & $\begin{array}{l}\text { AHEI } \\
\text { Continuous and } \\
\text { ordinal variable. } \\
\text { Quartiles compare } \\
\text { low quartile vs high } \\
\text { quartile } \\
\text { *Calculated index } \\
\text { based on } 24-\text { hour } \\
\text { recall by RD }\end{array}$ & $\begin{array}{l}\text { Proportional Hazard } \\
\text { Survival Models were } \\
\text { performed to compare } \\
\text { hazard ratios on time to } \\
\text { event (death and } \\
\text { hospitalizations. One- } \\
\text { way ANOVA, student's } \\
\text { t tests, chi-square tests, } \\
\text { or Mann-Whitney tests } \\
\text { were used to compare } \\
\text { variables between low }\end{array}$ \\
\hline
\end{tabular}




\begin{tabular}{|l|l|l|l|}
\hline & & & $\begin{array}{l}\text { quartile versus high } \\
\text { quartile of AHEI as } \\
\text { appropriate. }\end{array}$ \\
\hline & $\begin{array}{l}\text { NLR and NLR } \\
\text { quartiles } \\
\text { Continuous and } \\
\text { ordinal variable } \\
\begin{array}{l}\text { Hypothesis } \\
3 b\end{array}\end{array}$ & $\begin{array}{l}\text { AHEI } \\
\text { Continuous and } \\
\text { ordinal variable. } \\
\text { Quartiles compare } \\
\text { low quartile vs high } \\
\text { quartile }\end{array}$ & $\begin{array}{l}\text { Proportional Hazard } \\
\text { Models were performed } \\
\text { to compare hazard ratio. }\end{array}$ \\
& $\begin{array}{l}\text { Nebtained from } \\
\text { Lymphocyte \% in } \\
\text { blood }\end{array}$ & $\begin{array}{l}\text { *alculated index } \\
\text { based on 24-hour } \\
\text { recall by RD }\end{array}$ & \\
\hline
\end{tabular}

*Sources of variables 
References

1. U.S. Renal Data System, USRDS 2013 Annual Data Report: Atlas of End-Stage Renal Disease in the United States, National Institutes of Health, National Institute of Diabetes and Digestive and Kidney Diseases, Bethesda, MD 2018.

2. Harvinder GS, Chee Wss, Karupaiah T. et al. Comparison of malnutrition prevalence between hemodialysis and continuous ambulatory peritoneal dialysis patients: a cross-sectional study. Malays J Nutr 2013;19:271-283.

3. Carrero JJ, Thomas F, Nagy K., et al. Global Prevalence of Protein-Energy Wasting in Kidney Disease: A meta-analysis of contemporary observational studies from the international society of renal nutrition and metabolism. J Ren Nutr 2018 Nov;28(6):380-92.

4. De Mutsert R, Grootendorst DC, Boeschoten EW, et al. Subjective global assessment of nutritional status is strongly associated with mortality in chronic dialysis patients. Am J Clin Nutr 2009;89:787-793.

5. Lopes AA, Bragg-Gresham JL, Elder SJ, et al. Independent and joint associations of nutritional status indicators with mortality risk among chronic hemodialysis patients in the Dialysis Outcomes and Practice Patterns Study (DOPPS). J Ren Nutr 2010 Jul;20(4):224-234.

6. Kang SS, Chang JW, Park Y. Nutritional status predicts 10-year mortality in patients with end-stage renal disease on hemodialysis. Nutrients 2017 Apr;9(4):399.

7. Kovesdy CP, Shinaberger CS, Kalantar-Zadeh K. Epidemiology of dietary nutrient intake in ESRD. Semin Dial 2010;23: 353-258.

8. Kopple JD. Pathophysiology of protein-energy wasting in chronic renal failure. J Nutr 1999;129(Suppl):247S-251S.

9. Carrero JJ, Stenvinkel P, Cuppari L, et al. Etiology of the Protein-Energy Wasting Syndrome in Chronic Kidney Disease: A Consensus Statement from the International Society of Renal Nutrition and Metabolism (ISRNM).J Ren Nutr 2013(2):77-90.

10. Fouque D, Kalantar-Zadeh K, Kopple J, et al. A proposed nomenclature and diagnostic criteria for protein-energy wasting in acute and chronic kidney disease. Kidney Int 2008 Feb;73(4):391-398.

11. Ikizler TA. Nutrition, inflammation and chronic kidney disease. Curr Opin Nephrol Hypertens 2008;17:162-167. 
12. Kalantar-Zadeh K, Block G, McAllister CJ, et al. Appetite and inflammation, nutrition, anemia, and clinical outcome in hemodialysis patients. Am J Clin Nutr 2004 Aug;80(2):299-307.

13. Stenvinkel P, Ketteler M, Johnson RJ, et al. IL-10, IL-6, and TNF- alpha: Central factors in the altered cytokine network of uremia-the good, the bad, and the ugly. Kidney Int 2005;67:1216-1233.

14. Kaizu Y, Kimura M, Yoneyama T, et al. Interleukin-6 may mediate malnutrition in chronic hemodialysis patients. Am J Kidney Dis 1998 Jan;31 (1):93-100.

15. Gutiérrez OM, Muntner P, Rizk DV, et al. Dietary Patterns and Risk of Death and Progression to ESRD in Individuals with CKD: A Cohort Study. Am J Kidney Dis 2014 Aug;64(2):204-213.

16. Kelly J, Palmer SC, Wai, Ruospo M, Carrero JJ. Healthy Dietary Patterns and Risk of Mortality and ESRD in CKD: A Meta-Analysis of Cohort Studies. Clin J Am Soc Nephrol 2017 Feb;12(2):272-279.

17. Tsuruya K, Fukuma S. Dietary patterns and clinical outcomes in hemodialysis patients in Japan: a cohort study. PLOS One 2015 Jan; 21(10):1.

18. DaVita Kidney Care Overview. https://www.davita.com/about. 


\section{CHAPTER II: LITERATURE REVIEW}

\section{Chronic and End-Stage Renal Disease}

In 2002, the National Kidney Foundation (NKF), through the Kidney Disease Outcomes Quality Initiative (KDOQI) defined the most salient characteristics of chronic and end-stage renal disease. ${ }^{1}$ Later in 2004, the International Kidney Disease Improving Global Outcomes adopted these guidelines that defined a variety of disorders categorized by alterations in both kidney structure and function, with diverse causes and disease stages. ${ }^{2}$ Many risk factors have been recognized for renal failure, which includes genetic, socio-demographic and underlying conditions that may initiate and progress kidney disease. $^{3}$

End-stage renal disease (ESRD) refers to a condition of chronic kidney failure that is treated by replacement renal therapy (RRT), mostly chronic dialysis or transplantation. ${ }^{1,2}$ The United States Renal Data System (USRDS) estimated in the 2018 Annual Data Report ${ }^{4}$ that approximately 726, 331 patients are identified with ESRD annually with an estimated 5\% increase per year. ${ }^{4}$ Dialysis, in its two chronic modalities, hemodialysis and peritoneal dialysis, are life-saving and costly therapies for patients with ESRD. In the United States over 450,000 people are currently receiving hemodialysis, costing Medicare approximately $\$ 90,000$ per person annually in $2012,{ }^{5}$ part of this heavy economic burden comes from the high prevalence of hospitalization that affect this population..$^{3,5}$

Chronic Dialysis prevents death from uremia of patients with ESRD and even though during the past decade, an uptrend has been observed toward an earlier initiation 
of RRT, patient survival remains a critical matter. ${ }^{6}$ Mortality rates for dialysis patients are seven times higher than the rates of people with similar age in the general population. ${ }^{7}$ Once hemodialysis starts, the expected remaining lifespan was approximately eight years in the 2018 USRDS report, ${ }^{7}$ with an approximate mortality rates between $20 \%$ and $25 \%$ and a $35-40 \%$ five-year survival rate, including differences on race and age. ${ }^{8}$

There are several prevalent causes of mortality in dialysis patients, but the most frequent causes of death among ESRD patients are cardiovascular disease $(\sim 50 \%$ mortality), infections, which are related frequently to the HD vascular access $(\sim 20 \%$ mortality), and removal from dialysis which accounts from $15 \%$ to $25 \%$ of deaths. ${ }^{8}$

\section{Nutritional status of patients living with CKD and ESRD}

Dialysis, as a form of renal replacement therapy, has been implemented for almost 60 years in United States, and the number is currently approaching half-a-million patients living with dialysis. ${ }^{4}$ Despite major advances in protocols, dialysis technology, medical and pharmaceutical interventions, hemodialysis patients suffer from a high prevalence of several nutrition imbalances and malnutrition..$^{9,10,13}$

The estimation of the Glomerular filtration Rate (GFR) is a marker of kidney function and an indicator of stage of kidney disease. It is calculated by measuring the rate of the blood-flow through the kidneys. ${ }^{1}$ As GFR decreases, kidney disease progresses to advanced stages. Parallel to this renal function's decline, patients start facing nutritional challenges represented by a number of nutrient imbalances and altered nutrition-related markers. ${ }^{9,11,13}$ The Third United States NHANES found that a decrease in GFR under 30 
$\mathrm{mL} / \mathrm{min} / 1.73 \mathrm{~m}^{2}$ had an independent association with malnutrition among participants 60-year-old and older. ${ }^{11}$

\section{Assessment of nutritional status in HD patients}

Kidney disease progression and its chronic therapy may lead to a variety of metabolic and nutritional alterations. ${ }^{9,13} \mathrm{~A}$ recent publication, which discussed from historical perspective the evolution of the nutritional assessment tools in patients receiving $\mathrm{HD}$, from basic anthropometrics measurements to more sophisticated nutrition scores, highlighted the usefulness of a great deal of nutritional tools in assessing the nutritional status of HD patients. ${ }^{9}$

Many different tools and parameters are utilized to assess, treat and monitor the characteristics of malnutrition. ${ }^{12}$ Several biomarkers and multiple risk-factors have been used to elucidate the reasons behind the excessive mortality, infections and cardiovascular events prevalent among ESRD patients. ${ }^{13}$ Specifically in hemodialysis patients, several nutrition indicators and indexes are used to attain patient's nutritional status, including anthropometrics (BMI, skinfold thickness, waist circumference), biochemical markers (albumin, net protein catabolic rate, transferrin, lymphocyte count) and composite nutritional indexes such Subjective Global Assessment (SGA), Geriatric Nutritional Risk Index (GNRI) and Malnutrition Inflammation Score (MIS) among

others. ${ }^{9,12,13}$ Most of the studies that have examined the nutritional status of patients living with dialysis, regardless of the assessment tool used, report some degree of malnutrition and its relation to adverse disease outcomes. ${ }^{9}$ 
Unfortunately, the current reported global prevalence of protein-energy wasting (PEW) in CKD patients varies widely, from $10 \%$ to $90 \%{ }^{10}$ In a recent meta-analysis of contemporary observational studies published in November 2018 on behalf the International Society of Renal Nutrition and Metabolism (ISRNM), the reasons identified for this wide margin of prevalence were (1) the great variety of tools utilized in the different studies to assess nutritional status, (2) the differences in the criteria to diagnose malnutrition, and (3) the environmental circumstances surrounding the patient. This meta-analysis advocated for increased medical attention and resources allocation for PEW evaluation and treatment. ${ }^{10}$

Frequent and timely nutrition assessment constitutes an essential part of the routine care of maintenance dialysis patients, and it has paramount importance as it allows early recognition and treatment of malnutrition. ${ }^{9-13}$ Nutrition status and diet are of such consequences, that the United States government has mandated that every dialysis patient should be assigned a renal dietitian. ${ }^{14}$

The malnutrition that afflicts patients with renal disease has been described as a syndrome of adverse changes in nutrition rather than a single condition. ${ }^{15}$ This syndrome shares many etiologic factors with those seen in the cachexia syndrome experienced by non-CKD populations; including the presence of multiple underlying comorbid conditions, decreased physical activity, deterioration of functional status, decreased appetite, frailty, and aging. ${ }^{15}$ Making things more complicated, patients living with dialysis have increased metabolic demands for protein and energy, which are mobilized by the catabolic-inducing dialysis treatment itself. ${ }^{15,16}$ A constellation of metabolic alterations, including metabolic acidosis, increased resting energy expenditure (REE), 
multiple gastrointestinal and endocrine disorders and the well-known dialysis-associated inflammatory response, all together, add to these increased requirements for protein and enery. ${ }^{15,16}$ It has been recommended that all patients with a history of decreased protein and energy intake and/or with a sustained decrease in body reserves manifested as decrease in BMI, albumin, net protein catabolic rate (nPCR), among other markers, should be carefully assessed for malnutrition. ${ }^{13,15,16}$ In 2008 , Fouque et al., ${ }^{15}$ recommended to call protein-energy wasting (PEW) to the syndrome that describes loss of body protein mass and reserves of energy in patients with CKD and ESRD, in addition, the authors proposed a diagnosis criteria. Later in 2013, ISRNM provided a consensus statement ${ }^{16}$ with the multiple purpose of (1) raising more awareness around the high prevalence of malnutrition, (2) alleviate terminology confusion and (3) better identify research needs that, ultimately, could provide a better understanding of this syndrome. ${ }^{16}$ In this consensus statement, it is highlighted that insufficient dietary intake, diminished appetite, and multiple dietary restrictions imposed upon renal patients were not the only contributors to PEW syndrome. ${ }^{16}$ It was proposed that other highly prevalent factors among patients with kidney disease were also involved in the PEW development. This statement denotes the multifactorial and complex nature of the PEW syndrome. Hence, regardless of the tool being used to attain the nutrition assessment of renal patients, it is critically important that these evaluations are clinically meaningful. The assessment tool should be sensitive enough to identify, stratify and classify patients based on presence, degree and/or risk to develop PEW. In accordance with the standard of care for the development of the Nutrition Care Process of these patients, ${ }^{12}$ the ultimate goal of 
any nutrition assessment is to design a nutrition intervention to alleviate PEW's sign and symptoms. ${ }^{10,12,13,15,16}$

\section{The impact of inadequate nutritional status of patients with renal disease on morbidity and mortality.}

Malnutrition presents a considerable socioeconomic challenge in today's U.S. hemodialysis healthcare setting. ${ }^{4-9}$ Nutritional status parameters are consistently found to be the strongest predictors of morbidity and mortality in this population. ${ }^{17-23}$ Small and large observational studies conducted in patients with different stages of renal failure have provided sound epidemiological evidence about the significant relationship between malnutrition and mortality. ${ }^{17-21}$ For example, Acchiardo and colleagues, ${ }^{17}$ examined the nutritional status of 120 patients receiving hemodialysis by indirectly measuring dietary protein intake. This small, but remarkable study, reported that malnutrition was a crucial predicting factor that influences morbidity and mortality. The authors suggested that patients who have abnormal measurements of nutritional status must be stratified as patients at high nutritional risk, and be treated aggressively, according to their degree of malnutrition. In another study with larger study sample size, Dwyer et al, ${ }^{18}$ examined the association of nutrition markers measured prior to randomization to the well-known HEMO study with mortality. ${ }^{19}$ The nutrition markers included by the authors were biochemical markers, anthropometric and direct dietary indicators that were collected routinely. Biochemical indicators included serum albumin, $\mathrm{nPCR}$, serum creatine, and cholesterol. Anthropometric indicators included post-dialysis weight, BMI, calf circumference, middle arm circumference and skinfolds. ${ }^{18}$ The authors obtained 
measurements of dietary energy and protein intake from 24-hour diet recalls collected in two different days. The study showed that abnormal nutrition indicators, including anthropometrics, biochemical and dietary intake, increased the relative risk for mortality. The association between nutrition indicators and outcomes was found to be timedependent with greater effects within 6 months. ${ }^{18}$ In another highly cited large prospective epidemiological analysis, Pifer et al. ${ }^{20}$ included 7719 adult patients on hemodialysis from United States who were enrolled in the international Dialysis Outcomes and Practice Patterns Study (DOPPS), which is a study designed to evaluate dialysis practice patterns in random samples of patients across different countries. The authors examined the changes in commonly used nutritional parameters such as BMI, albumin, serum creatinine, and lymphocyte count, and the SGA score. This report examined the relationship of these nutritional parameters with mortality and found that low levels of albumin and creatinine at baseline were independently associated with higher risk for mortality. This remarkable study is cited very often as a reference by the renal research community, since it was the one that first proposed SGA as a clinical meaningful tool to attain the nutritional status of this population. Those patients with lower SGA scores exhibited a higher mortality risk. In agreement with the findings of the DOPPS, the authors highlighted the usefulness of employing several measurements of nutritional indicators to predict mortality among hemodialysis patients.

The usefulness of SGA as a predictor of mortality was confirmed by another frequently referenced study, The Netherlands Cooperative Study on the Adequacy of Dialysis-2 Study Group. De Mutsert et al. ${ }^{21}$ clearly demonstrated, through a longitudinal multicenter analysis that included over 1600 chronic dialysis patients, that malnutrition, 
measured at baseline by SGA, increased mortality risk by two-fold in seven years of follow-up. This study also demonstrated that the association between malnutrition and mortality is time-dependent. Interestingly, the association became stronger after adjustments by pre-determined covariates. ${ }^{21}$

Other authors have examined the association of malnutrition and dialysis outcomes, including inflammation, hospitalization and mortality, by using different composite nutrition scores, which share some similarities with SGA. Kalantar and colleageues $^{22}$ designed a composite score named the Malnutrition Inflammation Score (MIS), which is a modified version of SGA. This composite score, specifically designed and validated for its use in maintenance hemodialysis (HD) patients, showed significant correlations with common measurements of inflammation, nutrition and anemia. Patients with higher MIS score, as an indicator of the presence of malnutrition-inflammation status, had greater rate of hospitalization and mortality. The author concluded that MIS was a strong predictor for adverse outcomes in HD patients. ${ }^{22}$

In a different prospective analysis of the outcomes from the DOPPS, which encompassed data from 1996 to 2008, Lopes et al. ${ }^{23}$ included random samples of maintenance hemodialysis (MHD) patients from the United States, seven European countries, Canada, Australia, New Zealand, and Japan. The authors investigated the individual effect of nutrition indicators and their joint effect on mortality rate in a cohort of 40,950 MHD patients. The authors examined the individual and joint effects of a battery of biochemical and anthropometric measurements, including creatinine, albumin, $\mathrm{nPCR}$, and BMI, on mortality risk. They also reported that nutritional indicators significantly differed by country and by patient characteristics and exhibited high degree 
of variabilities. An impoverished nutritional status indicated by each nutrition parameter was independently associated with an increased mortality risk across the different regions. Interestingly, the specific correlation between low albumin and high mortality risk was found to be stronger for patients with lower body mass, as indicated by lower BMI and/or lower serum creatinine. ${ }^{23}$ These revealing facts clearly illustrated the multifactorial and complex characteristics of the malnutrition seen in this population, which was previously proposed. ${ }^{13,15}$ Therefore, the conclusions from this study confirmed the usefulness and the need of utilizing multiple tools to assess and monitor the nutritional status of patients receiving hemodialysis. ${ }^{20,23}$

Similarly, results that emerged from studies conducted in patients receiving another dialysis treatment modality, continuous ambulatory peritoneal dialysis (CAPD), have also shown a strong relationship between malnutrition and morbidity and mortality. For example, Harvinder et al. ${ }^{24}$ compared protein-energy malnutrition (PEM) prevalence and the risk for developing it between patients receiving hemodialysis (HD) and CAPD. The authors compared a total of 155 HD versus 90 CAPD. For assessing PEM, another composite nutrition score was used that was specifically designed for dialysis patients and was called Dialysis Malnutrition Score (DMS). The study compared individual nutrition parameters (albumin and BMI), DMS and indirect measurements of dietary intake, and concluded that PEM was more prevalent in patients receiving PD compared to those receiving HD, as 97\% of patients on PD had an albumin lower than $40 \mathrm{~g} / \mathrm{L}$ compared with $81 \%$ in the group of patients on HD. Low dietary protein intake $<1.2$ $\mathrm{g} / \mathrm{kg} /$ day was also more prevalent among PD patients with a $79 \%$ compared with $67 \%$ in HD modality. In contrast, when comparing the prevalence of PEM by using the criteria 
established by DMS in addition to a low dietary energy intake (cut-off value $<30$ $\mathrm{kcal} / \mathrm{kg} / \mathrm{day}$ ), the investigators did not detect statistically significant differences between the two treatment modalities. In both group of patients, PD and HD, the prevalence of PEM was greater than $70 \%$ and all patients had equally high risk for developing PEW. Based on their findings that dietary intake was independently associated with the risk of PEM for patients in both dialysis modalities (HD and PD), the authors emphasized the crucial role of periodic nutritional assessments and the paramount importance of conducting ongoing education and dietary counseling as an effective way to prevent PEM. ${ }^{24}$

The association between nutritional indicators and the risk for hospitalization has also been broadly examined. In Southern Brazil, Szuck and colleagues ${ }^{25}$ studied the association between nutrition parameters and hospitalization risk among 138 patients receiving hemodialysis at a local hospital. The authors found that patients that had at least one hospital admission during the study-period had higher BMI and lower albumin levels compared to those who were not hospitalized. The author did not find statistically significant differences in the nutritional status based on SGA of patients who were hospitalized compared with those who were not. In this single center cohort study, albumin was the only significant predictor for hospitalization. Patients with an albumin level lower than $3.8 \mathrm{~g} / \mathrm{dL}$ exhibited 2.47 greater incidence of hospitalization $(\mathrm{P}=0.003)$. In agreement with findings from Lopes et al. ${ }^{23}$ that low BMI jointly with low albumin were predictors of mortality, this study ${ }^{25}$ suggested that higher BMI had a protective effect against death, but, in contrast, that patients who were hospitalized had a significantly 
higher BMI. The controversies about the effect of low or high BMI on adverse outcomes are still under discussion by the renal research community. ${ }^{10}$

More recently, in 2018, Kang and colleagues ${ }^{26}$ conducted a retrospective observational study, which comprised a total of 144 HD patients, to investigate the relationship between mortality and nutritional parameters. A composite score (MIS) and a direct dietary assessment were included in this study. BMI, albumin, nPCR, protein and energy intakes and MIS were measured at baseline. Survivors had a significanlyt $(\mathrm{P}=$ 0.048) higher nPCR level compared to non-survivors. The average energy $(26.7 \pm 5.8$ $\mathrm{kcal} / \mathrm{kg})$ and protein intake $(0.91 \pm 0.21 \mathrm{~g} / \mathrm{kg})$ were significantly higher among patients who survived compared to patients who died (energy $=24.3 \pm 4.2 \mathrm{kcal} / \mathrm{kg}$ and protein intake $=0.82 \pm 0.24 \mathrm{~g} / \mathrm{kg}, \mathrm{P}<0.05)$. The MIS was significantly lower among survivors versus non-survivors $(5.2 \pm 2.3$ vs. $6.1 \pm 2.1, \mathrm{P}=0.039)$. In this study, the authors concluded that a higher MIS and lower energy intake were strong and independent predictors of mortality. These results added to the previous body of knowledge that highlights the usefulness of nutrition composite scores, specifically those designed for dialysis patients, for the detection of the PEW syndrome and their strong power for predicting adverse outcomes and signaling appropriate early interventions in this population. ${ }^{10,22,26}$

Mounting evidence is systematically emerging in the field of renal nutrition research that acknowledges and demonstrates the strong relationship between malnutrition and disease outcomes, including inflammation, comorbidities and mortality. Multiple biomarkers and score measurements of nutritional status are linked to the adverse outcomes seen in HD patients. ${ }^{22,26,28,29}$ Conversely, measures of good nutritional 
status are associated with increased survival, and the degree of recovery of the nutritional status after nutrition interventions has been found to be inversely related to the number of re-hospitalizations of HD patients. ${ }^{27}$ Moreover, nutrition recommendations are in place in order to prevent PEW from occurring, but no evidence- based consensus has yet been reached concerning which is the most sensible assessment tool, cut-off points, or the best management of the nutritional status of patients living with dialysis. ${ }^{10,28,40,66}$

\section{Inflammation in CKD and ESRD}

Lack of appetite, anorexia, decreased intake, and lean body mass losses are common contributing factors to PEW; however, they cannot explain completely the malnutrition and wasting syndrome seen in CKD patients. ${ }^{28,29}$ The excessive mortality in ESRD has been attributed, in part, to its pro-inflammatory state, characterized by increase in circulating pro-inflammatory cytokines, leading to leukocyte adhesion, and infiltration of the vascular endothelium. ${ }^{28,30,31}$ Several investigations support that PEW is a result of the chronic inflammatory processes that occur in patients with ESRD. ${ }^{10,28,30,31}$ Although pro-inflammatory cytokines are known to play a pivotal role by connecting inflammation and malnutrition; ${ }^{28,32}$ additional factors, including stress-induced by oxidative-carbonyl group imbalances, toxicity related to uremic load, metabolic acidosis and several nutrition imbalances, greatly contribute to this complex link. ${ }^{29-31,33,34}$ It has been suggested that there is more than one malnutrition in the context of renal disease. ${ }^{35}$ There is the classic malnutrition, easy to identify, related to low protein and energy intake, which can be improved with adequate nutrition and dialysis treatment; and a second type of malnutrition, which is more difficult to diagnose and reverse with nutrition support. 
This second type of malnutrition is associated with the development of chronic inflammation status and atherosclerotic cardiovascular disease. The successful treatment of this type of malnutrition requires that the underlying comorbid conditions, including chronic inflammation, are adequately and concomitantly treated as well. ${ }^{34,35}$ It is wellknown that many dialysis patients with chronic levels of inflammation develop a negative protein balance, which further leads to weight loss, despite good appetite and adequate intake. ${ }^{10,16,29,32}$ It has been suggested that in patients who report unavoidable weight loss with adequate intake might be a change in the synthesis of protein from muscle to acutephase proteins as renal function deteriorates and uremia increases. ${ }^{32}$

The broad range of metabolic and nutritional responses to inflammation seen in PEW, in the context of CKD-ESRD, are many and of great complexity, but of particular interest is the exacerbated protein catabolism. ${ }^{30-32,35-37}$ Inflammation causes increased energy expenditure, and pro-inflammatory cytokines are considered to have a determinant role in lean body mass catabolism. ${ }^{36,37}$ For example, elevated interleukin- 6 is associated with increased proteolysis of the muscle cells. ${ }^{36}$ Albumin is inversely related to the inflammation marker C-reactive protein, and pro-inflammatory cytokine levels and oxidative stress could potentially lead to protein wasting. ${ }^{32-34}$ Anorexia, which leads to an inadequate intake and weight loss, is a another well-recognized metabolic response to inflammation that could lead to PEW. ${ }^{15,31,35,60}$ Therefore, chronic inflammation may be a determinant factor that causally links PEW to increased morbidity and mortality among dialysis patients. ${ }^{10,15,28-31,39}$ However, the degree at which there is a link between PEW and inflammation and the independent effect of each upon adverse outcomes in patients with kidney disease are unclear. ${ }^{38,39}$ 
Chronic low-level inflammation is considered a frequent comorbid condition in CKD and in dialysis patients, which has been associated with many different factors from toxic uremic load to dialysis treatment itself. ${ }^{28}$ It has been proposed that in order to achieve optimal nutrition among HD patients, periodic measurements of markers of inflammation are useful to assess the severity and frequency of the inflammation status in patients with PEW. Ikizler, ${ }^{40}$ in his most recent review of "Optimal Nutrition for dialysis patients," suggested that, regardless of the method used, it is extremely important to guarantee repeated measurements and standardization of the techniques to reduce variability. The author emphasized that the results should always be analyzed considering the clinical setting and nutritional status of each individual patient. ${ }^{40}$

\section{Neutrophil-to-lymphocyte ratio (NLR) as a useful marker of inflammation and predictor of outcomes}

The critical role of inflammation in the development of cardiovascular disease and atherosclerosis, and its association with malnutrition in patients with renal disease, has been supported by extensive evidence-based data gathered by a variety of research studies. $^{22,28,26,33,34,39,40}$ However, there is no consensus on how to assess the severity of inflammation, and several measurements of inflammation have been used in both CKD and dialysis patients. ${ }^{28,39,40}$

NLR has emerged as a subrogate marker for systemic inflammation, and its associations with known inflammatory biomarkers has been investigated in patients with different stages of kidney disease. ${ }^{41}$ NLR is a cost effective and very simple marker, which it is calculated by dividing neutrophil to lymphocyte counts, which are obtained 
usually from peripheral blood samples. This convenient parameter allows for an easy assessment of a patient's inflammatory status. ${ }^{41,42}$

The association between NLR and pro-inflammatory cytokines, including among others tumor necrosis factor alpha (TNF- $\alpha$ ) and interleukin-6 (IL-6) levels, has been demonstrated by studies conducted in pre-dialysis and dialysis patients. ${ }^{41-44}$ NLR levels seems to predict worsening of renal function among diabetics. ${ }^{45,47}$ This novel marker has shown a strong predicting value for adverse major cardiovascular events by means of establishing a stratification criteria for mortality-associated risks after procedures such as coronary artery bypass grafting. ${ }^{46}$ It has also proven to be an important prognostic factor in several types of cancers, ${ }^{48,50,51}$ and it was found to be significant predictor of all-cause mortality in multiple chronic conditions. ${ }^{49}$

The usefulness of NLR in the settings of dialysis treatments is an emerging novel topic in the literature. It was demonstrated to have a strong predictive-value for cardiovascular events and all-cause mortality in HD patients. ${ }^{52-56}$ The relationship with other inflammatory markers, particularly, albumin and C-reactive protein was illustrated by Malhotra et al., ${ }^{43}$ who analyzed the results from two different international cohort studies within the Monitoring Dialysis Outcomes research collaboration which included 43,272 HD patients. The authors compared the predictive ability of NLR versus elevated C-reactive protein (CRP), a well-established marker of inflammation. These analysis showed that NLR was adequate for diagnosing inflammation in settings where CRP is not measured routinely, and supported that NLR can serve as a potential surrogate marker for inflammation and adverse outcomes among HD patients. ${ }^{43}$ An et al. ${ }^{52}$ examined the predictive value of NLR for mortality among 86 PD patients in China and found that 
elevated NLR greater than 4.5 was associated with arterial stiffness and a strong predictor of cardiovascular and all-cause mortality in this population.

In another prospective cohort study conducted in Japan, Kato et al. ${ }^{53}$ investigated the association between NLR at the start of dialysis therapy with some clinical biomarkers in 86 Japanese dialysis patients for an average 38.7 months of follow-up and found that a higher NLR was associated with increased risk of cardiovascular disease (CVD) events, and that index was a stronger predictor of future events. In this study the authors compared the prognostic power of NLR with nutrition (SGA, albumin) and inflammation (CRP and interleukin 6) markers and found that NLR was a superior maker. Based on these results, the author concluded that NLR was a useful marker for identifying patients at risk of CVD. ${ }^{53}$ Similar results have been published more recently by Li H. et al.,${ }^{54}$ who included $280 \mathrm{HD}$ patients in China; by Brendo et at.,${ }^{55}$ who included $203 \mathrm{HD}$ patients in Australia and by Erden et al., ${ }^{56}$ who included $95 \mathrm{HD}$ patients in Turkey. All studies mentioned above found that an increased NLR (greater than 3.5, 4.0 and 3.5; respectively) were strong predictors of mortality in this population.

Several NLR cut-off values obtained by different methods and in different populations suffering from a variety of chronic conditions such as cancer, diabetes, CKD, $\mathrm{HD}$ or PD or other debilitating conditions are recently cited in the literature and have proven to be clinically meaningful. ${ }^{40-56}$ However, no consensus and universal cut-off value is currently available. ${ }^{57}$ It remains unknown which NLR value is correlated with higher risk for disease or inflammation, or which cutoff value will differentiate normal from abnormal results and for which population will be a better predictor of adverse outcomes. ${ }^{5}$ 


\section{Dietary intake in CKD and ESRD}

Eating and drinking are required activities for species' survival. It is vital to provide the body with essential nutrients needed to maintain and repair tissues and cell structures, and to provide fuel for energy-demanding processes and activities. In CKD and ESRD patients as GFR decreases, a profound decline in protein and energy intake is observed. ${ }^{58}$ The prevalence of anorexia has been reported as high as $30-55 \%$ in ESRD, ${ }^{59}$ as a consequence, there is an inadequate intake, which is an important cause of malnutrition and itself related to adverse outcomes in ESRD. ${ }^{60-62}$ Araujo and collaborators $^{62}$ reported that a lower energy intake, at the start of hemodialysis, constituted a very strong risk factor for 10-year mortality among ESRD patients. In addition, anorexia, which a major cause for inadequate nutrient intake in ESRD has been associated with 4 times higher risk of death and with increased morbidity in a study of 344 HD patients conducted by Kalantar-Zadeh et al. in the United States. ${ }^{31}$

\section{Dietary intake assessment}

The main reason for conducting dietary assessments in HD patients is to obtain relevant information in relation to food, specific nutrients and diet patterns, and therefore, being able to identify how patients can modify their diet to change associated health risks. ${ }^{63-65}$ This information will help to determine whether patients are complying with dietary guidelines and recommend changes in life-style and diet that are tailored to the individual patient's needs. ${ }^{65,66}$

Careful dietary assessment is needed for determining present and future implications for individuals at risk for malnutrition. ${ }^{65}$ This may be of paramount 
importance in dialysis patients for whom the risk of death is high and strongly related to malnutrition. ${ }^{66}$ Unfortunately, dietary assessments are not performed routinely in dialysis patients, but they are essential and used extensively in research as they provide critical information on diet quality, nutrient intake, and clinical endpoints. ${ }^{66}$ There are diverse methods used to assess dietary intake in healthy populations and in those with chronic diseases. ${ }^{67}$ The most frequent, universally used methods for dietary assessment in CKD patients include dietary recalls (24-hour diet recall) and food records that are collected during short periods of time between 3 to 7 days, and food frequency questionnaires (FFQ), which are used to register average intake for longer periods of time (weeks to month). ${ }^{67-69}$

The 24-hour diet record collects the most current information about food intake. ${ }^{65}$ A trained interviewer, usually an experienced dietitian, administers a questionnaire face to face or through telephone interviews. The subject being interviewed is expected to detail information about all the food and drink consumed during the past 24 hours. Very often, different prompts are provided by the interviewer to aid the subject recall of actual food and drink consumed, and portion sizes are usually included in the questionnaire. Details about the cooking method, the use of additional items such as spread, sauces, condiments, dressings are also collected. The main advantage of this method is its convenience. It can be administered very quickly and could give as many details as participant's memory allows. The willingness to be accurate and detailed-oriented on his/her answers and the reliance on the memory of the participants are the main disadvantages. 
In addition, the level of comprehensiveness of the interviewer, as well as the effectiveness of prompting techniques, substantially influence the accuracy of the method ${ }^{65,70}$ In some patients, especially in dialysis patients, whose diet intake pattern may be significantly different on dialysis compared with non-dialysis days, it is recommended to take several 24-hour recalls in order to generate more accurate averaged data. This way, the collected 24-hour dietary intake information can be extrapolated to longer periods. ${ }^{65,66,69,70}$

The assessment of the dietary intake of CKD patients has been the main purpose of many early studies. ${ }^{61,71-75}$ Some of these studies compared the average patient intake with KDOQI Clinical Practice Guidelines. For example; Cooper et al. ${ }^{71}$ and Lorenzo et al. ${ }^{72}$ assessed the average dietary energy and protein intake in relation with KDOQI recommendations by using food records. Both set of authors concluded that Dietary Energy Intake (DEI) and Dietary Protein Intake (DPI) fall below nutrition recommendations from KDOQI guidelines (30-35 kcal/day; $1.2 \mathrm{gm} / \mathrm{kg} / \mathrm{day})$. Lorenzo and colleagues $^{72}$ reported that $92 \%$ and $81 \%$ of participants did not meet the recommended energy and protein intake, respectively. This study found a strong direct correlation between DPI and DEI $(r=0.74, \mathrm{P}<0.0001)$ and a direct significant correlation between serum albumin and DPI. ${ }^{72}$

Similar results have been described by Burrowes et al.,. ${ }^{73}$ who examined the dietary intake of 1,901 patients and reported an average of daily energy intake of $22.7 \pm$ $8.3 \mathrm{kcal} / \mathrm{kg} /$ day and protein of $0.93 \pm 0.35 \mathrm{~g} / \mathrm{kg} /$ day and concluded that most of the patients did not meet current KDOQI dietary recommendations. Comparable results have been reported in patients receiving $\mathrm{PD}^{74,75}$. Wang et al., ${ }^{74}$ in a cross-sectional analysis of a 
cohort study that included 266 patients on PD, analyzed the participants' intake using FFQ and found greater average intake for energy and protein $(25.1 \mathrm{kcal} / \mathrm{kg} / \mathrm{day} ; 1.11 \pm$ $0.45 \mathrm{~g} / \mathrm{kg} /$ day, respectively,) but still below KDOQI recommendations. Therrier et al., ${ }^{75}$ in a secondary data analysis, found that the daily protein and energy intake of a PD female group were significantly lower compared to the healthy female control group and below KDOQI guidelines.

These studies summarized above clearly demonstrated that most dialysis patients, including the two different treatment modalities, HD and PD, do not meet current KDOQI recommendations for daily protein and energy intake, which may in turn increase their susceptibility for PEW, that ultimately leads to adverse clinical outcomes and death. ${ }^{74}$

\section{Impact of quantitative nutrition deficiencies in outcomes of CKD-ESRD patients.}

The significant association between inadequate diet intake and mortality has been shown in several studies. ${ }^{74-79}$ Early in 1995 , Davies et al. ${ }^{61}$ showed a strong association of dietary energy and protein intake with mortality in patients treated with HD. Antunes et al. ${ }^{76}$ investigated the association between dietary intake and mortality in 79 adult patients receiving both $\mathrm{PD}$ and $\mathrm{HD}$. This study revealed the impact of energy deficiency in outcome prediction, in which DEI was significantly lower in non-survivors than survivors $(\mathrm{P}=0.008)$. In contrast, adequate protein intake (at least $1.2 \mathrm{~g} / \mathrm{kg} / \mathrm{day})$ was associated with increased survival in HD and PD patients.

Other controlled studies have found significant differences between HD patients and control groups (healthy patients) but these differences lost significance when 
adjusted for ideal weight. This was the case of the study conducted by Cupisti et al., ${ }^{77}$ who found significant differences in average daily energy and protein intake by comparing HD patients with non-CKD patients; the differences in their intake disappeared once DEI and DPI were adjusted for ideal weight.

Other authors have compared the dietary intake of hemodialysis patients with the recommendations prescribed by the American Heart Association Guidelines to reduce cardiovascular disease. Khoueiry et al. ${ }^{78}$ compared the dietary intake information of 70 HD patients with these guidelines and concluded that most patients did not meet diet recommendations for reducing the risk of cardiovascular disease. The DIET-HD study, ${ }^{79}$ a prospective cohort study that enrolled patients from January 2014 to June 2017 and included 9,757 adults treated with HD in Europe and South America, examined diet components of dialysis patients and their relationship with dialysis outcomes. In this study Saglimbene et al. ${ }^{79}$ reported that only one third of the participants enrolled consumed the minimum amount of n-3 PUFA (1.75 g/week), which is recommended for primary cardiovascular prevention. Even though participants had an insufficient intake of this cardio-protector nutrient, the association between the insufficient intake of n-3 PUFA and cardiovascular or all-cause mortality was not statistically significant in this cohort of HD patients. ${ }^{79}$

In agreement with multiple studies that have examined DEI and DPI in HD and PD patients, most dietary intakes of patients receiving both dialysis modalities fall below nutrition recommendations from KDOQI. Moreover, some of the studies have shown association between patient's diet intake and mortality. Deficient intake, in part ascribed to diminished appetite or many other constellations of physiological or metabolic 
abnormalities can be attributed to the onset and development of PEW. Nonetheless, it remains to be elucidated to what extend the inadequate intake of energy and protein can be causally linked to increased morbidity and mortality. ${ }^{10,29}$

\section{Dietary quality indexes}

Diet quality is determined by food choices. A high diet quality consists of, but it is not limited to whole grains and legumes, lean meat cuts, fresh fruits and vegetables and low to moderate fat milk consumption. ${ }^{80}$ Some components that can affect the quality of the diet are the low intakes of vitamins, minerals, healthy fats, whole grains and phytonutrients in general; then, when a diet has poor quality, the concern for developing chronic diseases rises. ${ }^{79-81}$ Hence, investigators in the field of nutrition research, based on the prevailing hypotheses about the role of diet in disease prevention, have utilized the principles underlying diet quality to investigate the potential association of diet quality patterns with morbidity and mortality. ${ }^{79-82}$

Diet quality indexes and studies of dietary patterns have arisen as useful and reliable approaches to evaluate not only the adequacy of dietary intake and the adherence to current dietary guidelines, but also to explore the relationship between diet and health

outcomes. ${ }^{81-83}$ The identification of dietary patterns and the evaluation of the overall diet quality become particularly important for examining the role of diet in the development of chronic diseases. Some studies have used diet quality indices based on the American Dietary Guidelines for diabetes and on heart disease and cancer disease prevention, while other indices are adapted to reflect the dietary guidelines of other countries. ${ }^{79} \mathrm{Well}-$ known healthy dietary patterns such as vegetarian, Mediterranean, and dietary approach 
to stop hypertension (DASH) have shown to be associated with a reduced risk of developing chronic diseases. ${ }^{83-87}$ The interest around the relationship of diet to outcomes has expanded to the field of renal outcome research and has increased awareness of the potential harm of innumerable dietary restrictions that characterized the standard renal diet. $^{78}$ Studies have examined the relationship between indices of diet quality and the progression to ESRD in individuals with CKD and the risk for mortality in ESRD patients. ${ }^{88,89,94-102}$ In a cohort study of older adults with CKD- ESRD living in the United States, the authors reported that a healthy diet, determined by the use of several different indices, is associated with a reduced risk of kidney-associated death and with the initiation of dialysis. ${ }^{89}$ The greater the quality of the diet, the better the outcomes. ${ }^{87,89,93} \mathrm{~A}$ recent meta-analysis of cohort studies provided sound evidence that quality dietary patterns are strongly associated with higher survival in people living with ESRD. ${ }^{90}$

\section{The Alternative Healthy Eating Index (AHEI)}

The Alternative Healthy Eating Index (AHEI) ${ }^{91}$ was created in 2002 to reflect the Dietary Guidelines for Americans and it is constituted by 12 components. The component scores are added to form a total score with a maximum of 100 points. The minimum score (2.5) represents the worst adherence and the maximum score (87.5) represents the best adherence to the guidelines. This scoring metric system was designed to measure diet quality, based on foods and nutrients that are predictive of chronic disease risk. ${ }^{91}$ The AHEI is a standardized tool that can be used in nutrition interventions, monitoring and research in different populations with different chronic conditions. ${ }^{91-94}$ Huffman, et al. ${ }^{94}$ used this index to predict the risk of cardiovascular heart disease among Cubans with and 
without diabetes living in South Florida. In another study, Chiuve et al. ${ }^{95}$ measured the association between the AHEI and the risk of chronic disease in 71,495 women enrolled in the Nurses' Health Study and 41,029 men enrolled in the Health Professionals FollowUp Study. All participants were free of chronic diseases at baseline. In this prospective analysis, which included a large sample size, AHEI was strongly associated with the development of coronary heart disease, diabetes, stroke and cancer. Based on the results, the authors recommended the use of AHEI to assess the quality of the diet and to modify the diet using the results of the score. This practice will improve the overall nutrient quality of the diet and decrease the vulnerability of this population to develop other chronic diseases..$^{95}$

\section{Consequences of qualitative deficiencies in nutritional intake in CKD-ESRD patients}

In the literature of diet quality in the context of CKD and ESRD, there is mounting, emerging evidence suggests that healthy dietary patterns are associated with improved survival in this special population, which is afflicted by a high rate of mortality. ${ }^{95-98}$ Chiu et al. ${ }^{96}$ developed a quality index specially for dialysis patients in Taiwan, called Hemodialysis Eating Index (HDEI). This specific index reflects the adequacy of the dietary recommendations from the U.S. National Kidney Foundation that was adapted to include the Taiwanese 2011 Daily Food Guide. Through a prospective study, the authors examined the risk factors associated with cardiovascular disease that were related to dialysis treatment. This HDEI index is composed by a total of 12 items, including the daily servings of vegetables and fruits, nuts and soy, whole grains, high- 
protein foods, read meat, fish and white meat; among the considered items. The authors also considered the daily consumption of fish oils, saturated and trans fatty acids, plus the duration of the use of multivitamins. ${ }^{96}$ This study included 108 participants who were further divided for the analyses into two groups based on the median value of the total HDEI score, which was 72.2. After a two-month follow-up, the group with the higher HDEI (above 72.2) exhibited a significant decrease in the serum cholesterol and an increase in hemoglobin blood's levels. The analysis of the relationships of the total HDEI score and its individual components with nutritional parameters demonstrated a direct correlation with serum albumin, which is a well-established nutritional marker for morbidity and mortality in this population..${ }^{96}$ Based on the results of their study, the authors proposed that HDEI can be used as a reliable and sensitive tool for nutrition assessment and intervention, hence, effectively preventing CVD in HD Taiwanese patients.

The Japan Dialysis Outcomes and Practice Patterns Study (JDOPPS) is a large ongoing, observational study that registers and analyzes the dialysis outcomes from hemodialysis patients across Japan. Tsuruya and colleages ${ }^{97}$ compared the diet of 1,355 participants in the JDOPPS with the diet of over 3000 non-dialysis participants (healthy individuals) and identified common dietary patterns. This study also examined the associations of diet parameters with clinical outcomes. Three different dietary patterns were pre-determined as "well-balanced", "unbalanced", and "other". The authors found a significant direct association between eating an "unbalanced diet" and the risk of developing important cardiovascular clinical events, including arrhythmia, cardiac valvular disease, cardiac myopathy, pericarditis and congestive heart failure among 
others $(\mathrm{HR}=1.90,95 \%$ C.I. 1.19-3.04). The authors concluded that "unbalanced" dietary patterns increase the susceptibility for morbidity and mortality in hemodialysis patients.

Smyth et al., ${ }^{98}$ in a 14-year follow-up study, evaluated the impact of diet quality and specific diet components, including sodium and potassium intakes, on major renal outcomes in a community dwelling adults living in six different states and two urban areas in the United States. The study included a total of 544,635 participants aged 51 to 70 years who were enrolled in the American Association of Retired Persons (AARP) diet and health study funded by the National Institutes of Health (NIH). The authors assessed diet quality of the participants using different indexes: the Mediterranean Diet Score (MDS), Recommended Food Score (RFS), Dietary Approaches to Stop Hypertension (DASH) and AHEI. Death and dialysis initiation were the endpoints of this study. A total of 4,848 deaths related to renal-cause or initiated dialysis were registered. By using a multivariable Cox regression model to explore the association between these outcomes and the quality of diet, it was concluded that diet quality represented by the score of AHEI, HEI, MDS, and DASH, were significantly associated with outcomes. These findings support a relationship between healthy dietary patterns and a reduced risk of developing poor outcomes in the settings of renal diseases. The authors concluded that, when it comes to the management of the diet of CKD patients, the quality of the diet matters the most. ${ }^{98}$

Hyerang et al, ${ }^{99}$ in a cross-sectional study, assessed the quality of the diet in 62 patients from Seoul Korea receiving hemodialysis. The authors employed the Dietary Quality Index (DQI) and examined the contributors of the individual nutrients to the overall diet quality index. The authors reported inadequate energy intake in most 
participants and that consumption of essential vitamins, minerals and nutrients, such as vitamin A, C, B1 (thiamin), B2 (riboflavin), B3 (niacin), folate, calcium, phosphorus, zinc and dietary fiber were inadequate among most subjects. The average of the DQI in this cohort of HD patients was very low and the consumption of vegetables and fruit groups were especially low compared with other food groups. The main contribution of this study was demonstrating that insufficient calorie intake was the single most limiting factor for improving diet quality. ${ }^{99}$

Wai et al. ${ }^{100}$ examined diet quality using an index called the "Heart-Wise Dietary Habits Questionnaire” (DHQ) and investigated the relationship between dietary patterns and renal-related clinical outcomes in CKD patients. Similar to the results from the previous study that used the DQI, ${ }^{99}$ this study also found that all-cause mortality had a significant association with intake of fruits and vegetables (HR: 0.35 ; 95\% CI, 0.15 0.83). The authors confirmed the beneficial effects of eating adequate amount of fruit and vegetables on reducing cardiovascular-associated mortality. In addition, the authors recommended that limiting alcohol consumption and consuming adequate intake of fruits and vegetables seemed to delay disease progression to more advanced stages. According to Hyerang et al. ${ }^{99}$ and Wai et al., ${ }^{100}$ adequate fruit and vegetable intakes improve survival in patients living with CKD disease. ${ }^{100}$

Another version of the Diet Quality Index (DQI) was employed by Fernandez and colleagues ${ }^{101}$ to reflect the adequacy of the Brazilian dietary guidelines in patients with renal failure. In this cross-sectional analysis of 3-day food records of $100 \mathrm{CKD}$ patients, the authors evaluated DQI and its components. As in previous reports, lower diet quality represented by lower DQI scores corresponded to lower adequacy of specific nutrients 
and food-group intake such as sodium and vegetables intake, whereas higher DQI scores corresponded to adequate intake of meat/egg, legumes and vegetables. The authors concluded that the diet quality of this cohort of patients was poor and inadequate in vegetables composition, food variety, and sodium intake. ${ }^{101}$ Reports from studies focusing on discovering a potential relationship between the diet of patients living with kidney disease and outcomes have suggested, through different methodologies and analyses, that poor diets may lead to poor nutritional status and worse health outcomes. ${ }^{98-}$ 103

Despite the variety of indices used to evaluate the diet quality of patients, and their presumable connection to patients' nutritional status and health outcomes; ${ }^{98-102}$ it is still not clear which specific diet quality index is a stronger predictor of morbiditymortality in HD hemodialysis. ${ }^{101}$ Hence, the potential prognostic implications of the adequacy of the quality and quantity of the diet in relation to the clinical outcomes of this population warrants further studies..$^{29,100,103}$

\section{Summary}

There is a large body of evidence in the literature of the relationship between the high prevalence of both, morbidity and mortality, and the nutritional status of ESRD patients, ${ }^{8}$ where inflammation and/or dietary intake seem to be crucial additional predictors for disease-related outcomes. ${ }^{10,13}$ However, factors generating these interrelationships are not well understood and mechanisms for these relationships are lacking. The substantial restrictions and poor diets of patient receiving hemodialysis may be important contributors to poor nutritional status and worse survival, however, there is 
an important and still undefined role for inflammation and metabolic abnormalities to affect and modify PEW. ${ }^{29}$

Thus, to achieve optimal nutrition among HD patients it is necessary to systematically assess their diet and nutrition status. In addition, periodic measurements of markers of inflammation can be useful to assess severity and frequency of inflammation in patients who are at risk for developing $\mathrm{PEW} .{ }^{4}$ Studies that examine the interrelationship between dialysis outcomes, nutritional status, inflammatory biomarkers, and the interplay of diet quality and quantity, such as the study conducted and described in this dissertation, are needed.

Most of the studies being discussed in this review of the literature have several limitations that demand further research, including small sample sizes, indirect measurements of dietary intake, inconsistent or contradicting findings, and crosssectional design.

Determining impact of an inadequate nutritional intake of hemodialysis patients in development of the PEW syndrome is clear; as its strong association with morbidity and mortality. Though, the implication of low diet quality for outcomes, and its interrelation with inflammation status in the literature is contradictory. ${ }^{64}$ Adequacy in nutritional intake and healthy dietary eating patterns that facilitate the supply of nutrients needed for cardiovascular, gut and immune health may have positive prognostic implications for patients' health, through mechanisms independent of BMI or protein status. ${ }^{29}$ Therefore, it is important to examine the relationships that exist between inflammation, nutritional status and the interplay of quality and quantity of the diet, to shed a light on the plausible mechanisms involved in these associations. Consequently, furthering the knowledge that 
we have on these relationships may be translated into clinical meaningful assessments and relevant diet recommendations to improve the well-being of patients living with hemodialysis.

\section{References}

1. National Kidney Foundation. K/DOQI clinical practice guidelines for chronic kidney disease: evaluation, classification, and stratification. Am J Kidney Dis 2002;39:S1.

2. Levey AS, Eckard KU, Tsukamoto Y, et al. Definition and classification of chronic kidney disease: a position statement from Kidney Disease: Improving Global Outcomes (KDIGO). Kidney Int 2005 Jun;67(6):2089-2100.

3. Saran R, Li Y, Robinson et al. US Renal Data System 2014 Annual Data Report: Epidemiology of Kidney Disease in the United States. Am J Kidney Dis 2015 Jul;66(1) S1-S305.

4. U.S. Renal Data System, USRDS 2013 Annual Data Report: Atlas of End-Stage Renal Disease in the United States, National Institutes of Health, National Institute of Diabetes and Digestive and Kidney Diseases, Bethesda, MD, 2014.

5. Centers for Medicare and Medicaid services: Annual Report ESRD clinical performance measure project. AM J kidney Dis 2002 May; 39 (suppl 2):S4-S98.

6. O'Hare AM, Choi AI, Boscardin W, et al. Trends in timing of initiation of chronic dialysis in the United States. Arch Intern Med 2011;171(18):1663-1669.

7. Collins AJ, Foley RN et al. Excerpts from the US Renal Data System 2009 Annual Data Report. Am J Kidney Dis 2010; 55(Suppl 1):S1-420.

8. Bloembergen WE, Port FK, et all. Causes of death in dialysis patients: racial and gender differences. J Am Soc Nephrol 1994;5(5):1231-1242.

9. Riella MC. Nutritional evaluation of patients receiving dialysis for the management of protein-energy wasting: what is old and what is new? J Ren Nutr 2013 May;23(3):195-198.

10. Carrero JJ, Thomas F, Nagy K., et al. Global Prevalence of Protein-Energy Wasting in Kidney Disease: A meta-analysis of contemporary observational studies from the international society of renal nutrition and metabolism. J Ren Nutr 2018 Nov;28(6):380-92. 
11. Garg AX, Blake PG, Clark WF, et al. Association between renal insufficiency and malnutrition in older adults: results from the NHANES III. Kidney Int 2001;60(5):1867-1874.

12. Gibson RS. Principles of nutritional assessment. Oxford university press, USA; 2005.

13. Kopple JD. Nutritional status as a predictor of morbidity and mortality in maintenance dialysis patients. ASAIO J 1997;43(3):246-250.

14. https://www.cms.gov/RegulationsGuidance/Guidance/Manuals/downloads/bp102 c11.pdf. Accessed April 6, 2019.

15. Fouque D, Kalantar-Zadeh K, Kopple J, et al. A proposed nomenclature and diagnostic criteria for protein-energy wasting in acute and chronic kidney disease. Kidney Int 2008;73(4):391-398.

16. Carrero JJ, Stenvinkel P, Cuppari L, et al. Etiology of the Protein-Energy Wasting Syndrome in Chronic Kidney Disease: A Consensus Statement from the International Society of Renal Nutrition and Metabolism (ISRNM). J Ren Nutr 2013;23(2):77-90.

17. Acchiardo SR, Moore LW, Latour PA. Malnutrition as the main factor in morbidity and mortality of hemodialysis patients. Kidney Int Suppl 1983; 24(Supp116):S199-S203.

18. Dwyer JT, Larive B Leung J, Rocco MV, Greene T. Are nutritional status associated with mortality in the HEMO study? Kidney Int 2005;68(4):1766-1776.

19. Rocco MV, Paranandi L, Burrowes JD, et al. Nutritional status in the HEMO Study cohort at baseline. Hemodialysis. Am J Kidney Dis 2002 Dic;39(2):245256.

20. Pifer TB, Mccullough KP, Port FK, et al. Mortality risk in hemodialysis patients and changes in nutritional indicators: DOPPS. Kidney Int 2002;62(6):2238-2245.

21. De Mutsert R, Grootendorst DC, Boeschoten EW, et al. Subjective global assessment of nutritional status is strongly associated with mortality in chronic dialysis patients. Am J Clin Nutr 2009;89(3):787-793.

22. Kalantar-Zadeh K, Kopple JD, Block G, Humphreys MH. A malnutritioninflammation score is correlated with morbidity and mortality in maintenance hemodialysis patients. Am J Kidney Dis 2001 Dec;38(6):1251-1263. 
23. Lopes A, Bragg-Gresham L, Elder S et al. Independent and joint associations of nutritional status indicators with mortality risk among chronic hemodialysis patients in the Dialysis Outcomes and Practice Patterns Study (DOPPS). J Ren Nutr 2010 Jul;20(4):224-234.

24. Harvinder GS, Chee W, Karupaiah T, et al. Comparison of malnutrition prevalence between hemodialysis and continuous ambulatory peritoneal dialysis patients: a cross-sectional study. Malays J Nutr 2013;19(3):271-283.

25. Szuck P, Furh LM, Garcia MF, et al. Association between nutritional indicators and risk of hospitalization among hemodialysis patients. Revista de Nutrição 2016 Jun;29(3):317-327.

26. Kang SS, Chang JW, Park Y. Nutritional status predicts 10 -year mortality in patients with end-stage renal disease on hemodialysis. Nutrients 2017Apr 18;9(4):399.

27. Stephan Thijssen.Nutritional Competence and Resilience among Hemodialysis Patients in the Setting of Dialysis Initiation and Hospitalization Clin J Am Soc Nephrol 2015 Sep 4;10(9):1593-1601.

28. Ikizler TA. Nutrition, inflammation and chronic kidney disease. Curr Opin Nephrol Hypertens 2008 Mar;17(2):162-167.

29. Kovesdy CP, Shinaberger CS, Kalantar-Zadeh K. Epidemiology of dietary nutrient intake in ESRD. Semin Dial 2010 Aug;23(4):353-358.

30. Qureshi AR, Alvestrand A, Divino-Filho JC, et al. Inflammation, malnutrition, and cardiac disease as predictors of mortality in hemodialysis patients. J Am Soc Nephrol 2002 Jan;13 (Suppl 1):S28-S36.

31. Kalantar-Zadeh K, Block G, McAllister CJ, et al, Appetite and inflammation, nutrition, anemia, and clinical outcome in hemodialysis patients. Am J Clin Nutr 2004;80(2):299-307.

32. Kaysen GA, Dubin JA, Müller HG, et al. Relationships among inflammation nutrition and physiologic mechanisms establishing albumin levels in hemodialysis patients. Kidney Int 2002 Jun; 61(6):2240-2249.

33. Spittle MA, Hoenich NA, Handelman GJ, et al. Oxidative stress and inflammation in hemodialysis patients. Am J Kidney Dis 2001 Dec;38(6):1408-1413.

34. Mezzano D, Pais EO, Aranda E, et al. Inflammation, not hyperhomocysteinemia, is related to oxidative stress and hemostatic and endothelial dysfunction in uremia. Kidney Int 2001 Nov;60(5):1844-1850. 
35. Stenvinkel P, Heimbürger O, Lindholm B, Kaysen GA, Bergström J. Are there two types of malnutrition in chronic renal failure? Evidence for relationships between malnutrition, inflammation and atherosclerosis (MIA syndrome). Nephrol Dial Transplant 2000 Jul 1;15(7):953-960.

36. Kaizu Y, Kimura M, Yoneyama T, et al. Interleukin-6 may mediate malnutrition in chronic hemodialysis patients. Am J Kidney Dis 1998 Jan;31(1):93-100.

37. Stenvinkel P, Ketteler M, Johnson RJ, et al. IL-10, IL-6, and TNF- alpha: Central factors in the altered cytokine network of uremia-the good, the bad, and the ugly. Kidney Int 2005;67:1216-1233.

38. Kovesdy CP, Kalantar-Zadeh K. Why is protein-energy wasting associated with mortality in chronic kidney disease? Semin Nephrol 2009 Jan; 29(1):3-14.

39. Nowak K.L, Chonchol M. Does inflammation affect outcomes in dialysis patients? Semin Dial 2018 Jul;31(4):388-397.

40. T. Alp Ikizler. Optimal Nutrition in Hemodialysis Patients. Adv Chronic Kidney Dis 2013 Mar;20(2):181-189.

41. Okyay GU, Inal S, Onec K, et al. Neutrophil to lymphocyte ratio in evaluation of inflammation in patients with chronic kidney disease. Ren Fail 2013;35(1):29-36.

42. Turkmen K, Guney I, Yerlikaya FH, Tonbul HZ. The relationship between neutrophil-to-lymphocyte ratio and inflammation in end- stage renal disease patients. Ren Fail 2012;34(2):155-159.

43. Malhotra R, Marcelli D, Von Gersdorff. Relationship of Neutrophil-toLymphocyte Ratio and Serum Albumin Levels with C - reactive protein in Hemodialysis Patients: Results from 2 International Cohort Studies. Nephron 2015;130(4):263-270.

44. Tatar E, Mirili C, Isikyakar T, et al. The association of neutrophil/lymphocyte ratio and platelet/lymphocyte ratio with clinical outcomes in geriatric patients with stage 3-5 chronic kidney disease. Acta Clinica Belgica 2016;71(4):221-226.

45. Azab B, Daoud J, Naeem FB, et al. Neutrophil-to-Lymphocyte Ratio as a Predictor of Worsening Renal Function in Diabetic Patients (3-Year Follow-Up Study), Ren Fail 2012;34(5):571-576.

46. Gibson PH, Croal BL, Cuthbertson BH, et al. Preoperative neutrophil-lymphocyte ratio and outcome from coronary artery bypass grafting. Am Heart $\mathbf{J}$ 2007;154(5):995-1002. 
47. Azab B, Chainani V, Shah N, McGinn JT. Neutrophil-lymphocyte ratio as a predictor of major adverse cardiac events among diabetic population: a 4-year follow-up study. Angiology 2012;64(6):456-65.

48. Hung HY, Chen JS, Yeh CY, et al. Effect of preoperative neutrophil-lymphocyte ratio on the surgical outcomes of stage II colon cancer patients who do not receive adjuvant chemotherapy. Int J Colorectal Dis 2011;26(8):1059-65.

49. Isaac V, Wu CY, Huang CT., et al. Elevated neutrophil to lymphocyte ratio predicts mortality in medical inpatients with multiple chronic conditions. Medicine 2016;95(23).

50. Azab B, Bhatt VR, Phookan J, et al. Usefulness of the neutrophil-to-lymphocyte ratio in predicting short- and long-term mortality in breast cancer patients. Ann Surg Oncol 2011;19(1):217-224.

51. Keizman D, Ish-Shalom M, Huang P, et al. The association of pre-treatment neutrophil to lymphocyte ratio with response rate, progression free survival and overall survival of patients treated with sunitinib for metastatic renal cell carcinoma. Eur J Cancer 2011;48(2):202-208.

52. An X, Mao HP, Wei X, et al. Elevated neutrophil to lymphocyte ratio predicts overall and cardiovascular mortality in maintenance peritoneal dialysis patients. Int urol nephrol 2012 Otc;44(5):1521-1528.

53. Kato S, Abe T, Tsuruta Y, et al. Neutrophil/Lymphocyte ratio as a predictor of cardiovascular events in incident dialysis patients: A Japanese prospective cohort study. Clin Exp Nephrol 2014;19(4):718-724.

54. Li H, Lu X, Xiong R, Wang S. High neutrophil-to-lymphocyte ratio predicts cardiovascular mortality in chronic hemodialysis patients. Mediators of inflammation 2017.

55. Brendon L. Neuen, Nicole Leather, Alice M. et al. Neutrophil-lymphocyte ratio predicts cardiovascular and all-cause mortality in hemodialysis patients. Ren Fail 2016;38(1):70-76.

56. Erdem E, Coşkun KA, Karatas A, Dilek M, Akpolat T. Neutrophil to lymphocyte ratio in predicting short-term mortality in hemodialysis patients. J Exp Clini Med 2013;30(2):129-132.

57. Forget $\mathrm{P}$, Khalifa C, Defour J-P, et al. What is the normal value of the neutrophilto-lymphocyte ratio? BMC Research Notes 2017;10:12. 
58. Kopple JD, Berg R, Houser H, Steinman TI, Teschan P. Nutritional status of patients with different levels of chronic renal insufficiency. Kidney Int Supplement 1989 Nov;2(27).

59. Bergstrm J. Mechanisms of uremic suppression of appetite. J Ren Nutr 1999;9(3):129-132.

60. Bossola M, Tazza L, Giungi S, Luciani G. Anorexia in hemodialysis patients: an update. Kidney int 2006;70(3):417-422.

61. Davies SJ, Russell L, Bryan J, Phillips L, Russell GI: Comorbidity, urea kinetics, and appetite in continuous ambulatory peritoneal dialysis patients: their interrelationship and prediction of survival. Am J Kidney Dis 1995 Aug;26(2):353-361.

62. Araujo IC, Kamimura MA, Draibe SA, et al. Nutritional parameters and mortality in incident hemodialysis patients. J Ren Nutr 2006 Jan;16(1):27-35.

63. Singhal S, Goyle A, Gupta R. Quantitative food frequency questionnaire and assessment of dietary intake. Natl Med J India 1998;11(6):268-275.

64. Nutrition Evidence Library. A Series of Systematic Reviews on the Relationship between Dietary Patterns and Health Outcomes 2014.

65. Nazanin N, Block, G, Kopple J and Kalantar-Zadeh K. Dietary Assessment of Individuals with Chronic Kidney Disease. Semin Dial 2010;23(4):359-364.

66. Fouque D, Guebre-Egziabher F. An update on nutrition in chronic kidney disease. Int Urol Nephrol 2007;39(1):239-246.

67. Hebert JR, Hurley TG, Chiriboga DE, Barone J. A comparison of selected nutrient intakes derived from three diet assessment methods used in a low-fat maintenance trial. Public Health Nutr 1998 Sep;1(3):207-214.

68. Bingham SA, Gill C, Welch A, et al. Comparison of dietary assessment methods in nutritional epidemiology: weighed records v. $24 \mathrm{~h}$ recalls, food-frequency questionnaires and estimated-diet records. Br J Nutr 1994 Oct;72(4):619-643.

69. Kloppenburg WD, Stegeman CA, Hooyschuur M, et al. Assessing dialysis adequacy and dietary intake in the individual hemodialysis patient. Kidney Int 1999 May;55(5):196-1969.

70. Kalantar-Zadeh K, Kopple JD, Deepak S, Block D. Food intake characteristics of hemodialysis patients as obtained by food frequency questionnaire. J Ren Nutr 2002 Jan;12(1):17-31. 
71. Cooper C and Beaven S. Protein and energy content of diets of patients undergoing hemodialysis for treatment of chronic renal failure-a short report. J Hum Nutr Diet 1993;6:521-523.

72. Lorenzo V, De Bonis E, Rufino M, et al. Caloric rather than protein deficiency predominates in stable chronic hemodialysis patients. Nephrol Dial Transplant 1995 Oct;10(10):1885-1889.

73. Burrowes JD, Larive B, Cockram DB, et al. Effects of dietary intake, appetite, and eating habits on dialysis and non-dialysis treatment days in hemodialysis patients: cross-sectional results from the HEMO study. J Ren Nutr 2003 Jul;13(3):191-198.

74. Wang AY, Sanderson J, Sea MM, et al. Important factors other than dialysis adequacy associated with inadequate dietary protein and energy intakes in patients receiving maintenance peritoneal dialysis. Am J Clin Nutr 2003 Apr;77(4):834841.

75. Therrien M, Byham-Gray L, Denmark R., and Beto J. Comparison of dietary intake among women on maintenance dialysis to a Women's Health Initiative cohort: results from the NKF-CRN Second National Research Question Collaborative Study. J Ren Nutr 2014 Mar;24(2):72-80.

76. Antunes AA, Delatim Vannini F, De Arruda Silveira L, et al. Influence of protein intake and muscle mass on survival in chronic dialysis patients. Ren Fail 2010;32(9):1055-1059.

77. Cupisti A, D'Alessandro C, Valeri A, et al. Food intake and nutritional status in stable hemodialysis patients. Ren Fail 2010;32(1):47-55.

78. Khoueiry G, Waked A, Goldman M, et al. Dietary intake in hemodialysis patients does not reflect a heart healthy diet. J Ren Nutr 2011 Nov;21(6):438-447.

79. Saglimbene VM, Wong G, Ruospo M, et al. Dietary n-3 polyunsaturated fatty acid intake and all-cause and cardiovascular mortality in adults on hemodialysis: the DIET-HD multinational cohort study Clin Nutr 2019 Feb;38(1):429-437.

80. George SM, Ballard-Barbash, Manson JE, et al. Comparing Indices of Diet Quality With Chronic Disease Mortality Risk in Postmenopausal Women in the Women's Health Initiative Observational Study: Evidence to Inform National Dietary Guidance. Am J Epidemiol 2014;180(6):616-625.

81. Hu FB. Dietary pattern analysis: a new direction in nutritional epidemiology. Curr Opin Lipidol 2002;13(1):3-9. 
82. Waijers PM, Feskens EJ, Ocke MC, et al A critical review of predefined diet quality scores. Br J Nutr 2007;97(2):219-231.

83. Kant AK. Dietary patterns and health outcomes. Inter. Act Consortium. J Am Diet Assoc 2004 Apr;104(4):615-635.

84. Orlich MJ, Singh PN, Sabate J, et al. Vegetarian dietary patterns and mortality in Adventist Health Study 2. JAMA Intern Med 2013 Jul;173(13):1230-1238.

85. Gerber M, Scali JD, Michaud A, et al. Profiles of a healthful diet and its relationship to biomarkers in a population sample from Mediterranean southern France. J Am Diet Assoc 2000 Oct;100(1):1164-1171.

86. Sofi F, Abbate R, Gensini GF, Casini A:Accruing evidence on benefits of adherence to the Mediterranean diet on health: An updated systematic review and meta-analysis. Am J Clin Nutr 2010 Nov;92(5):1189-1196.

87. Seymour JD, Calle EE, Flagg EW, et al. Diet quality index as a predictor of shortterm mortality in the American Cancer Society Cancer Prevention Study II nutrition cohort. Am J Epidemiol 2003 Jun;157(11):980-988.

88. Lichtenstein AH, Appel LJ, Brands M, et al. Diet and lifestyle recommendations revision 2006: a scientific statement from the American Heart Association Nutrition Committee. Circulation 2006;114(1):82-96.

89. Gutierrez OM, Muntner P, Rizk DV, et al. Dietary patterns and risk of death and progression to ESRD in individuals with CKD: a cohort study. Am J Kidney Dis 2014 Aug;64(2):204-213.

90. Kelly J, Palmer SC, Wai SN, et al. Healthy Dietary Patterns and Risk of Mortality and ESRD in CKD: A Meta-Analysis of Cohort Studies. Clin J Am Soc Nephrol 2017 Feb;12(2):272-279.

91. McCullough ML, Feskanich D, Stempher MJ, et al. Diet quality and major chronic disease risk in men and women: moving toward improved dietary guidance. Am J Clin Nutr 2002 Dec;76(6):1261-71.

92. Drewnowski A, Fiddler EC, Dauchet L, et al. Diet quality measures and cardiovascular risk factors in France: applying the Healthy Eating Index to the SU.VI.MAX study. J Am Col Nutr 2009 FEb;28(1):22-29.

93. Inter.Act. Consortium. Adherence to predefined dietary patterns and incident type 2 diabetes in European populations: EPIC-InterAct Study. Diabetologia 2014;57(2):321-33. 
94. Huffman FG, Zarini GG, McNamara E, Nagarajan A. The Healthy Eating Index and the Alternate Healthy Eating Index as predictors of 10-year CHD risk in Cuban Americans with and without type 2 diabetes. Public Health Nutr 2011 Nov;14(11):2006-2014.

95. Chiuve SE., Fung TT, Rimm EB, et al. Alternative Dietary Indices Both Strongly Predict Risk of Chronic Disease. J Nut 2012 Jun;142(6):1009-1018.

96. Chiu YF, Chen YC, Wu PY, et al. Association between the hemodialysis eating index and risk factors of cardiovascular disease in hemodialysis patients. J Ren Nutr 2014 May;24(3):163-171.

97. Tsuruya K, Fukuma S. Dietary patterns and clinical outcomes in hemodialysis patients in Japan: a cohort study. Plus One 2015 Jan 21;10(1).

98. Smyth A, Griffin M, Yusuf S, et al. Diet and major renal outcomes: a prospective cohort study. The NIH-AARP Diet and Health Study. J Ren Nutr 2016 Sep;26(5)288-298.

99. Hyerang Kim, A Better Diet Quality is Attributable to Adequate Energy Intake in Hemodialysis Patients Clin Nutr Res 2015 Jan;4(1):46-55.

100. Wai SN, Kelly JT, Johnson DW, Campbell KL. Dietary patterns and clinical outcomes in chronic kidney disease: the CKD. QLD nutrition study. J Ren Nutr 2017 May;27(3):175-182.

101. Fernandes S, Ramos C, Ishikawa N, et al. Diet Quality of Chronic Kidney Disease Patients and the Impact of Nutritional Counseling. J Ren Nutr 2018 Nov;28(6):403-410.

102. Teiber AL, Handu DJ, Cataline DR, et al. The impact of nutrition intervention on a reliable morbidity and mortality indicator: the hemodialysis-prognostic nutrition index. J Ren Nutr 2003 Jul;13(3)186-190.

103. Morais AA, Silva MA, Faintish J, et al. Correlation of nutritional status and food intake in hemodialysis patients. Clinics 2005 Jun; 60(3):185-192. 


\title{
CHAPTER III: ASSOCIATION BETWEEN NEUTROPHIL-TO-LYMPHOCYTE RATIO, NUTRITION PARAMETERS AND HEALTH OUTCOMES IN HEMODIALYSIS PATIENTS
}

\begin{abstract}
Objective: Adverse outcomes in hemodialysis patients have been attributed, in part, to the pro-inflammatory state prevalent in this population. This study examines the relationship between neutrophil-to-lymphocyte ratio (NLR) with nutrition parameters and health outcomes in hemodialysis (HD) patients.
\end{abstract}

Design: This is a 12-month prospective cohort study that recruited 77 participants from May to Jun 2017.

Settings and subjects: Patients receiving maintenance hemodialysis.

Main outcomes: Hospitalization, transplants and mortality.

Results: Of the 77 participants, $63.8 \%$ were hospitalized, 10(13\%) died of cardiovascular diseases and 6(7.8\%) had a kidney transplant. Hospitalized participants had lower mean BMI kg/m² at baseline compared to those not hospitalized $(26.22 \pm 5.34 \mathrm{vs} 29.11 \pm 5.4$, $\mathrm{P}=0.026)$ and the percentage of patients with the lowest level of inflammation (NLR $\leq$ 1.75) was greater for not hospitalized patients than for hospitalized $(39.3 \%$ vs. $16.3 \%$, $\mathrm{P}=0.025)$. Spearman's correlations showed an inverse correlation between NLR and albumin $(\mathrm{rho}=-0.218, \mathrm{P}=0.028)$; and a direct correlation between NLR and BMI (rho=0.22, $\mathrm{P}=0.026$ ). Participants were grouped by their NLR value into quartiles for outcomes analysis: quartile $1(\mathrm{NLR} \leq 1.75)$, quartile 2 (NLR 1.76-2.6), quartile 3 (NLR 2.7-3.9) and quartile 4 (NLR $\geq 4$ ). In a multivariate cox regression analysis, participants in the lowest quartile (NLR $\leq 1.75)$ were compared to the rest on hospitalization, 
mortality and transplant. Years in dialysis, BMI kg/m² and NLR $\leq 1.75$ were significant predictors of hospitalization after adjustment $(\mathrm{P}=0.021, \mathrm{P}=0.005, \mathrm{P}=0.039$; respectively) and we observed an association of low NLR with a hazard ratio $(\mathrm{HR}=0.44,95 \%$ CI 0.20 $0.96, \mathrm{P}=0.039), \mathrm{BMI}(\mathrm{HR}=0.90,95 \% \mathrm{CI} 0.85-0.97, \mathrm{P}=0.005)$ and years in dialysis $(\mathrm{HR}=0.90,95 \%$ CI $0.83-0.98, \mathrm{P}=0.021)$ for hospitalization in overall participants. In a further analysis comparing the effect of low NLR in the subgroup of diabetic participants versus non-diabetics, it was observed that BMI $\mathrm{kg} / \mathrm{m}^{2}$ was a significant predictor for hospitalization in the non-diabetic subgroup $(\mathrm{P}=0.04)$ but not significant in the case of diabetic $(\mathrm{P}=0.128)$ after adjustments. The covariates, years in dialysis and NLR $\leq 1.75$ were significant predictors of hospitalizations in the subgroup of diabetics participants after adjustment $(\mathrm{P}=0.049, \mathrm{P}=0.044$; respectively $)$. Thus, $\mathrm{NLR} \leq 1.75$ was only significant among diabetics. Survival and hospitalization curves were analyzed by comparing all participants in the lowest inflammation quartile versus the rest (NLR $\leq$ 1.75 vs NLR $>1.75$ ). Participants with NLR $\leq 1.75$ had $100 \%$ survival rate (log-rank test, $\mathrm{P}=0.059)$ and lower hospitalization rate (log-rank test, $\mathrm{P}=0.025)$. Participants with diabetes in the lowest inflammation quartile $(\mathrm{NLR} \leq 1.75)$ had lower hospitalization rate compared with participants with diabetes in the higher inflammation quartiles $(\mathrm{NLR}>1.75)$ (log-rank test, $\mathrm{P}=0.039)$. Having a low NLR decreases $73 \%$ the risk for hospitalization in this subgroup of diabetics HD participants ( $\mathrm{HR}=0.2795 \%$ CI 0.07 $0.96, \mathrm{P}=0.044)$.

Conclusion: NLR at baseline was associated with nutritional markers (albumin, BMI) and was a predictor of hospitalizations only for diabetic patients. Low NLR at baseline 
was a predictor of lower risk of hospitalizations during 12 months in HD patients with diabetes.

\section{Introduction}

Patients with end-stage renal disease (ESRD) receiving dialysis exhibit a high hospitalization rate - approximately two admissions yearly per patient - and a $20-25 \%$ mortality rate with a 5 -year survival rate of $35 \% .^{1,2}$ In this population, cardiovascular and infectious diseases account for approximately $50 \%$ and $20 \%$ of deaths, respectively. ${ }^{1}$ These outcomes have been attributed, in part, to the prevalent pro-inflammatory state that afflicts patients living with dialysis, including uremic burden, abnormal levels of circulating pro-inflammatory cytokines, oxidative-carbonyl stress, protein-energy wasting, increased incidence of infections, and anemia. ${ }^{3,4}$ Inflammation has been implicated in the initiation and progression of atherosclerosis and in cardiovascular mortality through leukocyte adhesion and infiltration of the vascular endothelium. ${ }^{5,6}$ In hemodialysis patients, T-lymphocytes and the antigen-presenting cell (APC) functions are frequently impaired producing immune disturbances that may lead to inflammation and metabolic imbalances that lead to malnutrition. ${ }^{7}$ The vicious cycle closed by infections and subsequent malnutrition supported by inflammatory cytokines, may lead to more frequent hospitalizations and ultimately to death. The important role of the impaired immune system in these events is the mechanistic link to its relationship with the Neutrophil-to-lymphocyte ratio (NLR).

Neutrophil-to-lymphocyte ratio (NLR) has emerged as a subrogate marker for systemic inflammation in Chronic Kidney Disease (CKD) and ESRD. ${ }^{8,9}$ It is obtained by 
dividing neutrophil count by lymphocyte count, which makes it a cost effective, simple parameter that allows to easily assess the inflammatory status of a subject. ${ }^{8}$ NLR has demonstrated potential diagnostic capacity in settings where C-reactive protein is not measured routinely. ${ }^{10}$ NLR has been useful in the stratification of mortality in major cardiac events, ${ }^{11}$ as a strong prognostic factor in several types of cancers, ${ }^{12}$ and in the prediction of worsening renal function in patients with diabetes. ${ }^{13}$ While the use of NLR as a predictor of cardiovascular and all-cause mortality in patients receiving dialysis has gained recognition, there remain many barriers to its robust application. ${ }^{14}$ The correlation between NLR value and a higher adverse risk has not been thoroughly defined; it remains unknown which cutoff value will discriminate normal from abnormal results and for which population NLR will be a better predictor of adverse outcomes. The aim of this study was to examine the relationship between neutrophil-to-lymphocyte ratio and nutrition parameters with health outcomes in hemodialysis patients.

\section{Methods}

\section{Design}

A 12-month prospective cohort study was conducted at one hemodialysis clinic located in South Florida. The study protocol was approved by the Florida International University Institution Review Board (FIU-IRB) and informed consent was obtained from each patient. The sample consisted of all adult male and female patients recruited from May to Jun 2017, who agreed to participate in the study and met the inclusion criteria, which were to be 19 years of age or older, undergo hemodialysis three times per week for at least three months and being medically stable without acute infection. Participants 
were excluded if they were receiving nutrition support (intradialytic parenteral nutrition) or enteral nutrition, had dementia interfering with completing the nutritional questionnaire, or refuse to participate or perform study activities.

\section{Demographic and Clinical data}

Clinical and demographic data were collected from clinical charts and through interviews with the patients. The demographic data collected from clinical charts included age, gender, ethnicity, hemodialysis start date, $\mathrm{BMI} \mathrm{kg} / \mathrm{m}^{2}$, and diabetes mellitus diagnosis.

The biochemical data included serum albumin, net protein catabolic rate (nPCR), neutrophils and lymphocytes percent, total iron binding capacity (TIBC), and dialysis adequacy $(\mathrm{Kt} / \mathrm{V})$. All these values were collected at multiple time points for 12 months.

\section{Endpoints: Hospitalization, transplants and mortality}

Hospitalization was defined as any hospital stay lasting one night or longer. The occurrence of hospitalization was verified over 12 months as well as kidney transplant and death (all- cause mortality).

\section{Statistical analysis}

We report absolute and relative frequencies, mean, standard deviation, median, and interquartile range assuming data normality. For the inferential statistics, normal data distribution was first determined using the Kolmogorov-Smirnov test and the equality of variances was confirmed using Levene's test. One-way ANOVA, Student's t tests, chi- 
square tests, or Mann-Whitney tests were used to compare variables between groups, as appropriate. Only baseline values were included in the correlation analysis of albumin, nPCR, NLR, TIBC and Kt/V and in the statistical models for endpoint analysis. Spearman correlations were used for bivariate analysis. Significant outcome's predictors were identified and further analyzed in univariate and multivariate models, and then a forward stepwise cox regression identified the most parsimonious model. The probability used for the stepwise regression was set at 0.05 for entry of variables and 0.10 for removal. Survival and hospitalization (time to first hospitalization) curves were estimated by Kaplan-Meier analysis and compared using the log-rank test. The hazard ratios were obtained from cox regression analysis. The level of statistical significance was $\mathrm{P}<0.05$. All statistical tests were performed with SPSS version 20 software (IBM Corp., Armonk, NY, USA).

\section{Results}

\section{Demographic analysis}

Seventy-seven hemodialysis participants were enrolled in this study, with a mean age of $63.2 \pm 15.7$ years; $28.8 \%$ were female, $18.2 \%$ were Hispanics, $39 \%$ were African Americans, $31.2 \%$ were Whites and $11.7 \%$ were West Indian. Their average time

receiving dialysis was $6.2 \pm 4.2$ years, and $58.4 \%$ of the patients had diabetes. In terms of dialysis parameters, the hemodialysis doses and duration were similar for all patients. 


\section{Endpoints analysis: Hospitalization, mortality and transplants}

During the planned 12-month monitoring period, 6 participants $(7.8 \%)$ were terminated due to kidney transplant, one participant (1.2\%) was transferred to another dialysis center, and 10 (13\%) died of cardiovascular diseases (CVD).

The percent of participants who were hospitalized during the study was $63.8 \%$ with a mean \pm SD of $1.1 \pm 0.73$ hospitalizations per patient per year (PPY); $38 \%$ of the participants were admitted only once, $10 \%$ were admitted twice, and $14.2 \%$ were admitted three times or more. The causes of hospitalizations varied from infections (48.5\%), and other causes (51.5\%) such as gastrointestinal issues, access-related issues, fluid overload and planned surgeries among others. The length of the hospitalization was not recorded for any case. The mean values of the biochemical variables, including albumin, nPCR, NLR, TIBC and Kt/V, were compared at baseline, 6 months, 12 months and year average, and no statistically significant differences were detected. (All Ps $>0.05$, data not shown)

Spearman correlations were determined among total number of hospitalizations registered in 12 months and baseline values of BMI kg/m², albumin, $\mathrm{nPCR}, \mathrm{NLR}, \mathrm{TIBC}$. There was an inverse significant correlation between the total number of hospitalizations and BMI kg/m² (BMI: rho=-0.37, $\mathrm{P}<0.001)$. Correlations between total numbers of hospitalizations with albumin, nPCR, NLR, and TIBC, did not achieve statistical significance (albumin: rho $=-0.04, \mathrm{P}=0.36$; $\mathrm{nPCR}$ : rho $=-0.13, \mathrm{P}=0.14$; NLR: rho=0.16, $\mathrm{P}=0.07$; TIBC: $\mathrm{rho}=0.18, \mathrm{P}=0.06$ ). We found a significant inverse correlation between NLR and albumin ( $\mathrm{rho}=-0.22, \mathrm{P}=0.028)$; and a significant direct correlation between

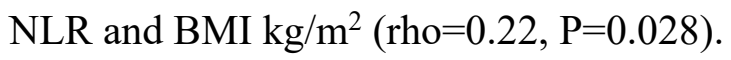


Participants were grouped by their NLR value into quartiles for the analysis of NLR as a marker of inflammation and endpoints (Table 1): quartile 1 (NLR $\leq 1.75$ ), quartile 2 (NLR 1.76-2.6), quartile 3 (NLR 2.7-3.9) and quartile 4 (NLR $\geq 4$ ). Baseline cohort characteristics, including demographic and baseline biochemical variables, are summarized in Table 1. Those examined variables that showed significance level with a $\mathrm{P} \leq 0.2$ (one-way ANOVA and chi-square test) and pre-determined variables, were further analyzed in multivariate and a stepwise cox regression model (Table 3).

Table 2 shows a comparison between hospitalized and not hospitalized patients. The BMI $\mathrm{kg} / \mathrm{m}^{2}$ (mean $\pm S D$ ) for not hospitalized patients was significantly higher than for hospitalized $(29.1 \pm 5.4,26.2 \pm 5.3 ; \mathrm{P}=0.026)$. The percent of participants with the lowest level of inflammation $(\mathrm{NLR} \leq 1.75)$ was greater for participants who were not hospitalized than for those hospitalized ( $39.3 \%$ vs. $16.3 \%, \mathrm{P}=0.025)$. No statistically significant difference was detected between participants who had at least one hospitalization and participants who did not have any hospitalization during the period of the study by age, gender, years in dialysis, diabetes, ethnicity, albumin, nPCR, TIBC and $\mathrm{Kt} / \mathrm{V}$, (all Ps $>0.05)$.

Table 3 shows a multivariate cox regression analysis that was constructed to test the contribution of each pre-determined variable to the dependent variable (all causehospitalization) in the entire cohort. Significant predictors were subsequently added to the multivariate model and forward stepwise Cox regression, which identified the most parsimonious model. The probability used for the stepwise regression was set at 0.05 for entry of variables and 0.10 for removal. Years in dialysis, BMI $\mathrm{kg} / \mathrm{m}^{2}$ and $\mathrm{NLR} \leq 1.75$ were significant predictors of hospitalization after adjustment. We observed an 
association of lower NLR (HR=0.44, 95\% CI 0.20-0.96, $\mathrm{P}=0.039)$, higher BMI $(\mathrm{HR}=0.90,95 \% \mathrm{CI} 0.85-0.97, \mathrm{P}=0.005)$ and more years in dialysis $(\mathrm{HR}=0.90,95 \% \mathrm{CI}$ 0.83-0.98, $\mathrm{P}=0.021)$ with hospitalization (Table 3).

Table 4 shows a multivariate cox regression analysis that was constructed to evaluate the contribution of each pre-determined variable to the dependent variable (all cause-hospitalization) in the subgroup diabetics versus non-diabetic participants. Following the same analysis, significant predictors were subsequently added to the multivariate model and forward stepwise cox regression identified the most parsimonious model. The probability used for the stepwise regression was set at 0.05 for entry of variables and 0.10 for removal. In this analysis, $\mathrm{BMI} \mathrm{kg} / \mathrm{m}^{2}$ was a significant predictor for hospitalization in non-diabetic subgroup $(\mathrm{P}=0.040)$ but not significant in the case of diabetics $(\mathrm{P}=0.128)$ after adjustments. The covariates, years in dialysis and NLR $\leq 1.75$ were significant predictors of hospitalizations in the subgroup of diabetics participants after adjustment $(\mathrm{P}=0.049, \mathrm{P}=0.044$; respectively). Thus, when the effect of low NLR was compared diabetics to non-diabetics, NLR $\leq 1.75$ was only significant among diabetics. Having a low NLR decreases $73 \%$ the risk for hospitalization in this subgroup of participants $(\mathrm{HR}=0.2795 \%$ CI 0.07-0.96, $\mathrm{P}=0.044)$ (Table 4).

In addition, to analyze the effect of the lowest level of inflammation on the endpoints of the study; survival and hospitalization curves were analyzed by comparing participants in the lowest quartile of inflammation versus the rest (NLR $\leq 1.75$ vs NLR $>1.75$ ). Figure 1(A) the Kaplan-Meier curve for mortality. Participants with NLR $\leq 1.75$ had a marginal significant $100 \%$ survival rate (log-rank test, $\mathrm{P}=0.059)$. Figure $1(\mathrm{~B})$ shows the hospitalization curve comparing all participants in the lowest quartile of inflammation 
versus the rest. Participants in the lowest quartile had a lower hospitalization rate (logrank test, $\mathrm{P}=0.025)$. When the subgroup of diabetics was analyzed; participants with diabetes and in the lowest quartile of inflammation $(\mathrm{NLR} \leq 1.75)$ had lower hospitalization rate compared with participants with diabetes in the higher quartile of inflammation $(\mathrm{NLR}>1.75)(\log$ - rank test, $\mathrm{P}=0.039)($ Figure $(\mathrm{C}))$. In total, there were 10 deaths in this cohort in 12 months: seven of them from quartile 2 and two from quartile 3 and one from quartile 4 . Survival was $100 \%$ in the lowest quartile of inflammation (quartile, NLR $\leq 1.75$ ). Further analysis may be needed with a larger sample and/or over longer period to clarify the role of inflammation on these particular health outcomes. Kaplan-Meier hospitalization curves still supported the findings that level of inflammation is predictive of hospitalization but not of mortality, [Figure 1 (A) (B) (C)]. Participants with NLR $\leq 1.75$ had lower hospitalization rate compared with participants with greater NLR levels (log-rank test, $\mathrm{P}=0.025)$ and this protective effect was more significant for diabetic participants (log- rank test, $\mathrm{P}=0.039)$.

\section{Discussion}

Several adverse clinical outcomes have been associated with systemic inflammation markers in CKD and ESRD, including cardiovascular events, kidney

disease progression, anemia, protein energy wasting, and all-cause mortality. ${ }^{7,10,13}$ In this study, we evaluated the predictive value of NLR for health outcomes: hospitalization, transplant, and mortality in patients receiving hemodialysis. The results indicated that NLR was a significant predictor of hospitalization in diabetic patients. Our results support previously reported findings that show the usefulness of this novel marker in 
outcomes prediction. NLR has been shown to be a strong and independent predictor of cardiovascular disease severity and mortality in the general population ${ }^{10}$ In 2012 , AnX. et al. ${ }^{15}$ reported the predictive value of NLR for cardiovascular mortality in patients receiving peritoneal dialysis, and more recently, in 2017, Han Li et al. ${ }^{16}$ found that NLR was an independent predictor of cardiovascular risk and mortality in patients receiving maintenance hemodialysis. In 2013, Erdem et al. ${ }^{17}$ also reported the usefulness of NLR in predicting short-term mortality among Turkish patients receiving hemodialysis in a hospital setting. However, in our study, the effect of NLR on mortality did not reach significance.

The hospitalization of hemodialysis patients in the United States varies from 51.0 to $67.0 \% .{ }^{1}$ In our cohort $(\mathrm{N}=77)$, the percent of participants who were hospitalized was $63.8 \%$ and mean hospitalization patient-per-year (PPY) was $1.1 \pm \mathrm{SD} 0.73$, which is below the adjusted rate of hospitalizations for hemodialysis patients reported in 2014, which was 1.7 PPY. ${ }^{1}$ When we compared the hospitalization rate of participants in the lowest level of inflammation versus the rest, we found that a low NLR had a significant protective effect among patients with diabetes. Interestingly, a similar significant effect was not observed in participants without diabetes. In agreement with our findings, Azab et al., in two long-term follow-up studies, analyzed the usefulness of NLR specifically for patients with diabetes and reported a correlation between high NLR and worsening of kidney function. ${ }^{13,18}$ Furthermore, they found that NLR was a predictor of major adverse cardiac events among patients with diabetes with stage five kidney disease. ${ }^{18}$

While our analyses did not reveal a significant correlation between inflammation and mortality, there seems to be a possible effect to be further investigated, as there were 
no deaths in the lowest NLR quartile, and the ten deaths registered during the study occurred in the higher NLR quartiles. The reason behind this finding needs to be studied in the future with a larger sample size.

Our study also showed an unusual relationship between BMI $\mathrm{kg} / \mathrm{m}^{2}$ and number of hospitalizations; as BMI kg/m² increased, the number of hospitalizations decreased $(\mathrm{rho}=-0.37 \mathrm{P}<0.001)$.This trend has the opposite direction to that observed in the general population, where the higher the BMI, the greater the risk of morbidity and mortality. ${ }^{19}$ This epidemiological paradox, in which high BMI $\mathrm{kg} / \mathrm{m}^{2}$ is associated with improved survival, is found in patients with CKD and undergoing hemodialysis and it has been previously reported. ${ }^{20,21}$

In our cohort, participants with higher BMI $\mathrm{kg} / \mathrm{m}^{2}$ had $10 \%$ lower risk of hospitalization $(\mathrm{HR}=0.90,95 \% 0.85-0.97, \mathrm{P}=0.005)$, and participants with greater number of years in dialysis had less risk for hospitalization ( $\mathrm{HR}=0.90,95 \% \mathrm{CI}$ 0.83-0.98, $\mathrm{P}=0.021$ ). This might suggest that, in hemodialysis patients with increased BMI, increased body fat, and more years in dialysis is related to less adverse events that ultimately require hospitalizations. The known 5-year survival rate is 35\% for ESRD patients, ${ }^{1}$ therefore, long-term survivors seem to be more stable and resilient to hospitalization in our cohort. Not hospitalized patients had a mean of $7.1 \pm \mathrm{SD} 4.8$ year in dialysis versus $5.6 \pm \mathrm{SD} 3.7$ for participants who were hospitalized, at least once, in 12 months. This difference became significant after adjustment $(\mathrm{P}=0.021)$ for all participants (Table 3) and for diabetics $(\mathrm{P}=0.049)$ (Table 4).

NLR had an inverse correlation with albumin $($ rho $=-0.218, \mathrm{P}=0.028)$; and a direct, significant correlation with $\mathrm{BMI} \mathrm{kg} / \mathrm{m}^{2}(\mathrm{rho}=0.222, \mathrm{P}=0.026)$. The inverse 
correlations between several makers of inflammation and albumin are well established. ${ }^{22,}$ ${ }^{23}$ It has been known that albumin levels decrease with inflammation due to diminished synthesis, augmented catabolism, and translocation of albumin to extravascular pools. ${ }^{23}$ Likewise, the direct correlation between BMI and markers of inflammation have been reported recently in hemodialysis patients. ${ }^{24}$ This 12 -month cohort study suggested that NLR values were significantly associated with parameters of nutritional status and inflammation (albumin and BMI) and hospitalizations. Lower quartile of inflammation $(\mathrm{NLR} \leq 1.75)$ predicted hospitalization and had a stronger protective effect in hemodialysis patients with diabetes than in those hemodialysis patients without diabetes. Inflammation characterized by increased levels of pro-inflammatory cytokines has been recognized as having the potential for numerous complications in chronic dialysis, including mortality. ${ }^{25,26}$ The etiology of this observation remains unknown, and a thorough understanding of the mechanisms behind this relationship between inflammation and adverse outcomes needs to be more clearly explained, as this topic is a continuous subject of current investigations and controversies. ${ }^{27,}{ }^{28}$ In conclusion, the knowledge that this study adds to close the gap in the renal literature, is that NLR is an adequate novel marker of inflammation strongly associated with nutritional markers (albumin, BMI) and is a predictor of hospitalizations. The mechanism through which high or low inflammation influences the mortality and hospitalization rate of hemodialysis patients, however, needs further elucidation. 


\section{Limitations}

The generalization of our findings to other hemodialysis populations are limited by a small sample size of participants from only one clinic facility. Despite multiple measures of NLR through 12 months, a longitudinal analysis of this marker needs to be performed and only baseline values were examined as predictors. This study did not compare the predictive strength of NLR with other potential inflammation markers, such as C-reactive protein and interleukin-6, only with albumin. Further studies are needed to answer which NLR cutoff values are clinically meaningful and for which population NLR will be a better predictor of adverse outcomes.

\section{Conclusion}

Our study supports the use of neutrophil-to-lymphocyte ratio, an inexpensive and convenient inflammation marker, as a predictor of adverse outcomes in hemodialysis patients. This study provides significant information regarding risk factors for hospitalization and confirms the protective value that a low neutrophil-to lymphocyte ratio might have on the risk of hospitalizations in hemodialysis patients with diabetes, identifying patients in need of intervention. 
Table 1: Baseline characteristics of the overall participants and comparing participants grouped into NLR quartiles ${ }^{\mathrm{a}}$

\begin{tabular}{|c|c|c|c|c|c|c|}
\hline \multirow[t]{2}{*}{ Variable } & overall & $\begin{array}{c}\text { quartile } 1 \\
\text { NLR } \\
(\leq 1.75)\end{array}$ & $\begin{array}{c}\text { NLR } \\
(1.76-2.6)\end{array}$ & $\begin{array}{c}\text { NLR } \\
(2.7-3.9)\end{array}$ & $\begin{array}{c}\text { quartile } 4 \\
\text { NLR } \\
(\geq 4.0)\end{array}$ & \multirow[t]{2}{*}{$\begin{array}{l}P- \\
\text { values }^{b}\end{array}$} \\
\hline & $\mathrm{N}=77$ & $\mathrm{~N}=19$ & $\mathrm{~N}=21$ & $\mathrm{~N}=18$ & $\mathrm{~N}=19$ & \\
\hline Baseline & Mean $\pm S D$ & $M e a n \pm S D$ & Mean $\pm S D$ & Mean $\pm S D$ & \multicolumn{2}{|c|}{ Mean $\pm S D$} \\
\hline Age & $62.3 \pm 12.7$ & $62.4 \pm 12$ & $61.3 \pm 16$ & $64.8 \pm 13.9$ & $64.8 \pm 20.3$ & $0.861^{*}$ \\
\hline Female & $28.6 \%$ & $36.8 \%$ & $14.3 \%$ & $22.2 \%$ & $42.1 \%$ & $0.174 * *$ \\
\hline $\begin{array}{l}\text { Years in } \\
\text { dialysis }\end{array}$ & $6.2 \pm 4.2$ & $6.4 \pm 4.8$ & $6.8 \pm 3.9$ & $6.5 \pm 5.0$ & $5.1 \pm 2.9$ & $0.598^{*}$ \\
\hline BMI & $27.2 \pm 5.5$ & $26.8 \pm 5$ & $25.6 \pm 4.7$ & $28.8 \pm 5.9$ & $28.1 \pm 5.2$ & $0.290^{*}$ \\
\hline Diabetes & $58.4 \%$ & $42.1 \%$ & $47.6 \%$ & $66.7 \%$ & $78.9 \%$ & $0.068 * *$ \\
\hline Ethnicity: & & & & & & \\
\hline Hispanic & $18.2 \%$ & $10.5 \%$ & $19.0 \%$ & $22.2 \%$ & $21.1 \%$ & $0.024 * *$ \\
\hline Black & $39.0 \%$ & $52.6 \%$ & $52.4 \%$ & $33.3 \%$ & $15.8 \%$ & \\
\hline White & $31.2 \%$ & $15.8 \%$ & $14.3 \%$ & $44.4 \%$ & $52.6 \%$ & \\
\hline West & $11.7 \%$ & $21.1 \%$ & $14.3 \%$ & $0.0 \%$ & $10.5 \%$ & \\
\hline Indian & & & & & & \\
\hline Albumin & $3.8 \pm 0.3$ & $3.8 \pm 0.3$ & $3.9 \pm 0.2$ & $3.7 \pm 0.3$ & $3.7 \pm 0.3$ & $0.098^{*}$ \\
\hline $\mathrm{Kt} / \mathrm{V}^{1}$ & $1.4 \pm 0.2$ & $1.5 \pm 0.2$ & $1.5 \pm 0.2$ & $1.4 \pm 0.2$ & $1.5 \pm 0.2$ & $0.396^{*}$ \\
\hline TIBC $^{2}$ & $214 \pm 30$ & $214 \pm 31$ & $210 \pm 27$ & $217 \pm 31$ & $218 \pm 32$ & $0.845^{*}$ \\
\hline $\mathrm{nPCR}^{3}$ & $0.9 \pm 0.2$ & $0.9 \pm 0.3$ & $0.9 \pm 0.2$ & $0.9 \pm 0.3$ & $1.1 \pm 0.34$ & $0.147^{*}$ \\
\hline $\mathrm{NLR}^{4}$ & $2.9 \pm 1.8$ & $1.1 \pm 0.4$ & $2.2 \pm 0.2$ & $3.2 \pm 0.3$ & $5.4 \pm 1.7$ & $0.000 *$ \\
\hline $\begin{array}{l}\text { \# Hosp. per } \\
\text { patient }\end{array}$ & $1.1 \pm 0.73$ & $0.9 \pm 1.6$ & $1.4 \pm 1.1$ & $2.0 \pm 0.4$ & $1.4 \pm 1.1$ & $0.628 *$ \\
\hline Hospitalized & $63.8 \%$ & $42.1 \%$ & $90.5 \%$ & $38.9 \%$ & $78.9 \%$ & $0.043 * *$ \\
\hline Transplanted & $7.8 \%$ & $10.5 \%$ & $4.8 \%$ & $11.1 \%$ & $5.3 \%$ & $0.820 * *$ \\
\hline Mortality & $13 \%$ & $0 \%$ & $33.3 \%$ & $11.1 \%$ & $5.3 \%$ & $0.001 * *$ \\
\hline
\end{tabular}

*one-way ANOVA test **likelihood ratio chi-square test ${ }^{a}$ quartiles: quartile 1 (NLR $\left.\leq 1.75\right)$, quartile 2 (NLR 1.76-2.6), quartile 3 (NLR 2.7-3.9) and quartile 4 (NLR $\left.\geq 4.0\right)$ $b_{\text {Statistically significant, } P<0.05}$

${ }^{1} \mathrm{Kt} / \mathrm{V}=$ dialysis clearance, ${ }^{2} \mathrm{TIBC}=$ total iron binding capacity, ${ }^{3} \mathrm{nPCR}=$ net protein catabolic rate, ${ }^{4} \mathrm{NLR}=$ neutrophil-tolymphocite ratio, $\#=$ number of hospitalizations per patient 
Table 2: Table of characteristic comparing not hospitalized versus hospitalized

\begin{tabular}{lccc}
\hline Variable & $\begin{array}{c}\text { Not Hospitalized } \\
\mathrm{N}=28\end{array}$ & $\begin{array}{c}\text { Hospitalized } \\
\mathrm{N}=49\end{array}$ & P-value $^{a}$ \\
\hline Baseline & mean \pm SD & mean $\pm S D$ & \\
Age & & & \\
Female & $63.2 \pm 14.7$ & $63.3 \pm 16.4$ & $0.981^{*}$ \\
Years in dialysis & $28.6 \%$ & $28.6 \%$ & $0.607^{*}$ \\
BMI & $7.1 \pm 4.8$ & $5.6 \pm 3.7$ & $0.132^{*}$ \\
Diabetes & $29.1 \pm 5.4$ & $26.2 \pm 5.3$ & $0.026^{*}$ \\
Ethnicity & $50.0 \%$ & $36.7 \%$ & $0.185^{* *}$ \\
Hispanic & & & \\
Black & $17.9 \%$ & $18.4 \%$ & $0.373^{* *}$ \\
White & $46.4 \%$ & $34.7 \%$ & \\
West Indian & $32.1 \%$ & $30.6 \%$ & \\
& $3.6 \%$ & $16.3 \%$ & \\
Albumin & & & \\
Kt $^{1}$ & $3.7 \pm 0.3$ & $3.8 \pm 0.3$ & $0.501^{*}$ \\
TIBC $^{2}$ & $1.5 \pm 0.2$ & $1.4 \pm 0.2$ & $0.828^{*}$ \\
nPCR $^{3}$ & $207.5 \pm 30.3$ & $218.6 \pm 29.8$ & $0.141^{*}$ \\
NLR $^{4}$ & $0.9 \pm 0.2$ & $0.9 \pm 0.3$ & $0.862^{*}$ \\
NLR $^{4} \leq 1.75$ & $2.6 \pm 1.7$ & $3.2 \pm 1.8$ & $0.215^{*}$ \\
\hline
\end{tabular}

${ }^{*}$ student $T$ test $* *$ chi-square test, ${ }^{a}$ statistically significant, $P<0.05$

${ }^{1} \mathrm{Kt} / \mathrm{V}=$ dialysis clearance, ${ }^{2} \mathrm{TIBC}=$ total iron binding capacity, ${ }^{3} \mathrm{nPCR}=$ net protein catabolic rate, ${ }^{4} \mathrm{NLR}=$ neutrophil-tolymphocite ratio. 
Table 3: Multivariate Cox regression model for all-cause of hospitalizations in all participants

\begin{tabular}{|c|c|c|c|c|c|c|c|c|}
\hline \multirow[b]{2}{*}{ Covariate } & \multirow[b]{2}{*}{$\begin{array}{c}\text { un- } \\
\text { adjusted } \\
\mathrm{HR}^{\mathrm{b}}\end{array}$} & \multicolumn{2}{|c|}{$95 \% \mathrm{CI}$} & \multirow[b]{2}{*}{$\begin{array}{c}P- \\
\text { value }^{a}\end{array}$} & \multirow[b]{2}{*}{$\begin{array}{c}\text { adjusted } \\
\mathrm{HR}^{\mathrm{b}}\end{array}$} & \multicolumn{2}{|c|}{$95 \% \mathrm{CI}$} & \multirow[b]{2}{*}{$\begin{array}{c}P- \\
\text { value }^{a}\end{array}$} \\
\hline & & Lower & Upper & & & Lower & Upper & \\
\hline Age & 0.99 & 0.98 & 1.01 & 0.869 & - & - & - & - \\
\hline Sex & 1.00 & 0.54 & 1.87 & 0.985 & - & - & - & - \\
\hline Ethnicity & 1.16 & 0.84 & 1.59 & 0.349 & - & - & - & - \\
\hline Diabetic & 1.42 & 0.79 & 2.55 & 0.229 & - & - & - & - \\
\hline $\begin{array}{l}\text { Years in } \\
\text { dialysis }\end{array}$ & 0.94 & 0.88 & 1.01 & 0.134 & 0.90 & 0.83 & 0.98 & 0.021 \\
\hline BMI* & 0.94 & 0.89 & 0.99 & 0.044 & 0.90 & 0.85 & 0.97 & 0.005 \\
\hline Albumin* & 1.39 & 0.49 & 3.92 & 0.525 & - & - & - & - \\
\hline nPCR*3 & 0.74 & 0.26 & 2.08 & 0.573 & - & - & - & - \\
\hline TIBC $* 2$ & 1.00 & 0.99 & 1.01 & 0.137 & - & - & - & - \\
\hline $\mathrm{Kt} / \mathrm{V}^{* 1}$ & 0.82 & 0.19 & 3.53 & 0.794 & - & - & - & - \\
\hline $\mathrm{NLR}^{4} \leq 1.75^{*}$ & 0.44 & 0.20 & 0.95 & 0.038 & 0.44 & 0.20 & 0.96 & 0.039 \\
\hline
\end{tabular}

*baseline

${ }^{a}$ statistically significant, $P<0.05$, ${ }^{\mathrm{b}} \mathrm{HR}=$ Hazard ratio

${ }^{1} \mathrm{Kt} / \mathrm{V}=$ dialysis clearance, ${ }^{2} \mathrm{TIBC}=$ total iron binding capacity, ${ }^{3} \mathrm{nPCR}=$ net protein catabolic rate, ${ }^{4} \mathrm{NLR}=$ neutrophil-tolymphocite ratio 
Table 4: Multivariate Cox regression model for all-cause of hospitalizations in diabetic and non-diabetic patients

\begin{tabular}{|c|c|c|c|c|c|c|c|c|}
\hline \multirow[b]{2}{*}{ Covariate } & \multirow[b]{2}{*}{$\begin{array}{c}\text { un } \\
\text { adjusted } \\
\text { Hazard } \\
\text { ratio }\end{array}$} & \multicolumn{2}{|c|}{$95 \%$ CI } & \multirow[b]{2}{*}{$\begin{array}{c}\text { P- } \\
\text { value }^{\mathrm{a}}\end{array}$} & \multirow[b]{2}{*}{$\begin{array}{c}\text { adjusted } \\
\text { Hazard } \\
\text { ratio } \\
\end{array}$} & \multicolumn{2}{|c|}{$95 \%$ CI } & \multirow[b]{2}{*}{$\begin{array}{c}\text { P- } \\
\text { value }^{\mathrm{a}}\end{array}$} \\
\hline & & Lower & Upper & & & Lower & Upper & \\
\hline \multicolumn{9}{|c|}{ NON-DIABETIC } \\
\hline Age & 1.01 & 0.98 & 1.04 & 0.458 & - & - & - & - \\
\hline Sex & 1.48 & 0.52 & 4.18 & 0.452 & - & - & - & - \\
\hline Ethnicity & 1.04 & 0.63 & 1.71 & 0.873 & - & - & - & - \\
\hline $\begin{array}{l}\text { Years in } \\
\text { dialysis }\end{array}$ & 0.99 & 0.89 & 1.09 & 0.856 & 0.97 & 0.87 & 1.08 & 0.593 \\
\hline BMI* & 0.91 & 0.83 & 1.00 & 0.050 & 0.90 & 0.83 & 0.99 & 0.040 \\
\hline Albumin* & 1.66 & 0.24 & 11.51 & 0.606 & - & - & - & - \\
\hline $\mathrm{nPCR} * 1$ & 0.57 & 0.06 & 5.23 & 0.619 & - & - & - & - \\
\hline $\mathrm{TIBC} * 2$ & 1.00 & 0.98 & 1.02 & 0.561 & - & - & - & - \\
\hline $\mathrm{Kt} / \mathrm{V} * 3$ & 3.45 & 0.19 & 60.36 & 0.395 & - & - & - & - \\
\hline $\begin{array}{l}\mathrm{NLR}^{4} \\
\leq 1.75^{*}\end{array}$ & 0.63 & 0.22 & 1.79 & 0.394 & 0.60 & 0.21 & 1.72 & 0.347 \\
\hline \multicolumn{9}{|c|}{ DIABETIC } \\
\hline Age & 0.98 & 0.96 & 1.00 & 0.240 & - & - & - & - \\
\hline Sex & 0.72 & 0.33 & 1.58 & 0.425 & - & - & - & - \\
\hline Ethnicity & 1.20 & 0.82 & 1.90 & 0.295 & - & - & - & - \\
\hline $\begin{array}{l}\text { Years in } \\
\text { dialysis }\end{array}$ & 0.91 & 0.83 & 1.01 & 0.082 & 0.89 & 0.80 & 0.99 & 0.049 \\
\hline BMI* & 0.97 & 0.90 & 1.04 & 0.398 & 0.93 & 0.85 & 1.02 & 0.128 \\
\hline Albumin* & 1.45 & 0.43 & 4.87 & 0.540 & - & - & - & - \\
\hline nPCR*1 & 0.93 & 0.28 & 3.06 & 0.911 & - & - & - & - \\
\hline TIBC $* 2$ & 1.00 & 0.99 & 1.01 & 0.240 & - & - & - & - \\
\hline $\mathrm{Kt} / \mathrm{V} * 3$ & 0.50 & 0.08 & 2.89 & 0.441 & - & - & - & - \\
\hline $\begin{array}{l}\mathrm{NLR}^{4} \\
\leq 1.75^{*}\end{array}$ & 0.33 & 0.10 & 1.11 & 0.075 & 0.27 & 0.07 & 0.96 & 0.044 \\
\hline
\end{tabular}


Figure A: Kaplan-Meier estimates of mortality for overall participants

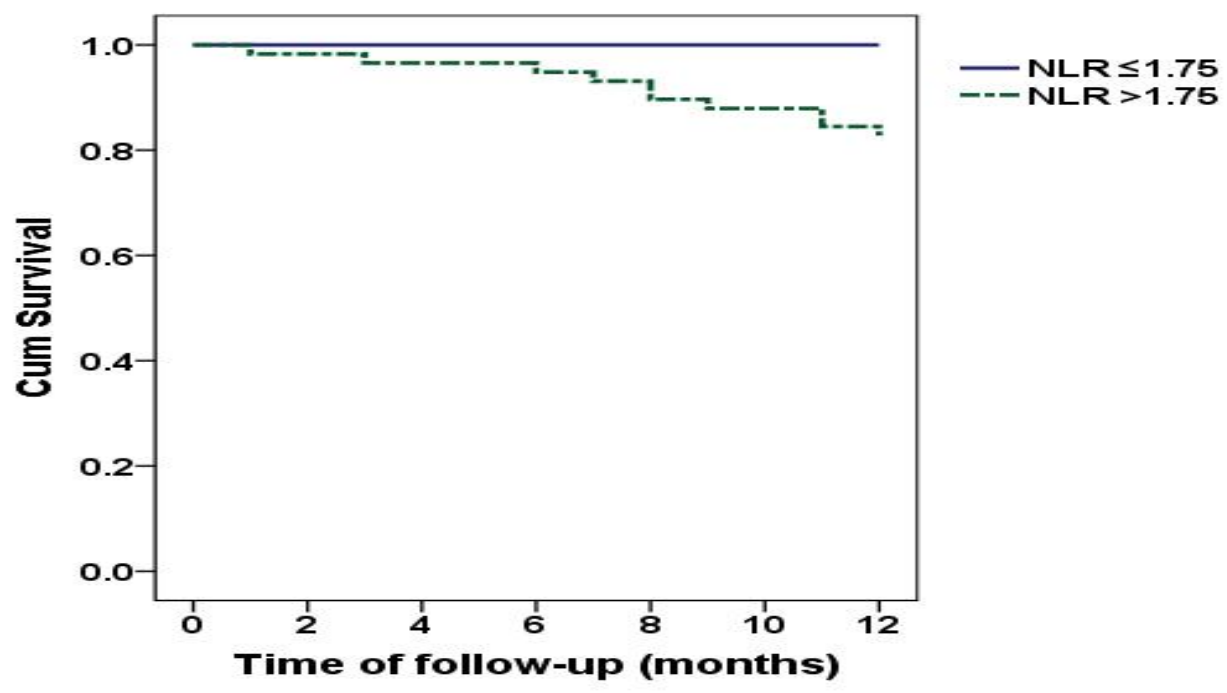

Figure B: Kaplan-Meier estimates of hospitalization for overall participants

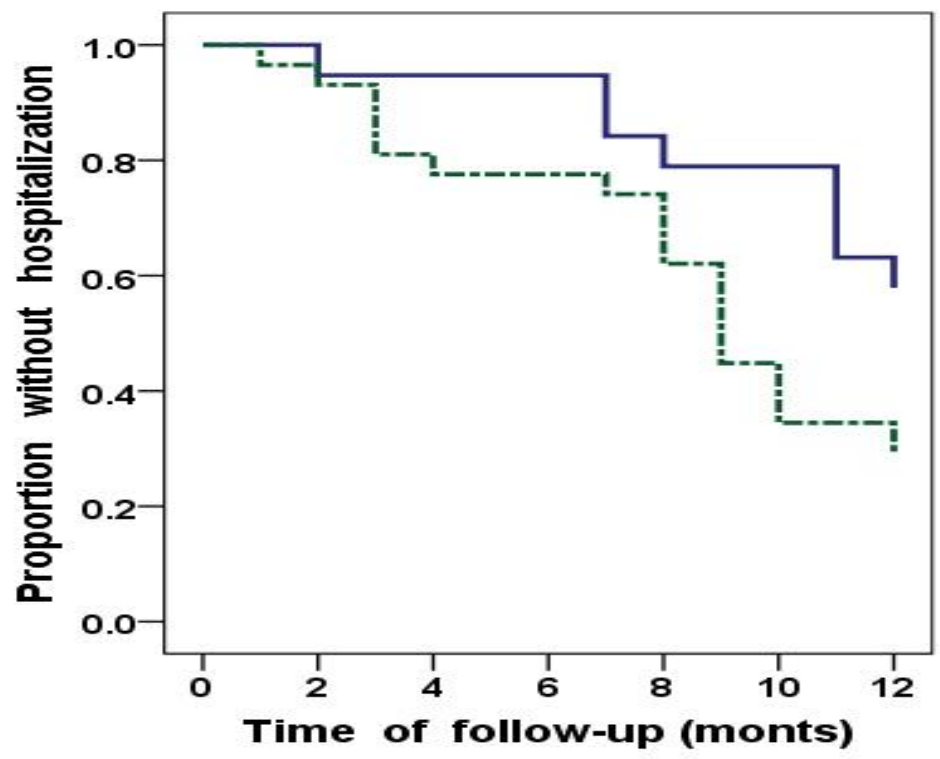

$-N L R \leq 1.75$

NLR $>1.75$ 
Figure C: Kaplan-Meier estimates of hospitalization for participants with diabetes

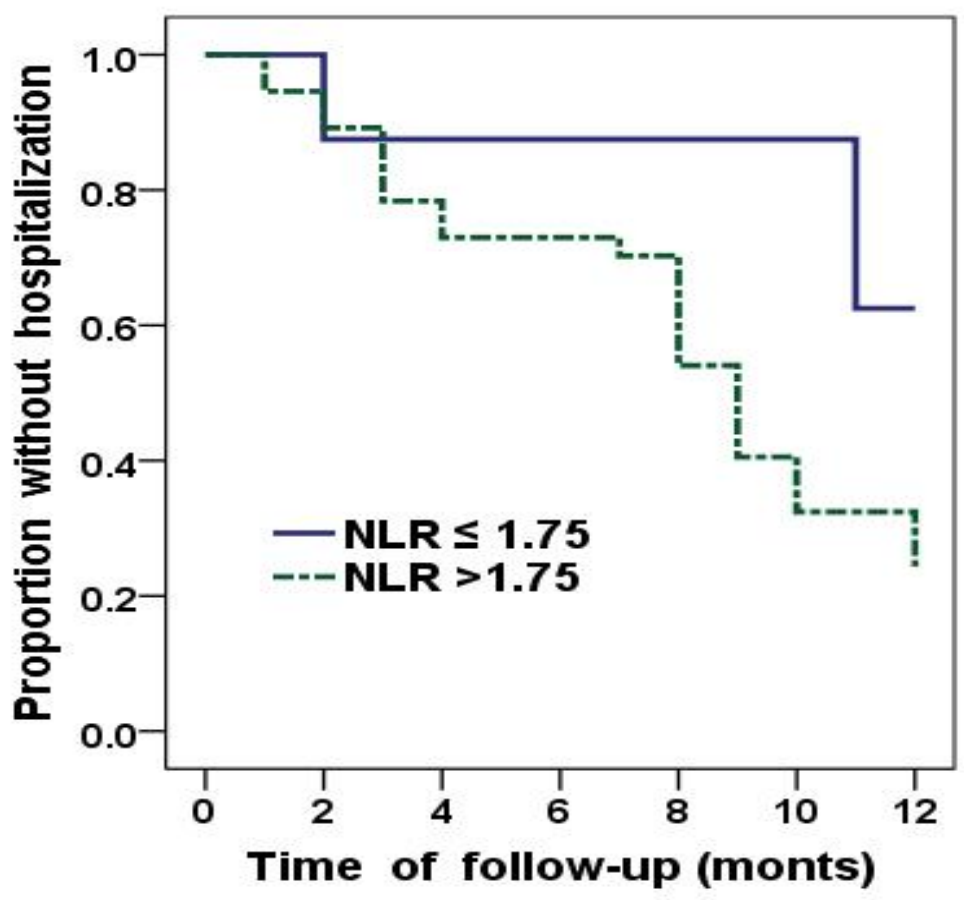

Kaplan-Meier estimates of mortality and hospitalization. Participants stratified by two groups based on the neutrophillymphocyte ratio (NLR): quartile 1 corresponding to the lowest inflammation quartile $(N L R \leq 1.75)$ vs the rest of quartiles (NLR >1.75).

Fig $A$ showed that NLR was not associated with mortality (log-rank test, $P=0.059$ )

Fig $B$ showed that NLR was associated with hospitalization (log-rank $P=0.025$ )

Fig $C$ showed that NLR was associated with hospitalization in participants with diabetes (log-rank test, $P=0.039)$ 
References

1. Foley RN, Collins AJ. End-stage renal disease in the United States: an update from the United States Renal Data System. J Am Soc Nephrol 2007 Oct;8(10):2644-2648.

2. Collins AJ, Foley RN, Gilbertson DT, Chen SC. United States Renal Data System public health surveillance of chronic kidney disease and end-stage renal disease. Kidney Int Suppl 2015 Jun;5(1):2-7.

3. de Mutsert R, Grootendorst DC, Axelsson J, Boeschoten EW, Krediet RT, Dekker FW, NECOSAD Study Group. Excess mortality due to interaction between protein-energy wasting, inflammation and cardiovascular disease in chronic dialysis patients. Nephrol Dial Transplant 2008 Apr 9;23(9):2957-2964.

4. Ikizler TA. Optimal nutrition in hemodialysis patients. Adv Chronic Kidney Dis 2013 Mar;20(2):181-189.

5. Libby P. Inflammation in atherosclerosis. Arterioscler Thromb Vasc Biol 2012 Sep;32(9):2045-2051.

6. Iseki K, Tozawa M, Yoshi S, Fukiyama K. Serum C-reactive protein (CRP) and risk of death in chronic dialysis patients. Nephrol Dial Transplant 1999 Aug;14(8):1956-1960.

7. Eleftheriadis T, Antoniadi G, Liakopoulos V, et al. Basic science and dialysis: disturbances of acquired immunity in hemodialysis patients. Sem Dial 2007;20(5):440-451.

8. Okyay GU, İnal S, Öneç K, et al. Neutrophil to lymphocyte ratio in evaluation of inflammation in patients with chronic kidney disease. Ren Fail 2013;35(1):29-36.

9. Turkmen K, Guney I, Yerlikaya FH, Tonbul HZ. The relationship between neutrophil-to-lymphocyte ratio and inflammation in end-stage renal disease patients. Ren Fail 2012;34(2):155-159.

10. Malhotra R, Marcelli D, Von Gersdorff G, et al. Relationship of neutrophil-tolymphocyte ratio and serum albumin levels with $\mathrm{C}$-reactive protein in hemodialysis patients: results from 2 international cohort studies. Nephron 2015;130(4):263-70.

11. Isaac V, Wu CY, Huang CT, et al. Elevated neutrophil to lymphocyte ratio predicts mortality in medical inpatients with multiple chronic conditions. Medicine (Baltimore) 2016 Jun;95(23):3832.

12. Keizman D, Ish-Shalom M, Huang P, et al. The association of pre-treatment neutrophil to lymphocyte ratio with response rate, progression free survival and 
overall survival of patients treated with sunitinib for metastatic renal cell carcinoma. Eur J Cancer 2012 Jan;48(2):202-208.

13. Azab B, Daoud J, Naeem FB, et al. Neutrophil-to-lymphocyte ratio as a predictor of worsening renal function in diabetic patients (3-year follow-up study). Ren Fail 2012;34(5):571-576.

14. Neuen BL, Leather N, Greenwood AM, et al Neutrophil-lymphocyte ratio predicts cardiovascular and all-cause mortality in hemodialysis patients. Ren Fail 2016;38(1):70-76.

15. An X, Mao HP, Wei X, et al. Elevated neutrophil to lymphocyte ratio predicts overall and cardiovascular mortality in maintenance peritoneal dialysis patients. Int Urol Nephrol 2012 Oct;44(5):1521-1528.

16. Li H, Lu X, Xiong R, Wang, S. High neutrophil-to-lymphocyte ratio predicts cardiovascular mortality in chronic hemodialysis patients. Mediators of inflamma 2017.

17. Erdem E, Coşkun KA, Karatas A, Dilek M, Akpolat T. Neutrophil to lymphocyte ratio in predicting short-term mortality in hemodialysis patients. J Exp Clin Med 2013;30(2).

18. Azab B, Chainani V, Shah N, McGinn JT. Neutrophil-lymphocyte ratio as a predictor of major adverse cardiac events among diabetic population: a 4-year follow-up study. Angiology 2012; 4(6):456-465.

19. Jensen MD, Ryan DH, Apovia CM, et al. AHA/ACC/TOS Guideline for the management of overweight and obesity in adults: a report of the American College of Cardiology/American Heart Association Task Force on Practice Guidelines and The Obesity Society. Circulation 2014;129:S102.

20. Rahimlu M, Shab-Bidar S, Djafaria K. Body Mass Index and All-cause Mortality in Chronic Kidney Disease: A Dose-response Meta-analysis of Observational Studies. J Ren Nutr 2017 Jul;27(4):225-232.

21. Leavey SF, McCullough K, Hecking E, et al. Body mass index and mortality in 'healthier' as compared with 'sicker' haemodialysis patients: results from the Dialysis Outcomes and Practice Patterns Study (DOPPS). Nephrol Dial Transplant 2001 Dec;16(12):2386-2394.

22. Kalantar-Zadeh K, Kopple JD, Humphreys MH, Block G. Comparing outcome predictability of markers of malnutrition-inflammation complex syndrome in haemodialysis patients. Nephrol Dial Transplant 2004;19(6):1507-1519. 
23. Doweiko JP, Nompleggi DJ. Reviews. The Role of Albumin in Human Physiology and Pathophysiology. Albumin and Disease States. JPEN J Parenter Enteral Nutr 1991 Aug;15(4):476-483.

24. Delgado C, Chertow G, Kaysen GA, et al. Associations of body mass index and body fat with markers of inflammation and nutrition among patients receiving hemodialysis. Am J Kidney Dis, 2017 Dec;70(6):817-825.

25. Zimmermann J, Herrlinger S, Pruy A, et al. Inflammation enhances cardiovascular risk and mortality in hemodialysis patients. Kidney Int 1999 Feb;55(2):648-658.

26. Pecoits-Filho R, Stenvinkel P, Wang AY, et al. Chronic inflammation in peritoneal dialysis: the search for the holy grail? Perit Dial Int 2004 JulAug;24(4):327-339.

27. Kalantar-Zadeh K, Fouque D, Kopple JD. Outcome research, nutrition, and reverse epidemiology in maintenance dialysis patients. J Ren Nutr 2004 Apr;14(2):64-71.

28. Nowak KL, Chonchol M. Does inflammation affect outcomes in dialysis patients? Semin Dial 2018 Jul;31(4):388-397. 


\title{
CHAPTER IV: NUTRITIONAL STATUS AND DIETARY INTAKE AS PREDICTORS OF POOR OUTCOMES IN HEMODIALYSIS PATIENTS.
}

\begin{abstract}
Objective: Malnutrition is prevalent in hemodialysis (HD) patients, ranging from $16 \%$ to $62 \%$ depending on the methods used to assess nutritional status. There is a growing evidence that malnutrition is a significant risk factor for morbidity and mortality in this population. This study examines the predictive value of measuring dietary intake and two assessment tools of nutritional status and their relationship with hospitalization and mortality in HD patients.
\end{abstract}

Design: This is a 12-month prospective cohort study that recruited 77 participants from May to Jun 2017.

Results: Fifty-five men and 22 women participated in this study; their mean age was 63.2 \pm 15.7 years. Their average time receiving dialysis was $6.2 \pm 4.2$ years and $58.4 \%$ of the patients had a diagnosis of diabetes mellitus in their medical chart; $18.2 \%$ were Hispanics, 39\% were Black, 31.2\% were Whites and 11.7\% were West Indians. During the period of the study (12 months) $63.6 \%$ of participants had at least one hospital admission, 6 participants $(7.8 \%)$ had a kidney transplant and a total of 10 participants $(13 \%)$ died, and all death-related causes were from cardiovascular diseases. Based on SGA 55\% were well-nourished and 45\% moderate-to-severe malnourished. Based on MIS 49\% were well-nourished and 50.6\% moderate-to-severe malnourished. Only 53\% of the participants met energy recommendations (ER). Comparing hospitalized versus not hospitalized participants, those with higher BMI (29.11 \pm 5.44 vs $26.22 \pm 5.34$; 
$\mathrm{P}=0.02)$, had greater SGA score $(5.67 \pm 1.44$ vs. $4.81 \pm 1.69 ; \mathrm{P}=0.04)$ and lower MIS score $(5.25 \pm 2.07$ vs. $7.25 \pm 3.69 ; \mathrm{P}=0.01)$. SGA was associated with mortality $(\mathrm{HR}=12.09,95 \% \mathrm{CI}=1.53-95.4, \mathrm{P}=0.018)$ but this relationship lost significance after adjustments $(\mathrm{P}=0.067)$. The association of $\mathrm{SGA}$ with hospitalization remained significant after adjustments $(\mathrm{HR}=2.67,95 \% \mathrm{CI}=1.29-5.10, \mathrm{P}=0.003)$. Participants with moderate-tosevere malnutrition based on SGA had a 2.67 hazard risk for having a hospitalization event. MIS $>5$ was associated with hospitalization $(\mathrm{HR}=2.11,95 \% \mathrm{CI}: 1.12-3.97$, $\mathrm{P}=0.019)$ and with mortality $(\mathrm{HR}=13.87,95 \% \mathrm{CI}: 1.56-123.045, \mathrm{P}=0.018)$ even after adjustments. Meeting energy recommendations (ER) reduced the chances of hospitalization by $59 \%(\mathrm{HR}=0.4195 \% \mathrm{CI}: 0.21-0.79, \mathrm{P}=0.008)$ and mortality was reduced by $81 \%(\mathrm{HR}=0.19,95 \% \mathrm{CI}: 0.03-0.98, \mathrm{P}=0.049)$, after adjustment. Kaplan-Meier curves for SGA showed that well-nourished participants lived longer ( $\log$ Rank test $\mathrm{P}=0.002)$ and had less hospitalizations than those moderate-to-severe malnourished (Log Rank test $\mathrm{P}=0.007)$. Kaplan-Meier curves for MIS $\leq 5$ showed that well- nourished participants, lived longer and had less hospitalizations than those with MIS $>5$ (Log Rank test $\mathrm{P}=0.033$ ). Kaplan-Meier for energy intake showed that participants who met KDOQI recommendations for energy intake survived longer (Log Rank test $\mathrm{P}=0.018$ ) and had less hospitalizations ( $\log$ Rank test $\mathrm{P}=0.005$ ) than participants who did not meet them. Meeting or not protein recommendations did not achieve significance $(\mathrm{P}=0.35)$. Albumin was directly correlated with DEI $(\mathrm{r}=0.533, \mathrm{P}<0.001)$ and DPI $(\mathrm{r}=0.369, \mathrm{P}=0.001)$, and MIS was inversely correlated with DEI $(\mathrm{r}=-0.495, \mathrm{P}<0.001)$ and DPI $(\mathrm{r}=-0.471$, $\mathrm{P}<0.001)$. SGA was inversely correlated with DEI $(\mathrm{r}=-0.687, \mathrm{P}<0.001)$ and DPI $(\mathrm{r}=-$ 
0.525, $\mathrm{P}<0.001)$ and BMI was directly correlated DEI $(\mathrm{r}=0.300, \mathrm{P}=0.04)$ and DPI $(\mathrm{r}=0.221, \mathrm{P}=0.027)$.

Conclusion: Our findings support that MIS and energy intake are strong independent predictors for hospitalization and mortality. Being well-nourished and meeting KDOQI energy recommendations reduces the risk for mortality and hospitalization among hemodialysis patients.

\section{Introduction}

Malnutrition is exceedingly prevalent in hemodialysis (HD) patients, ranging from $16 \%$ to $62 \%$ depending on method being used to assess the nutritional status. ${ }^{1}$ There is a growing evidence that diet is a significant risk factor for morbidity and mortality in this population..$^{2-4}$ Conversely, measures of good nutritional status, such as high Body Mass Index (BMI) in combination with high muscle mass, are associated with increased survival. ${ }^{5,6}$ In addition, nutritional competence increases resilience to adverse events, such as hospitalization, in HD patients. ${ }^{7}$

In 2011, The International Society of Renal Nutrition and Metabolism (ISRNM) coined the term protein-energy wasting (PEW) to the syndrome characterized by the loss of body protein mass and fuel reserves in patients with CKD and ESRD in dialysis. ${ }^{8}$ The ISRNM developed an objective criteria to incorporate all the different aspects of malnutrition and other metabolic and/or nutritional derangements, such as inflammation, and facilitated the timely and sensible diagnosis of PEW in this population vulnerable to malnutrition. ${ }^{8}$ 
Lack of appetite, anorexia, decreased intake, and lean body mass losses are very common among hemodialysis patients. Each one of these signs, individually and in combination, can be causally linked to the development of PEW syndrome. ${ }^{9}$ To prevent the syndrome from happening, the National Kidney Foundation Kidney Disease Outcomes Quality Initiative (KDOQI) ${ }^{10}$ and the European Best Practice guidelines ${ }^{11}$ established dietary recommendations for energy around 30 to $35 \mathrm{kcal} / \mathrm{kg}$ of calories and for protein intake around $1.2 \mathrm{~g} / \mathrm{kg}$ per day, of which at least $50 \%$ of protein should come from foods containing high biological value protein.

The complexity of PEW and its significant impact on morbidity and mortality has been widely recognized in HD patients. ${ }^{12}$ Among the most important determinants of PEW in the context of renal disease, without any hesitation, are inadequate intakes of protein and energy; however, it remains unclear which aspects of the PEW are a direct cause of the poor renal outcomes, or if they are merely surrogate markers of other clinical conditions. ${ }^{13}$ Early and sensitive detection of PEW through the continuous monitoring of the nutritional status, followed by a prompt development of nutritional interventions, when needed, is pivotal in improving clinical outcomes in hemodialysis patients. ${ }^{14}$

This study aims to assess the nutritional status of HD patients using the subjective global assessment (SGA), malnutrition-inflammation score (MIS), and participants' dietary energy and protein intakes and to examine the relationship of these variables with hospitalization and mortality over one year. 


\section{Methods}

\section{Study design and population}

This is a 12-month prospective, single center study to evaluate energy and protein intake and nutritional status of hemodialysis patients using two different assessment tools. The outcomes and endpoints of this study are hospitalization, mortality and kidney transplant. The study was approved by the Florida International University Institutional Review Board (IRB\# 17-0198-CR01). Seventy-seven participants were enrolled in the study from May 2016 to Jun 2017 and informed consent was obtained. The inclusion criteria were to be 19 years of age or older, receiving hemodialysis three times per week for at least three months (maintenance hemodialysis) and being medically stable without the reported existence of any acute infection. Patients were excluded if they were receiving nutritional support via intradialytic parenteral nutrition or artificial feedings via enteral nutrition, had a diagnosis of dementia or any other medical condition that could interfere with completing the nutritional questionnaire, or if they refuse to participate or comply with the study activities.

\section{Demographic and biochemical data}

Demographic data and biochemical parameters of interest were collected from clinical charts and through interviews with the patients during the period of the study. The demographic data collected included gender, age, ethnicity, hemodialysis start date, baseline BMI and diagnosis of diabetes mellitus (DM). The biochemical data of interest 
that were collected from medical documentation were serum albumin, total iron binding capacity and dialysis adequacy $(\mathrm{Kt} / \mathrm{V})$.

\section{Subjective Global Assessment (SGA) ${ }^{15}$}

Nutritional status was determined at baseline, six month and 12 months using the 7-point SGA scale consisting of 2 categories: medical history and physical examination. The medical history component included changes in weight, dietary intake, gastrointestinal impairments, overall functional capacity, and data on disease and other comorbidities. The physical examination section was estimated by identifying visible signs of muscle wasting, loss of subcutaneous fat, and the presence of edema. The registered dietitian assigned to this facility and who is responsible for the nutrition management of these participants, rated each item using a scale from 1 to 7 and decided the total SGA score. Based on the total SGA score, the patients were further categorized into 3 groups as follows: Well-nourished SGA-A (score 6-7), moderate malnourished SGA-B (score 3-5) and severely malnourished SGA-C (score 1-2).

\section{Malnutrition Inflammation Score (MIS) ${ }^{16}$}

MIS was also determined at baseline, six month and 12 months. MIS, described elsewhere, ${ }^{16}$ has 10 components (weight change, dietary intake, gastrointestinal symptoms, functional capacity, comorbidity, subcutaneous fat, muscle wasting, BMI, serum albumin level, and total iron-binding capacity) and each has four levels of severity, from 0 (normal) to 3 (very severe). The sum of all composite scores of $10 \mathrm{MIS}$ components ranges from 0 to 30 , denoting the increased severity of malnutrition and 
inflammation. The higher the MIS score, the worse the nutritional status is. MIS $>5$ was set as the cut-off value to start indicating an abnormal nutritional status and the concomitant presence of malnutrition and inflammation. ${ }^{17}$

\section{Assessment of dietary intake and its compliance to current dietary recommendations}

During their routine visit for dialysis, all HD patients receive specific and individualized dietary counseling together with menus examples, strategies and advices based on Clinical Practice Guidelines for Nutrition in Chronic Renal Failure established through the Kidney Disease Outcomes Quality Initiative (KDOQI). ${ }^{10}$ To conduct this study, we assessed the dietary intake of the enrolled participants by using three 24-hour diet recalls, taken during dialysis and non-dialysis days. The daily dietary intake was calculated to represent the average of the three 24-hour diet recall and by using a database from NutriBase 1986-2019 version 11.64 by CyberSoft, Inc. Participants' dietary protein intake (DPI) and dietary energy intake (DEI) were compared to current KDOQI guidelines ( $\sim 1.2 \mathrm{~g} / \mathrm{kg}$ protein; 30 to $35 \mathrm{kcal} / \mathrm{kg}$ of calories per day)

\section{Endpoints: Hospitalization, mortality and transplants}

Hospitalization was defined as any hospital visit considered as a full admission. The occurrence of all hospitalization events was verified over 12 months, it included diagnosis and cause for hospitalization. Kidney transplants and all deaths were recorded during the period of the study. 


\section{Statistical analysis}

The main outcomes of interest in the present study were hospitalization and death. For these outcomes, we reported absolute and relative frequencies, mean, standard deviation, median, assuming data normality. For the inferential statistics, normal data distribution was determined using the Kolmogorov-Smirnov test and the equality of variances was confirmed using Levene's test. The comparisons between groups were performed using unpaired Student-t test for normally distributed variables and the MannWhitney test for non-normally distributed variables as deemed appropriated. Categorical variables were described using proportions and were analyzed by the chi-square test. Odds ratios and 95\% confidence intervals were calculated. Pearson and Spearman correlations were used for bivariate analysis. Survival and hospitalization (time to first hospitalization) curves were estimated by Kaplan-Meier analysis and compared using the log-rank test. Cox proportional hazard model analyses were used to evaluate independent predictors of hospitalizations and survival. The hazard ratios were obtained from Cox regression analysis. The level of statistical significance was set at $\mathrm{P}<0.05$. All statistical tests were performed with SPSS version 20 software (IBM Corp., Armonk, NY, USA).

\section{Results}

\section{Demographics participant's characteristics}

Fifty-five men and 22 women participated in this study; their mean age was 63.2 \pm 15.7 years. Their average time receiving dialysis was $6.2 \pm 4.2$ years and $58.4 \%$ of the patients had a DM diagnosis in their medical chart; 18.2\% were Hispanics, 39\% were Black, 31.2\% were Whites and 11.7\% were West Indians. During the 12-month study, 
$63.6 \%$ participants had at least one hospital admission, 6 participants $(7.8 \%)$ had a kidney transplant, one participant $(1.2 \%)$ dropped out of the study (transferred to another dialysis center). A total of $13 \%(10 / 77)$ died, and all death-related causes were from cardiovascular disease.

\section{Subjective Global Assessment}

Fifty-five percent (42/77) of participants were classified by their SGA year average score as well-nourished (SGA-A), 36\% (28/77) were moderate malnourished (SGA-B) and 9\% (7/77) were severe malnourished (SGA-C). Since the number of severely malnourished participants were only 7, thus, too small to be analyzed separately, a decision was made to collapse (SGA-B and SGA-C ) into only one group. The final two groups were comprised of 55\% well-nourished (SGA-A) and 45\% moderate-tosevere malnourished (SGA-BC) (Table 1).

\section{Malnutrition Inflammation Score}

Forty-nine percent (38/77) participants had a year average score of MIS $\leq 5$ who were considered well- nourished and 50.6\% (39/77) MIS $>5$, indicating the presence of

malnutrition-inflammation status and were considered moderate-to-severe malnourished (Table 1). 


\section{Diet intake and KDOQI guidelines compliance}

The mean dietary energy intake (DEI) was $1867.3 \pm$ SD $367.9 \mathrm{kcal} / \mathrm{kg} / \mathrm{day}$, and the mean dietary protein (DPI) was $80.0 \pm 15.8 \mathrm{~g} / \mathrm{kg} /$ day. When DEI was compared with DPI and KDOQI guidelines (30-35kcal/kg; $1.2 \mathrm{~g} / \mathrm{kg}$ daily); only 53\% (41/77) of the participants met energy recommendations (ER) and 45\% (35/77) did not.

\section{Hospitalization and mortality analysis}

Table 2 shows a comparison of hospitalized versus not hospitalized participants and survivors versus non survivors. In this univariate analysis, survivors had greater SGA score than those who died $(5.49 \pm 1.36$ vs. $3.0 \pm 1.76 ; \mathrm{P}=0.01)$ and lower MIS score (6.12 \pm 2.9 vs. $10.21 \pm 3.91 ; \mathrm{P}<0.00)$. Both scores indicated that patients that survived had a better average nutritional status during the study period.

When comparing not hospitalized with hospitalized participants, we found that BMI was higher in those with non-registered hospitalization $(29.11 \pm 5.44$ vs $26.22 \pm$ 5.34; $\mathrm{P}=0.02)$, had greater SGA score $(5.67 \pm 1.44$ vs. $4.81 \pm 1.69 ; \mathrm{P}=0.04)$ and lower MIS score $(5.25 \pm 2.07$ vs. $7.25 \pm 3.69 ; \mathrm{P}=0.01)$. These finding, as the previous ones, indicated that patients who exhibited better average nutritional status did not have any admission to the hospital in the last12 months.

The effect of nutritional status measured by SGA on outcomes was further analyzed in Table 3, which shows multivariate Cox regression models analyzing the relationship between SGA (year-average) and hospitalizations and mortality. In this analysis, we found that participants who were moderate to malnourished, as estimated by SGA BC, had higher probability of death $(\mathrm{HR}=12.09,95 \% \mathrm{CI}=1.53-95.4, \mathrm{P}=0.018)$. 
However, this relationship lost significance after adjusting for age, gender, ethnicity and years in dialysis $(\mathrm{P}=0.067)$. SGA BC was associated with hospitalization and this relationship remained significant after adjustments $(\mathrm{HR}=2.67,95 \% \mathrm{CI}: 1.29-5.10$, $\mathrm{P}=0.003$ ) (Table 3). This indicates that participants with moderate-to-severe malnutrition have a 2.67 hazard risk for having at least one hospitalization event.

The effect of the nutritional status measured by MIS on outcomes was further analyzed in Table 4, which shows the multivariate Cox regression models that analyzed the association of MIS (year-average) with mortality and hospitalizations. These analyses show that the mortality of HD patients was directly associated with MIS $>5$. After adjusting for age, gender, ethnicity and years in dialysis $(\mathrm{HR}=13.87$ 95\% CI:1.56-123.04, $\mathrm{P}=0.018)$. Similarly, hospitalization was associated with $\mathrm{MIS}>5(\mathrm{HR}=2.11,95 \%$ CI:1.12-3.97, $\mathrm{P}=0.019)$ even after adjustments (Table 4), which indicated that participants diagnosed with Malnutrition-Inflammation Status, determined by the cut-off value of greater than 5 had an increased hazard risk for both hospitalizations and mortality.

The effect of meeting KDOQI energy recommendations on outcomes was further analyzed. Table 5 shows multivariate Cox regression models that analyzed the effect of meeting KDOQI energy recommendations and its association with hospitalization and mortality. This analysis shows that meeting the energy recommendations (ER) reduces the chances of hospitalization by $59 \%$ after adjusting for age, gender, ethnicity, albumin, diabetes and years in dialysis $(\mathrm{HR}=0.4195 \% \mathrm{CI}: 0.21-0.79, \mathrm{P}=0.008)$. Similarly, mortality of HD patients was reduced by $81 \%$ in those who met ER after adjusting for age, gender, ethnicity albumin, diabetes and years in dialysis $(\mathrm{HR}=0.1995 \% \mathrm{CI}: 0.03-0.98, \mathrm{P}=0.049)$ 
(Table 4). These results suggest that meeting recommendation for energy lowers the possibility of hospitalization and mortality.

\section{Kaplan Meier curves for hospitalizations and mortality}

Kaplan-Meier survival curve for SGA-year average is shown in Figure A, indicating that well-nourished participants (SGA-A) lived longer than participants who were moderate-to severe malnourished (SGA-BC) during the study follow-up (Log Rank test, $\mathrm{P}=0.002$ ). Kaplan-Meier curve for hospitalization is shown in Figure $\mathrm{B}$, indicating that well-nourished participants (SGA-A) had lower hospitalization rate than participants who were moderate-to severe malnourished (SGA-BC) during the study follow-up (Log Rank test, $\mathrm{P}=0.007)$.

The Kaplan-Meier survival curve for MIS-year average (Figure C) showed that participants with a MIS $\leq 5$ classified as well- nourished, lived longer than participants with MIS $>5$ who were classified as moderate-to severe malnourished (Log Rank test, $\mathrm{P}=0.007$ ) and Kaplan-Meier curve for hospitalization (Figure D) showed that MIS $\leq 5$ had less hospitalizations that participants with MIS $>5$ (Log Rank test $\mathrm{P}=0.033)$, indicating that having a good nutritional status determined by MIS $\leq 5$ protected against both hospitalization and mortality.

The Kaplan-Meier survival curve for energy intake is shown in Figure E; participants who did not meet KDOQI recommendations for energy intake died sooner than participants who did ( $\log$ Rank test $\mathrm{P}=0.018)$. The Kaplan-Meier curve for hospitalization and energy intake shown in Figure F, demonstrated that participants who did not meet KDOQI recommendations for energy intake had more hospitalizations than 
participants who met recommendations (Log Rank test $\mathrm{P}=0.005$ ). However, meeting KDOQI protein recommendations did not have any significant impact on hospitalization and mortality $(\mathrm{P}=0.35)$.

\section{Correlation between intake and nutritional status}

Pearson correlations exhibited a strong direct correlation between DEI and DPI $(\mathrm{r}=0.59, \mathrm{P}<0.001)$. Albumin was directly correlated with $\mathrm{DEI}(\mathrm{r}=0.533, \mathrm{P}<0.001)$ and DPI $(r=0.369, \mathrm{P}=0.001)$, and MIS was inversely correlated with DEI $(\mathrm{r}=-0.495, \mathrm{P}<0.001)$ and DPI ( $\mathrm{r}=-0.471, \mathrm{P}<0.001)$. SGA was inversely correlated with DEI $(\mathrm{r}=-0.687$, $\mathrm{P}<0.001)$ and DPI $\mathrm{r}=-0.525, \mathrm{P}<0.001)$ and $\mathrm{BMI}$ was directly correlation $\mathrm{DEI}(\mathrm{r}=0.300$, $\mathrm{P}=0.04)$ and $\mathrm{DPI}(\mathrm{r}=0.221, \mathrm{P}=0.027)$.

\section{Discussion}

To examine the presence of PEW and its impact on HD patient outcomes, a variety of clinical and biochemical parameters have been successfully used, including $\mathrm{BMI},{ }^{18}$ muscle mass $,{ }^{19} \mathrm{nPCR},{ }^{20}$ dietary protein and energy intakes,${ }^{21}$ serum albumin or prealbumin levels, ${ }^{22}$ and more complex compositive scores such as SGA ${ }^{15}$ and MIS; $;{ }^{16}$ however, no single tool or parameter could definitively diagnose PEW effectively. Prior studies have reported a wide range of patients diagnosed with malnutrition. The differences in ranges may be attributed to the characteristics of the study population, and the variety of tools, assessment methods, and diagnosis criteria. ${ }^{1}$

In our cohort, MIS was more sensitive than SGA to detect the presence of PEW and was a better predictor for hospitalization and mortality. In agreement with our findings, other authors have reported that PEW prevalence using SGA was lower than 
PEW detected by MIS. ${ }^{23}$ Among the reasons for this discrepancy may be that MIS tends to report a larger proportion of patients with a PEW diagnosis by considering serum albumin levels and total iron binding capacity as part of its total score components. These two biomarkers have a scale score, and both are strongly related to nutritional status and inflammation. ${ }^{1,24}$ Another potential reason underlying these findings is the current lack of a MIS gold-standard cut-off value for PEW diagnosis. ${ }^{1}$ In our study, we selected a conservative MIS cutoff (MIS $>5$ ) based on the prediction of mortality by a previous review of articles. ${ }^{17}$ Other authors have used this same cut-off point for the diagnosis of PEW in peritoneal dialysis patients, and compared its usefulness with other nutritional tools; ${ }^{18}$ however, this might not be necessarily the best cut-off value for diagnosing PEW. Also, in our study the results of the 7-point SGA were dichotomized as either wellnourished or moderate to severe malnourished for the analysis. As patients may be at different stages of PEW based on the ratings of the scoring tools, in our study using these cutoff points may affect the final results of this study. Therefore, future studies determining the appropriate cut-off points for the scoring tools may further strengthen the predicting value of the 7-point SGA and the MIS score for adverse outcomes and for identifying the risk of developing PEW in patients receiving dialysis.

Based on our results, MIS, at the cut-off point of less or equal than 5, was a better predictor of mortality than SGA, which lost significance after adjustment for other related variables. Our results showed that both, MIS and SGA, were good predictors of hospitalizations and mortality. Numerous prior studies have demonstrated that SGA is a significant independent predictor of mortality in patients undergoing hemodialysis, ${ }^{3,4}$ and 
MIS, which was developed specifically for dialysis patients, has been considered a good predictor of morbidity and mortality. ${ }^{16,17,26}$

By determining the average participant's DPI and DEI, and whether they met current KDOQI recommendations for protein and energy intake, we found that, despite advice from their dietitians, nurses, doctors, and other health professionals, to promote adequate intake among participants, a large proportion of them did not meet KDOQI for energy and protein recommendations. In our cohort, approximately half (53\%) met KDOQI energy recommendations, while 55\% met protein recommendations and only $21 \%$ met both energy and protein recommendations. These results are supported by previous reports of DEI and DPI in dialysis patients that clearly demonstrated that the majority of dialysis patients do not meet current KDOQI recommendations, which may in turn increase their risk of PEW and ultimately increase morbidity and mortality in this population. ${ }^{21,23}$ In agreement with our findings, Araujo et al. ${ }^{21}$ reported that inadequate protein and energy intake was associated with worse survival in a single center study and Antunes et al. ${ }^{23}$ also emphasized the importance of protein intake on survival in chronic dialysis patients.

In our study, meeting dietary energy recommendations was a better predictor for hospitalizations and mortality than meeting protein recommendations. Our results on energy intake are supported by findings reported recently by Kang et al., ${ }^{25}$ who found that energy intake $<25 \mathrm{kcal} / \mathrm{kg}$ and MIS $>5$ were associated with 10 -year mortality in HD patients. However, our results on the relationships of protein intake and the disease outcomes contradicted what has been reported about low protein dietary intake and its relationship with increased death rates previously reported by Kalantar-Zadeh et al., ${ }^{24}$ 
who demonstrated that protein intake measured indirectly by means of nPCR was associated with outcomes. In our study, the average participant's protein intake was assessed as an average of three 24-hour diet recalls taken on dialysis and not dialysis days by a trained dietitian, which reflects with more accuracy the average patient's intake and the customary diet. Contrasting with the report by Kalantar-Zadeh et al., ${ }^{24}$ reports by other researchers have shown that greater protein intake $>1.4 \mathrm{~g} / \mathrm{kg} /$ day are associated with increased phosphorus levels, which ultimately can be related to mortality. Based on these results, researches proposed the impact of adequate energy intake is more important for disease outcomes than protein intake, and that excessive protein intake should be avoided, since it appears to be deleterious. ${ }^{14}$

Additionally, to the above discussed discrepancies about the impact of protein intake on patient outcomes, there are other conditions that could explain our results; most of our participants received protein supplements at certain point during the study according to their albumin levels in plasma, and they were followed using the latest nutritional recommendations for the management of hypoalbuminemia. However, the impact of protein supplements on outcomes are still not known and controlled studies are needed to elucidate their effect. ${ }^{28}$

This study has numerous limitations that should be considered in interpreting its findings. First, the sample size was small and only included subjects from a single dialysis center, therefore its generalizability to other populations is limited. In addition, given that it is an observational study, it is difficult to separate the complex interactions of variables. In this study, we examined the 12-month average scores of SGA and MIS and their predictive impact on hospitalization and mortality; however, we did not 
examine changes in nutritional status and the impact of those changes in hospitalizations and mortality. Even though our study confirmed that inadequate energy and protein intakes are important determinants for PEW, and that meeting energy recommendations is significantly linked to adverse outcomes, due to the complex and multifactorial characteristics of PEW syndrome, we cannot rule out that other disease-related factors may directly or indirectly influence energy and protein intakes, so their deficiencies may be the consequence and not the cause of the adverse outcomes.

\section{Conclusions}

Our findings support an association of the nutrition-inflammation status, detected by sensitive indices, and energy intake with reduced hospitalization and mortality risks among hemodialysis patients. Meeting energy recommendations has a positive impact on preventing hospitalization and decreasing mortality rates. This study provides observational evidence for early detection of patients at risk of PEW and initiating timely nutrition interventions that aim to improve nutrition-inflammation status and promote adequate protein and energy intake. Further controlled studies with adequate sample size should evaluate other nutrients that may modulate malnutrition in these patients. 
Table 1: Classification of participants in well-nourished and moderate-to-severe malnourished (year average) by nutrition assessment tools

\begin{tabular}{ccc} 
Nutrition assessment tools & Well-nourished & Moderate-to-severe malnourished \\
\hline $\begin{array}{c}\text { Subjective Global } \\
\text { Assessment }\end{array}$ & SGA-A & SGA-BC \\
\hline $\begin{array}{c}\text { Malnutrition Inflammation } \\
\text { Score }\end{array}$ & $55 \%(42 / 77)$ & $45 \%(35 / 77)$ \\
\hline
\end{tabular}

$\mathrm{N}=77$, SGA-A = participants classified as well nourished by Subjective Global Assessment, SGA-BC= participants classified as moderate-to-severe malnourished by Subjective Global Assessment, MIS $>5=$ participants classified as moderate-to-severe malnourished by Malnutrition Inflammation Score greater than 5 (year average)

Table 2: Table of characteristic comparing not hospitalized versus hospitalized and survivors versus non-survivors

\begin{tabular}{lllllll}
\hline Variable & $\begin{array}{l}\text { Not- } \\
\text { Hospitalized } \\
\mathrm{N}=28\end{array}$ & $\begin{array}{l}\text { Hospitalized } \\
\mathrm{N}=49\end{array}$ & $\begin{array}{l}P_{-} \\
\text {value }^{*}\end{array}$ & $\begin{array}{l}\text { Survivors } \\
\mathrm{N}=67\end{array}$ & $\begin{array}{l}\text { Non- } \\
\text { Survivors } \\
\mathrm{N}=10\end{array}$ & $\begin{array}{l}P_{-} \\
\text {value }^{*}\end{array}$ \\
\hline Age & $63.21 \pm 14.79$ & $63.3 \pm 16.46$ & 0.98 & $62.7 \pm 17.23$ & $67.1 \pm 12.28$ & 0.14 \\
& & & & & & \\
Female & $10.14 \%$ & $14 \%$ & 0.67 & $26.0 \%$ & $2.6 \%$ & 0.41 \\
Diabetes & $18.2 \%$ & $40.3 \%$ & 0.18 & $48.1 \%$ & $10.4 \%$ & 0.12 \\
Years in & $7.15 \pm 4.83$ & $5.65 \pm 3.73$ & 0.13 & $6.30 \pm 4.28$ & $5.53 \pm 3.74$ & 0.59 \\
dialysis & & & & & & \\
BMI & $29.11 \pm 5.44$ & $26.22 \pm 5.34$ & 0.02 & $27.56 \pm$ & $25.36 \pm 4.92$ & 0.24 \\
& & & & 5.58 & & \\
Albumin & $3.70 \pm 0.30$ & $3.86 \pm 0.30$ & 0.80 & $3.52 \pm 0.26$ & $3.91 \pm 0.34$ & 0.59 \\
KtV & $1.49 \pm 0.20$ & $1.50 \pm 0.18$ & 0.89 & $1.50 \pm 0.17$ & $1.46 \pm 0.24$ & 0.51 \\
SGA & $5.67 \pm 1.44$ & $4.81 \pm 1.69$ & 0.04 & $5.49 \pm 1.36$ & $3.0 \pm 1.76$ & 0.01 \\
MIS & $5.25 \pm 2.07$ & $7.25 \pm 3.69$ & 0.01 & $6.12 \pm 2.9$ & $10.21 \pm 3.91$ & 0.00 \\
\hline
\end{tabular}

${ }^{*}$ Student T test, statistically significant $P<0.05$

$\mathrm{BMI}=$ Body mass index, $\mathrm{Kt} / \mathrm{V}=$ dialysis clearance, $\mathrm{SGA}=$ Subjective Global Assessment, $\mathrm{MIS}=$ Malnutrition Inflammation Score 
Table 3: Multivariate Cox regression models analyzing SGA (year-average) for mortality and hospitalizations

\begin{tabular}{ccccc}
\hline Covariate & $\begin{array}{c}\text { Unadjusted } \\
\text { Hazard Ratio } \\
95 \% \mathrm{CI}^{\mathrm{a}}\end{array}$ & P-value & $\begin{array}{c}\text { Adjusted } \\
\text { Hazard Ratio } \\
95 \% \mathrm{CI}^{\mathrm{a}}\end{array}$ & P-value \\
\hline MORTALITY & & & \\
Age & $1.01(0.97-1.06)$ & 0.400 & $1.01(0.97-1.06)$ & 0.977 \\
Gender & $1.64(0.35-7.76)$ & 0.528 & $1.64(0.35-7.76)$ & 0.338 \\
Ethnicity & $1.35(0.67-2.69)$ & 0.393 & $1.35(0.67-2.69)$ & 0.617 \\
Years-in-dialysis & $0.94(0.80-1.12)$ & 0.540 & $0.94(0.80-1.12)$ & 0.068 \\
KtV & $0.24(0.01-8.54)$ & 0.432 & $0.10(001-9.078)$ & 0.317 \\
Diabetes & $3.08(0.65-15.51)$ & 0.155 & $3.08(0.65-15.51)$ & 0.414 \\
Albumin & $2.22(0.20-23.79)$ & 0.509 & $33.05(0.86-1264.69)$ & 0.060 \\
SGA BC & $12.09(1.53-95.49)$ & 0.018 & $7.479(0.870-64.03)$ & 0.067 \\
& & & & \\
Albe & $\underline{\text { HOSPITALIZATIONS }}$ & & \\
Gender & $0.99(0.98-1.01)$ & 0.851 & $0.98(0.96-1.00)$ & 0.168 \\
Ethnicity & $1.00(0.54-1.87)$ & 0.977 & $1.08(0.55-2.13)$ & 0.811 \\
Years-in-dialysis & $1.16(0.84-1.69)$ & 0.355 & $1.06(0.76-1.52)$ & 0.674 \\
KtV & $0.94(0.88-1.01)$ & 0.131 & $0.94(0.87-1.01)$ & 0.133 \\
Diabetes & $1.17(0.25-5.32)$ & 0.838 & $1.75(0.32-9.64)$ & 0.516 \\
Albumin & $1.44(0.80-2.57)$ & 0.218 & $1.43(0.78-2.64)$ & 0.245 \\
SGA BC & $1.16(0.38-3.56)$ & 0.787 & $1.82(0.49-6.71)$ & 0.366 \\
& $2.06(1.17-3.64)$ & 0.012 & $2.67(1.39-5.10)$ & 0.003 \\
\hline
\end{tabular}

${ }^{a} C I=$ confident interval, statistically significant $P<0.05$

$\mathrm{Kt} / \mathrm{V}=$ dialysis clearance, $\mathrm{SGA} \mathrm{BC}=$ participants classified as moderate-to-severe malnourished by Subjective Global Assessment tool (year average) 
Table 4: Multivariate Cox regression models analyzing MIS (year-average) for mortality and hospitalizations

\begin{tabular}{|c|c|c|c|c|}
\hline Covariate & $\begin{array}{c}\text { Unadjusted } \\
\text { Hazard Ratio } \\
95 \% \text { CI* }^{*}\end{array}$ & P-value & $\begin{array}{c}\text { Adjusted } \\
\text { Hazard Ratio } \\
\text { 95\% CI* }\end{array}$ & P-value \\
\hline \multicolumn{5}{|c|}{$\underline{\text { MORTALITY }}$} \\
\hline Age & $1.01(0.97-1.06)$ & 0.400 & $1.00(0.96-1.05)$ & 0.497 \\
\hline Gender & $1.64(0.35-7.76)$ & 0.528 & $1.27(0.49-11.06)$ & 0.780 \\
\hline Ethnicity & $1.35(0.67-2.69)$ & 0.393 & $1.10(0.47-2.59)$ & 0.773 \\
\hline $\begin{array}{l}\text { Years-in- } \\
\text { dialysis }\end{array}$ & $0.94(0.80-1.12)$ & 0.540 & $0.94(0.77-1.14)$ & 0.797 \\
\hline $\mathrm{KtV}$ & $0.24(0.01-8.54)$ & 0.434 & $0.31(0.00-31.44)$ & 0.622 \\
\hline Diabetes & $3.08(0.65-14.51)$ & 0.155 & $2.89(0.49-16.94)$ & 0.239 \\
\hline Albumin & $2.22(0.01-8.54)$ & 0.509 & $15.63(0.451-540.84)$ & 0.128 \\
\hline MIS $>5$ & $9.91(1.25-78.29)$ & 0.030 & $13.87(1.56-123.05)$ & 0.018 \\
\hline \multicolumn{5}{|c|}{$\underline{\text { HOSPITALIZATIONS }}$} \\
\hline Age & $0.99(0.98-1.01)$ & 0.851 & $0.98(0.97-1.00)$ & 0.253 \\
\hline Gender & $1.00(0.54-1.87)$ & 0.977 & $1.13(0.60-2.12)$ & 0.699 \\
\hline Ethnicity & $1.16(0.84-1.69)$ & 0.355 & $1.02(0.72-1.45)$ & 0.876 \\
\hline $\begin{array}{l}\text { Years-in- } \\
\text { dialysis }\end{array}$ & $0.94(0.88-1.01)$ & 0.131 & $0.93(0.85-1.00)$ & 0.079 \\
\hline $\mathrm{KtV}$ & $1.17(0.25-5.32)$ & 0.839 & $2.52(0.42-6.71)$ & 0.036 \\
\hline Diabetes & $2.52(0.42-14.87)$ & 0.306 & $1.45(0.78-2.68)$ & 0.229 \\
\hline Albumin & $1.16(0.38-3.56)$ & 0.787 & $1.71(0.43-6,71)$ & 0.442 \\
\hline $\mathrm{MIS}>5$ & $1.79(1.01-3.17)$ & 0.045 & $2.11(1.12-3.97)$ & 0.019 \\
\hline
\end{tabular}

${ }^{*} C I=$ confident interval, statistically significant $P<0.05$

${ }^{1} \mathrm{Kt} / \mathrm{V}=$ dialysis clearance, MIS=Malnutrition Inflammation Score, MIS $>5=$ participants classified as moderate-tosevere malnourished by MIS score greater than 5 (year average) 
Table 5: Multivariate Cox regression models analyzing participants that met KDOQI/energy recommendations for mortality and hospitalizations

\begin{tabular}{ccccc}
\hline Covariate & $\begin{array}{c}\text { Unadjusted } \\
\text { Hazard Ratio } \\
95 \% \text { CI* }\end{array}$ & P-value & $\begin{array}{c}\text { Adjusted } \\
\text { Hazard Ratio } \\
95 \% \text { CI* }\end{array}$ & P-value \\
& \multicolumn{3}{c}{ MORTALITY } & \\
Age & $1.01(0.97-1.06)$ & 0.400 & $1.00(0.95-1.04)$ & 0.992 \\
Gender & $1.64(0.35-7.76)$ & 0.528 & $1.47(0.26-8.31)$ & 0.662 \\
Ethnicity & $1.35(0.67-2.69)$ & 0.393 & $1.13(0.54-2.26)$ & 0.745 \\
Years-in-dialysis & $0.94(0.80-1.12)$ & 0.540 & $0.98(0.81-1.20)$ & 0.915 \\
KtV & $0.24(0.01-8.54)$ & 0.434 & $0.16(0.002-15.40)$ & 0.439 \\
Diabetes & $3.08(0.65-15.51)$ & 0.155 & $2.20(0.43-11.21)$ & 0.341 \\
Albumin & $2.22(0.20-23.79)$ & 0.059 & $3.47(0.34-34.93)$ & 0.290 \\
Met ER (yes) & $0.19(0.04-0.91)$ & 0.038 & $0.19(0.03-0.98)$ & 0.049 \\
& & & & \\
Age & HOSPITALIZATIONS & & \\
Gender & $0.99(0.98-1.01)$ & 0.851 & $0.98(0.96-1.00)$ & 0.131 \\
Ethnicity & $1.00(0.54-1.87)$ & 0.977 & $1.07(0.53-2.14)$ & 0.850 \\
Years-in-dialysis & $1.16(0.84-1.69)$ & 0.355 & $0.97(0.69-1.37)$ & 0.891 \\
KtV & $094(0.88-1.01)$ & 0.131 & $0.93(0.86-101)$ & 0.099 \\
Diabetes & $1.17(0.25-5.32)$ & 0.838 & $1.56(0.44-5.48)$ & 0.482 \\
Albumin & $1.44(0.80-2.57)$ & 0.218 & $1.21(0.65-2.25)$ & 0.537 \\
Met ER(yes) & $1.16(0.38-3.56)$ & 0.787 & $1.56(0.27-9.25)$ & 0.484 \\
& $0.46(0.26-0.82)$ & 0.008 & $0.41(0.21-0.79)$ & 0.008 \\
\hline
\end{tabular}

${ }^{*} C I=$ confident interval, statistically significant $P<0.05$

$\mathrm{Kt} / \mathrm{V}=$ dialysis clearance, Met ER (yes)= met KDOQI/energy recommendations 
Table 6: Multivariate Cox regression models analyzing participants that met $\mathrm{KDOQI} /$ protein recommendations for mortality and hospitalizations

\begin{tabular}{|c|c|c|c|c|}
\hline Covariate & $\begin{array}{c}\text { Unadjusted HR } \\
95 \% \mathrm{CI}^{*}\end{array}$ & P-value & $\begin{array}{c}\text { Adjusted HR } \\
95 \% \mathrm{CI}^{*}\end{array}$ & P-value \\
\hline \multicolumn{5}{|c|}{$\underline{\text { MORTALITY }}$} \\
\hline Age & $1.01(0.97-1.06)$ & 0.400 & $1.00(0.96-1.05)$ & 0.738 \\
\hline Sex & $1.64(0.35-7.76)$ & 0.528 & $1.53(0.28-8.30)$ & 0.618 \\
\hline Ethnicity & $1.35(0.67-2.69)$ & 0.393 & $1.03(0.48-2.21)$ & 0.929 \\
\hline Years-in-dialysis & $0.94(0.80-1.12)$ & 0.540 & $0.94(0.76-1.17)$ & 0.627 \\
\hline Diabetes & $3.08(0.65-14.51)$ & 0.155 & $3.00(0.61-14.67)$ & 0.174 \\
\hline Albumina & $2.22(0.20-23.79)$ & 0.509 & $5.35(0.42-68.03)$ & 0.196 \\
\hline $\mathrm{KtV}$ & $0.24(0.01-8.54)$ & 0.434 & $0.37(0.00-23.37)$ & 0.645 \\
\hline MET PR & $3.20(0.90-11.37)$ & 0.068 & $0.15(0.01-1.27)$ & 0.082 \\
\hline \multicolumn{5}{|c|}{$\underline{\text { HOSPITALIZATIONS }}$} \\
\hline Age & $0.99(0.98-1.01)$ & 0.851 & $0.99(0.97-1.01)$ & 0.399 \\
\hline Sex & $1.00(0.54-1.87)$ & 0.977 & $0.96(0.47-1.94)$ & 0.915 \\
\hline Ethnicity & $1.16(0.84-1.59)$ & 0.355 & $1.11(0.80-1.56)$ & 0.515 \\
\hline Years-in-dialysis & $0.94(0.88-1.01)$ & 0.131 & $0.93(0.86-1.01)$ & 0.122 \\
\hline Diabetes & $1.44(0.80-2.57)$ & 0.218 & $1.50(0.82-2.74)$ & 0.182 \\
\hline Albumina & $1.16(0.38-3.56)$ & 0.787 & $1.14(0.31-4.25)$ & 0.837 \\
\hline $\mathrm{KtV}$ & $1.17(0.25-5.32)$ & 0.838 & $1.70(0.29-10.02)$ & 0.554 \\
\hline MET PR & $1.41(0.78-2.52)$ & 0.247 & $1.07(0.56-2.05)$ & 0.827 \\
\hline
\end{tabular}

${ }^{*} C I=$ confident interval, statistically significant $P<0.05$

$\mathrm{Kt} / \mathrm{V}=$ dialysis clearance, Met $\mathrm{PR}$ (yes)= met KDOQI/protein recommendations 
Figure A: Kaplan-Meier curve for Mortality and SGA (year average)

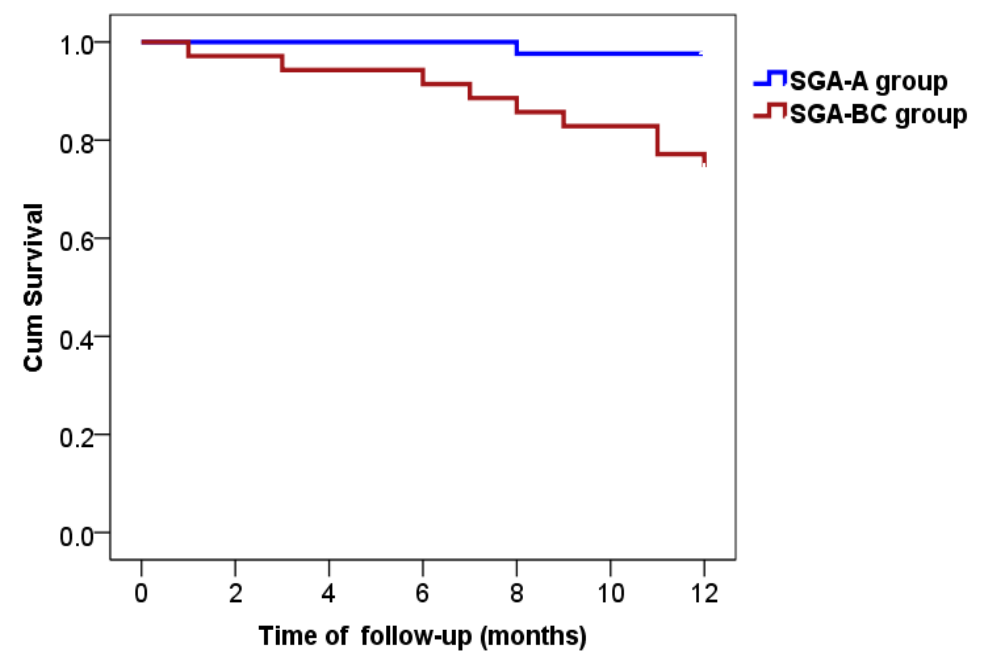

Figure B: Kaplan-Meier curve for Hospitalization and SGA (year average)

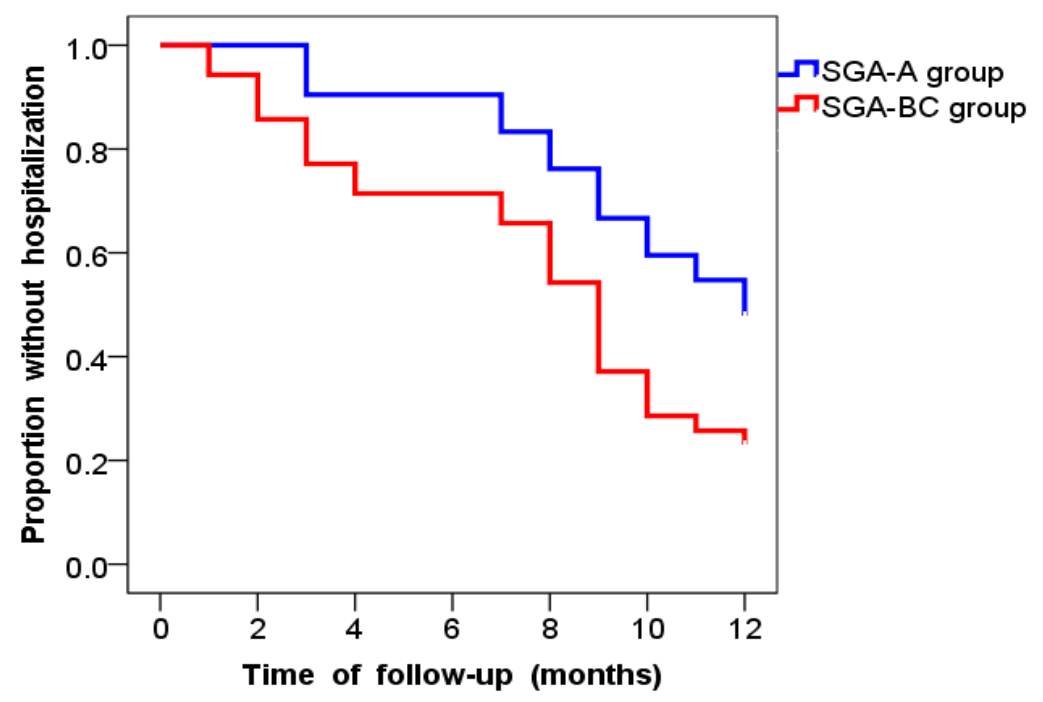


Figure C: Kaplan-Meier curve for Mortality and MIS (year average)

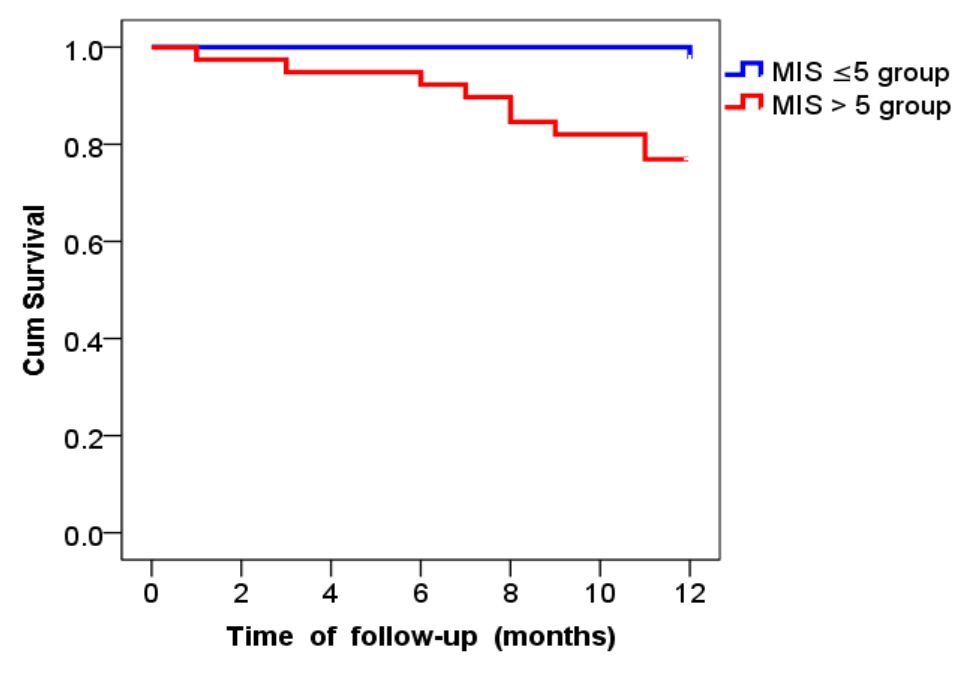

Figure D: Kaplan-Meier curve for Hospitalization and MIS (year average)

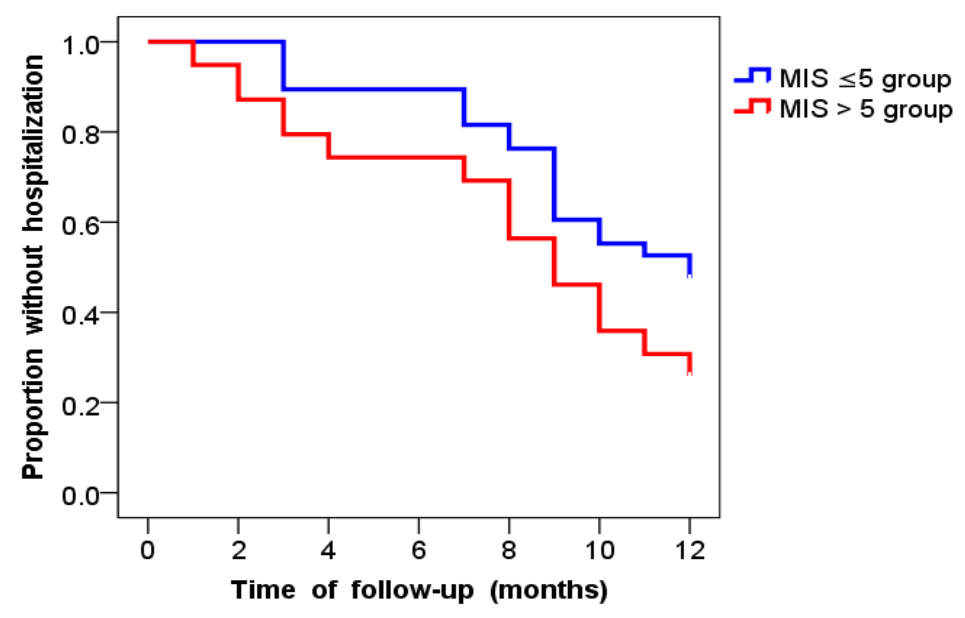


Figure E: Kaplan-Meier curve for Mortality and energy intake

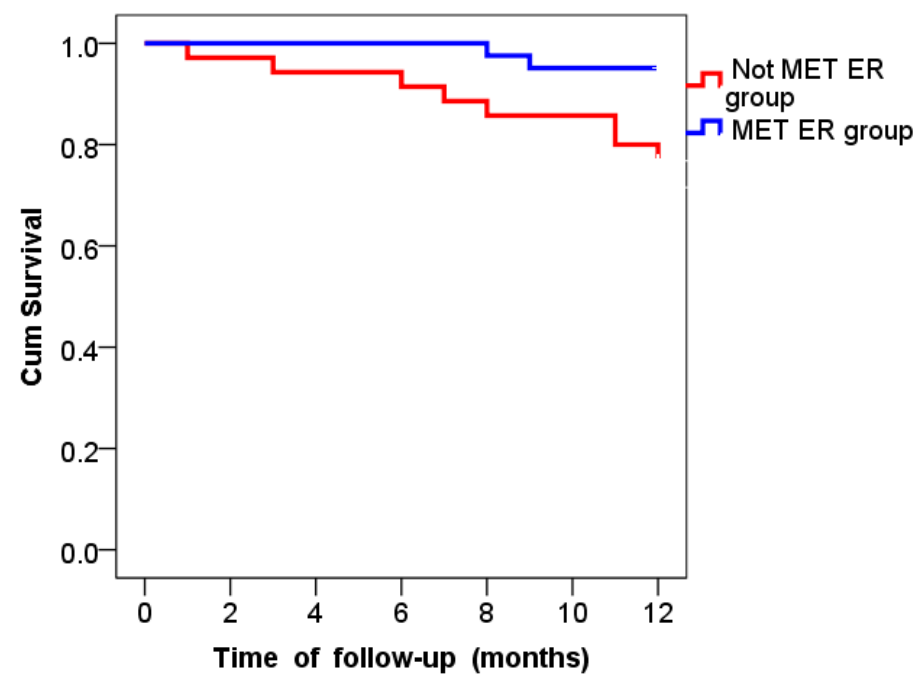

Figure F: Kaplan-Meier curve for Hospitalization and energy intake

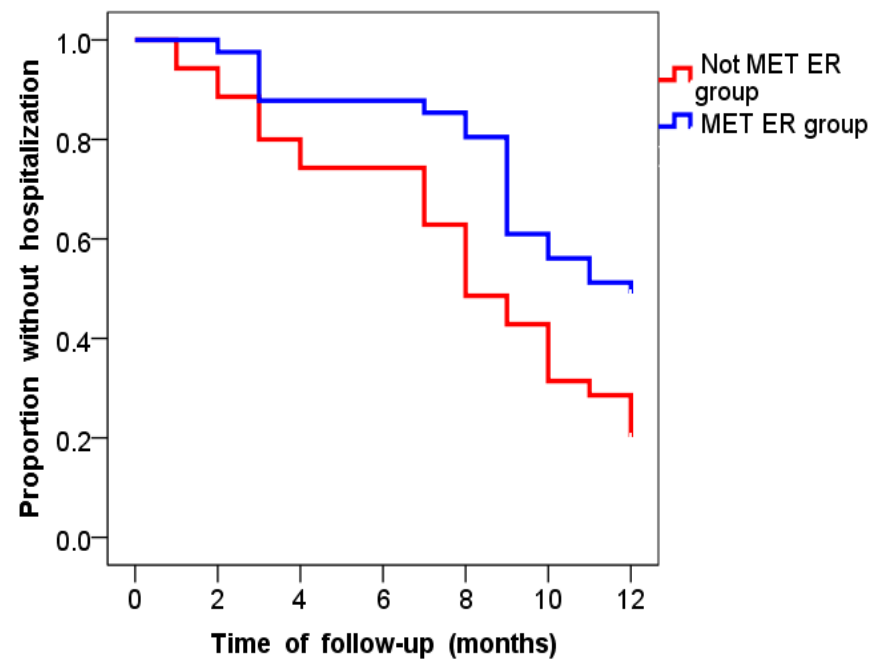

Fig A showed that participants in SGA-A group lived longer than participants in SGA-BC (Log rank test $\mathrm{P}=0.002)$ Fig $B$ showed that SGA-A group had lower hospitalization rate than group SGA-BC (Log rank test $\mathrm{P}=0.007$ )

Fig $\mathrm{C}$ showed that patients in MIS $\leq 5$ group longer than participants in MIS $>5$ group (Log rank test $\mathrm{P}=0.007$ ) Fig D showed that participants in the group MIS $\leq 5$ had less hospitalizations than participants in MIS $>5$ group (Log rank test $\mathrm{P}=0.033$ )

Fig E showed that patients that met energy recommendations (MET ER) lived longer that patients that did not(Not MET ER) (log rank test, $\mathrm{P}=0.018$ )

Fig F showed that patients that met energy recommendations (MET ER) had less hospitalizations that patients that did not (Not MET ER)(Log rank test $\mathrm{P}=0.005)$ 
References

1. Carrero JJ, Thomas F, Nagy K., et al. Global Prevalence of Protein-Energy Wasting in Kidney Disease: A meta-analysis of contemporary observational studies from the international society of renal nutrition and metabolism. J Ren Nutr 2018 Nov;28(6):380-392.

2. Pifer TB, McCullough KP, Port FK, et al. Mortality risk in hemodialysis patients and changes in nutritional indicators: DOPPS. Kidney Int 2002;62(6):2238-2245.

3. Mutsert R, Grootendorst DC, Boeschoten EW, et al. Subjective global assessment of nutritional status is strongly associated with mortality in chronic dialysis patients. Am J Clin Nutr 2009;89(3):787-793.

4. Kwon YE, Kee YK, Yoon CY, et al. Change of nutritional status assessed using subjective global assessment is associated with all-cause mortality in incident dialysis patients. Medicine 2016;95(7).

5. Ramkumar N, Pappas LM, Beddhu S. Effect of body size and body composition on survival in peritoneal dialysis patients. Perit Dial Int 2005;25(5):461-469.

6. Kakiya R, Shoji T, Tsujimoto Y, et al. Body fat mass and lean mass as predictors of survival in hemodialysis patients. Kidney Int 2006 Aug;70(3):549-556.

7. Stephan Thijssen Nutritional Competence and Resilience among Hemodialysis.Patients in the Setting of Dialysis Initiation and Hospitalization Clin J Am Soc Nephrol 2015;10(9):1593-1601.

8. Fouque D, Kalantar-Zadeh K, Kopple J, et al. A proposed nomenclature and diagnostic criteria for protein-energy wasting in acute and chronic kidney disease. Kidney Int 2008 Feb;73(4):391-398.

9. Bossola M, Muscaritoli M, Tazza L, et al. Variables associated with reduced dietary intake in hemodialysis patients. J Ren Nutr 2005 Apr;15(2):244-252.

10. K/DOQI National Kidney Foundation. Clinical Practice Guidelines for nutrition in chronic renal failure. Am J Kidney Dis 2000; 35(suppl. 2):s1-s140. Available from www.kidney.org/Professionals/kdoqi/guidelines_updates/doqi_nut.html. Accessed on April, 2019.

11. Fouque D, Vennegoor M, Ter Wee P, et al. ERA-EDTNA European Best Practice Guideline On Nutrition. Nephrol Dial Transplant 2007;22 (2): Available http://ndt.oxfordjournals.org/content/vol22/suppl_2/index.dtl. Accessed on April, 2019. 
12. Dwyer JT, Larive B, Leung J, et al. Are nutritional status indicators associated with mortality in the Hemodialysis (HEMO) Study? Kidney Int 2005 Oct; 68(4):1766-1776.

13. Kovesdy CP, Kalantar-Zadeh K. Why is protein-energy wasting associated with mortality in chronic kidney disease? Semin Nephrol 2009 Jan;29(1):3-14.

14. T. Alp Ikizler. Optimal Nutrition in Hemodialysis Patients. Adv Chronic Kidney Dis 2013 Mar; 20(2):181-189.

15. SteiberAL, Kalantar-ZadehK, SeckerD, et al. Subjective Global Assessment in chronic kidney disease: a review. J Ren Nutr 2004 Oct;14(4):191-200.

16. Kalantar-Zadeh K, Kopple JD, Block G, Humphreys MH. A malnutritioninflammation score is correlated with morbidity and mortality in maintenance hemodialysis patients. Am J Kidney Dis 2001 Dec;38(6):1251-1263.

17. Rambod M, Bross R, Zitterkoph J, et al. Association of MalnutritionInflammation Score with quality of life and mortality in hemodialysis patients: a 5-year prospective cohort study. Am J Kidney Dis 2009 Feb;53(2):298-309.

18. Harvinder GS, Swee WC, Karupaiah T, et al. Dialysis Malnutrition and Malnutrition Inflammation Scores: screening tools for prediction of dialysisrelated protein-energy wasting in Malaysia. Asia Pac J Clin Nutr 2016;25(1):2633.

19. Abbott KC, Glanton CW, Trespalacios FC, et al. Body mass index, dialysis modality, and survival: analysis of the United States Renal Data System Dialysis Morbidity and Mortality Wave II Study. Kidney Int 2004 Feb;65(2):597-605.

20. Beddhu S, Pappas LM, Ramkumar N, Samore M. Effects of body size and body composition on survival in hemodialysis patients. J Am Soc Nephrol 2003 Sep;14(9):2366-2372.

21. Araujo IC, Kamimura MA, Draibe SA, et al. Nutritional parameters and mortality in incident hemodialysis patients. J Ren Nutr 2006 Jan;16(1):27-35.

22. Kalantar-Zadeh K, Kilpatrick RD, Kuwae N, et al. Revisiting mortality predictability of serum albumin in the dialysis population: time dependency, longitudinal changes and population-attributable fraction. Nephrol Dial Transplant 2005 Sep;20(9):1880-1888.

23. Bross R, Zitterkoph J, Pithia J, et al. Association of serum total iron-binding capacity and its changes over time with nutritional and clinical outcomes in hemodialysis patients. Am J Nephrol 2009;29(6):571-581. 
24. Antunes A, Delatim V, De Arruda Silveira, et al. Influence of protein intake and muscle mass on survival in chronic dialysis patients. Ren Fail 2010;32(9):10551059.

25. Kalantar-Zadeh K, Supasyndh O, Lehn RS, McAllister CJ, Kopple JD. Normalized protein nitrogen appearance is correlated with hospitalization and mortality in hemodialysis patients with Kt/V greater than 1.20. J Ren Nutr 2003 Jan;13(1):15-25.

26. Kang SS, Chang JW, Park Y. Nutritional status predicts 10-year mortality in patients with end-stage renal disease on hemodialysis. Nutrients 2017; 18;9(4):399.

27. Shinaberger CS, Greenland S, Kopple JD, et al. Is controlling phosphorus by decreasing dietary protein intake beneficial or harmful in persons with chronic kidney disease?. The American journal of clinical nutrition 2008;88(6):15111518.

28. Biruete A, Jeong JH, Barnes JL, Wilund KR. Modified nutritional recommendations to improve dietary patterns and outcomes in hemodialysis patients. J Ren Nutr 2017 Jan;27(1):62-70. 


\title{
CHAPTER V: DIET QUALITY AS A PREDICTOR OF POOR OUTCOMES IN HEMODIALYSIS PATIENTS AND ITS RELATIONSHIP WITH INFLAMMATION
}

\begin{abstract}
Objective: Despite major advances in dialysis technology, protocols and pharmacological treatment, hospitalization and mortality rates are highly prevalent among hemodialysis (HD) patients. Multiple diet restrictions placed upon HD patients add to the very common problem of poor diet, inadequate intake and poor dialysis outcomes. This study evaluates the association of the hemodialysis patient's diet quality index with hospitalization and mortality, and explores the relationship between diet quality and inflammation.
\end{abstract}

Design: This is a 12-month prospective cohort study that recruited 77 participants from May to Jun 2017.

Results: Fifty-five men and 22 women participated in this study; the mean age for the cohort was $63.2 \pm 15.7$ years. Their average time receiving dialysis was $6.2 \pm 4.2$ years and $58.4 \%$ of the patients were diagnosed with Type 2 diabetes mellitus; $18.2 \%$ were Hispanics, 39\% were Black, 31.2\% were Whites and 11.7\% were West Indians. In 12 months, $63.6 \%$ of participants had at least one hospitalization, 6 participants $(7.8 \%)$ underwent kidney transplant and 10 (13\%) died of cardiovascular diseases. The mean hospitalization per patient in 12 months $(\mathrm{PPY} \pm \mathrm{SD})$ was $1.1 \pm 0.2$. Survivors had a significant greater energy intake when compared with non-survivors; DEI (1917 kcal \pm 400 vs. $1615 \pm 321, \mathrm{P}=0.026)$ significant greater cereal-fiber intake (11.5 g \pm 4.4 vs 7.4 $\pm 4.4, \mathrm{P}=0.007$ ); and significant greater fruit intake (servings/day) $2.38 \pm 0.99 \mathrm{vs} 1.5 \pm$ 
0.84, $\mathrm{P}=0.009$. Participants who were not hospitalized consumed more fruit servings $(2.6$ \pm 1.06 vs. $2.08 \pm 0.95, \mathrm{P}=0.029)$ than hospitalized. The intake of two or more fruit servings per day was associated lowered mortality risk by $75 \%(\mathrm{HR}=0.246,95 \% \mathrm{CI}$ : 0.069- $0.880, \mathrm{P}=0.031$ ); and the intake of at least 7 grams of cereal fiber a day, lowered mortality risk by $81 \%(\mathrm{HR}=0.187 ; 95.0 \% \mathrm{CI}: 0.050-0.693, \mathrm{P}=0.012)$. Participants with the lowest level of inflammation $(\mathrm{NLR}<1.75)$ had a statistically significant greater AHEI score and cereal-fiber (g/day) than the rest $(\mathrm{P}<0.005)$.

Conclusion: Hemodialysis patients should be encouraged to use various food sources to meet their energy and protein requirements, as well as to satisfy at least two portions of fruits and 7 grams of cereal fiber per day to prevent cardiovascular mortality. The current MNT for dialysis should be re-considered and be liberalized to allow a more relaxing approach that facilitates greater intake and ultimately improves outcomes.

\section{Introduction}

Despite major advances in dialysis technology, protocols and pharmacological treatments, ESRD patients still are experiencing a high hospitalization and mortality rate. ${ }^{1}$ There are different factors underlying mortality in dialysis patients but the major cause of death is cardiovascular disease, which accounts for approximately $50 \%$ of deaths. ${ }^{2}$ Other causes of death are mainly from infections and withdrawal from dialysis. ${ }^{2,3}$ While the consumption of food and fluids is a vital activity for species' survival, in CKD and ESRD patients as GFR decreases, a profound decline in energy and protein intakes are manifested. ${ }^{4}$ The prevalence of anorexia has been reported between $30-55 \%$ in ESRD. ${ }^{5}$ Anorexia, itself, is an important independent cause of adverse outcomes; it has 
been associated with four times higher risk of death in this population. ${ }^{6}$ To make things even worse, the standard renal diet, distinctive by its innumerable food and nutrient's restrictions, adds to the problem of poor diet, inadequate intake and malnutrition prevalent among ESRD patients. ${ }^{7}$

The study of dietary patterns and diet quality indexes have attracted greater attention in the last decades. ${ }^{8}$ The concept of "diet quality" can be very broad, but there is a general consensus that a high-quality diet is a balanced diet that meets the individual nutritional needs and guarantees good health. ${ }^{8}$ Many new methods and approaches have recently emerged as reliable ways of determining the adequacy of dietary intake compared to specific guidelines. ${ }^{8-12,16-21}$

Dietary quality indexes have many potential applications in the field of health assessment or disease-risk assessment. ${ }^{11}$ They have proven to be practical and reliable to investigate the relationship between diet and health outcomes. ${ }^{10-12}$ Particularly, quality indexes are an easily way to assess the risk for the development of chronic diseases such as cardiovascular disease. ${ }^{12}$

An eating index is a mathematical algorithm that combines epidemiological observations about food-related concepts, in order to quantify and assign a score to the total quality of the overall diet and or eating patterns. ${ }^{11}$

Healthy dietary patterns have shown to be associated with lower mortality in people with ESRD and HD patients. ${ }^{13}$ However, dietary intake in hemodialysis patients does not reflect a heart-healthy diet, ${ }^{14}$ on the contrary, it has been reported that, in average, a dialysis patient has low consumption of fruits and vegetables and whole grains, which have been associated with cardiovascular disease risk. ${ }^{15}$ All-cause mortality 
in this population have been shown to a have significant association with inadequate intake of fruits and vegetables. ${ }^{16}$ Insufficient calorie intake has been reported as the single most limiting factor for a better diet quality and adequate energy intake improves outcomes in patients living with dialysis. ${ }^{17}$

The interrelation of diet quality with inflammation status in hemodialysis patients is not clear and the literature is contradictory. ${ }^{18,19}$ There is no specific diet quality index that has been found to better predict morbidity and mortality, specifically in patients treated with hemodialysis. ${ }^{8,9,15,20}$ Adequate nutritional intake and dietary eating patterns, including the quality of the diet may have prognostic implications for patients outcomes through mechanisms independent of nutritional status, which warrants further studies. The assessment of the diet quality of hemodialysis patients can be a useful tool for the development and application of new nutritional strategies aiming to make meaningful changes in patient's eating habits to improve their overall well-being.

To fill this gap in the literature, this study evaluated the association of the hemodialysis patient's diet quality index with hospitalization and mortality and explored the relationship between diet quality and inflammation.

\section{Methods:}

\section{Study design and population}

This is a 12-month prospective, single center study to evaluate the diet quality index of hemodialysis patients using the Alternative Healthy Eating Index (AHEI). The outcomes and endpoints of this study are hospitalization and mortality. The study was approved by the Florida International University Institutional Review Board (IRB). 
Seventy-seven participants were enrolled in the study from May 2016 to Jun 2017 and informed consent was obtained. The inclusion criteria were as follows: participants were 19 years of age or older, received hemodialysis three times per week for at least three months and were medically stable without acute infection. Patients were excluded if they were receiving any type of nutrition support via intradialytic parenteral nutrition or al nutrition, were suffering from dementia that interfered with completing the nutritional questionnaires, or refused or were unwilling to enroll in the study.

\section{Demographic and biochemical data}

Clinical and demographic data were collected from clinical charts and through ongoing interviews with the patients for 12 months. The demographic data included gender, age, ethnicity, hemodialysis start date, body max index (BMI), and diagnosis of diabetes mellitus (DM).

\section{Assessment of dietary intake}

During their hemodialysis treatments, all patients received specific dietary counseling together with menus examples, strategies and advices based on KDOQI Clinical Practice Guidelines for Nutrition in Chronic Renal Failure. ${ }^{1}$ For the purpose of this particular study, the average dietary intake of the enrolled participants were calculated from three 24-hour diet recalls, obtained during dialysis and non-dialysis days by a registered dietitian. The daily dietary intake was estimated by using a database from NutriBase 1986-2019 version 11.64 by CyberSoft, Inc. 


\section{Diet quality assessment}

The diet quality was assessed by the Alternative Healthy Eating Index (AHEI) originally developed by McCullough et al. ${ }^{21}$ using the information collected from the average of the 24-hr recalls. The total AHEI score is based on the points assigned to each food group, each contributed $0-10$ points to the total, as described elsewhere; ${ }^{21}$ a score of 10 indicates that the recommendations were fully met, a score of 0 indicates the least healthy dietary behavior and intermediate intakes were scored proportionately between 0 and 10, based on the dietitian's judgement. The items included in the original version of the AHEI score are as follows: the consumption of vegetables, fruits, nuts \&soy protein, all representing by servings per day. The white-to-red meat ratio and the cereal- fiber (g/day). The indices also include different type of fats including trans fatty acids $(\%$ of total energy), polyunsaturated -to -saturated fatty acid ratio, duration of vitamin use and alcohol intake (servings/day). The rationale for including each component and the scoring criteria are described elsewhere. ${ }^{21}$ The multivitamin component has not scaling score, it is dichotomous variable that contributes to the total AHEI score to either 2.5 points (for nonuse) or 7.5 points (for use). After all component scores are calculated and added up, then the total AHEI score ranged from 2.5, which presents the worst diet quality to 87.5, the best diet quality.

In our cohort, all participants were taking vitamins and mineral supplements, according to their prescription. A 7.5-point score was ascribed to the entire cohort for multivitamin use. None of the patients were drinking alcohol at the time that the 24-hour recalls were obtained. For alcohol consumption, all patients were ascribed a score of zero, corresponding to nonuse. 


\section{Analysis of inflammation measured by Neutrophil-lymphocyte ratio (NLR) and its relationship with diet quality}

Neutrophil-to-lymphocyte ratio (NLR) has emerged as practical marker for systemic inflammation in Chronic Kidney Disease (CKD) and ESRD. ${ }^{22}$ The ratio is calculated by dividing neutrophil count by lymphocyte count, which makes it a costeffective, simple parameter that allows to easily assess the inflammatory status of a subject. ${ }^{22,23}$ It has shown a direct correlation with albumin levels and with C-reactive protein in hemodialysis patients. ${ }^{23}$

For the analysis of the relationship between inflammation and diet, we measured NLR at baseline and participants were grouped by their NLR value into quartiles for the analysis and comparison of different levels of inflammation. quartile 1 (NLR $\leq 1.75$ ), quartile 2 (NLR 1.76-2.6), quartile 3 (NLR 2.7-3.9) and quartile 4 (NLR $\geq 4$ ), which represents the lowest to the highest level of inflammation.

\section{Endpoints: Hospitalization and mortality}

Hospitalization was defined as any hospital stay lasting one night or longer. The occurrence of hospitalization was verified over 12 months, the data included type of diagnosis for hospitalization, kidney transplant as well as death (all-cause mortality).

\section{Statistical analysis}

The final outcomes of interest in the present study were mortality and hospitalization. Normal data distribution was confirmed by the Kolmogorov-Smirnov test, the equality of variances was confirmed by Levene's test. Unpaired Student-t test, 
Mann-Whitney test were used as deemed appropriated for groups comparison.

Categorical variables were described using proportions and compared by chi-square test, odds ratios and 95\% confidence interval were calculated. Pearson and Spearman correlations were used for bivariate analysis. To evaluate independent predictors of survival we used Cox proportional hazard models. The hazard ratios were obtained from Cox regression analysis. The level of statistical significance was $\mathrm{P}<0.05$. All statistical tests were performed with SPSS version 20 software (IBM Corp., Armonk, NY, USA).

\section{Results}

\section{Demographics participant's characteristics}

Fifty-five men and 22 women participated in this study; the mean age for the cohort was $63.2 \pm \mathrm{SD} 15.7$ years. Their average time receiving dialysis was $6.2 \pm 4.2$ years and $58.4 \%$ of the patients were diagnosed with Type 2 DM; $18.2 \%$ were Hispanics, $39 \%$ were Black, $31.2 \%$ were Whites and $11.7 \%$ were West Indians. In 12 months, $63.6 \%$ of participants had at least one hospitalization, 6 participants (7.8\%) were terminated due to kidney transplant, one participant (1.2\%) was transferred to another dialysis center, and $10(13 \%)$ died of cardiovascular diseases. The mean hospitalization per patient in 12 months $(\mathrm{PPY} \pm \mathrm{SD})$ was $1.1 \pm 0.2$.

\section{Diet intake assessment}

Survivors had a significant greater energy intake when compared with nonsurvivors; DEI (1917 kcal \pm 400 vs. $1615 \pm 321, \mathrm{P}=0.026)$ while protein intake between survivors and non-survivors did not achieve statistical significance ( $81 \mathrm{~g} \pm 16$ vs. $66 \pm 11$, 
$\mathrm{P}=0.06)$. Survivor had also greater cereal-fiber intake $(11.5 \pm 4.4$ vs $7.4 \pm 4.4, \mathrm{P}=0.007)$ and greater fruit intake $(2.38 \pm 0.99$ vs $1.5 \pm 0.84, \mathrm{P}=0.009)$. No statistically significant differences were detected with the rest of the examined variables (Table 2).

When comparing patients who were not hospitalized with hospitalized patients, differences in fruit intake was statistically significant $(2.6 \pm 1.06$ vs. $2.08 \pm 0.95$, $\mathrm{P}=0.029)$ (Table 2).

\section{Multivariate cox regression analysis models for hospitalization and mortality}

Variables that were significant in univariate analysis (cereal-fiber $\mathrm{P}=0.007$; fruit $\mathrm{P}=0.009, \mathrm{P}=0.029$ ) were further analyzed in a multivariate cox regression analysis for hospitalization and mortality (Table 3 and 4).

Table 3 and Table 4 show a multivariate cox regression analysis models for mortality and hospitalization using gender, age and diabetes as covariates. The intake of two or more fruit portions per day reduced mortality risk by $75 \%(\mathrm{HR}=0.246$, 95\%CI:0.069- 0.880, $\mathrm{P}=0.031$ ); and the intake of at least 7 grams of cereal fiber a day, decreased mortality risk by $81 \%(\mathrm{HR}=0.187 ; 95.0 \% \mathrm{CI}: 0.050-0.693, \mathrm{P}=0.012)$; after adjusting by age, gender and diabetes the relationships remained significant.

\section{Diet quality-AHEI calculation}

Table 5 shows the comparison of the AHEI between survivors and non-survivors; not hospitalized and hospitalized. When survivors were compared with non-survivors, the only statistically significant differences that were detected in this analysis were in the cereal -fiber score $(6.02 \pm 2.2$ vs. $4.4 \pm 2.4 ; \mathrm{P}=0.035)$ and fruit score $(5.72 \pm 2.6$ vs. 3.4 
$\pm 2.4 ; \mathrm{P}=0.010$ ). The total score for AHEI and its individual components did not show statistically significant differences neither for mortality nor hospitalization.

\section{Analysis of inflammation measured by Neutrophil-lymphocyte ratio (NLR) and its relationship with diet quality}

Table 6 shows the comparison of the total AHEI score, sub-scores and diet components by comparing participants grouped into NLR quartiles: quartile 1 (NLR $\leq$ 1.75), quartile 2 (NLR 1.76-2.6), quartile 3 (NLR 2.7-3.9) and quartile 4 (NLR $\geq 4.0$ ). In this one-way ANOVA analysis, we detected statistically significant differences in cerealfiber $(\mathrm{g})$ across the different quartiles of inflammation; quartile 1: $9.4 \pm 4.2$, quartile 2 : 13.4 \pm 3.1 , quartile 3: $11.1 \pm 5.7$, quartile $4: 10.2 \pm 4.5 ; \mathrm{P}=0.04$ ). Total AHEI and the rest of the score and diet components did not achieve statistically significant differences among inflammation quartiles.

In addition, to analyze the differences between the lowest level of inflammation and the rest on diet quality and its components (NLR $\leq 1.75$ vs NLR $>1.75$ ). In this analysis, participants with the lowest level of inflammation had a statistically significant greater AHEI, $\mathrm{P}=0.046$; cereal fiber score, $\mathrm{P}=0.014$ and cereal-fiber ( $\mathrm{g} /$ day), $\mathrm{P}=0.008$ than the rest (Table 7). 


\section{Discussion}

In the current study, we investigated the diet quality of participants receiving hemodialysis therapy using the AHEI and examined its association with hospitalizations that were registered during the period of the study (12 months) and mortality. We also explored the association of diet quality and diet components with inflammation. The following discussion interprets these findings in the context of the existing literature.

By comparing survivors with non-survivors, we found that patients who died had lower energy intake (DEI:1615 kcal \pm 321 vs. $1917 \pm 400, \mathrm{P}=0.026)$, cereal-fiber $(11.5 \mathrm{~g}$ \pm 4.4 vs. $7.4 \pm 4.4, \mathrm{P}=0.007)$, and fruit servings per day $(1.5 \pm 0.84$ vs. $2.38 \pm 0.99$ $\mathrm{P}=0.009$ ). When comparing hospitalized with not hospitalized patients, only the intake of fruit (servings/day) was significant lower in the hospitalized participants $(2.08 \pm 0.95$ vs. $2.60 \pm 1.06, \mathrm{P}=0.029)$.

Analyzing AHEI and its components between survivors and non survivors, hospitalized and not hospitalized patients; we found that consuming at least two fruit servings per day, decreased mortality risk by $75 \%(\mathrm{HR}=0.246 ; 95.0 \%$,CI $0.069-0.880$, $\mathrm{P}=0.031$ ), and eating at least 7 grams of cereal fiber a day, decreased mortality risk by $81 \%(\mathrm{HR}=0.187 ; 95.0 \%, \mathrm{CI} 0.050-0.693, \mathrm{P}=0.012)$; when adjusted by age, gender and diabetes the relationships remained significant; however, neither AHEI total score not its individual components' scores had any significant effect on hospitalization.

Recent systematic reviews and meta-analyses stated that many dietary guidelines agree that the daily fiber intake for the general population should be at least $20-35 \mathrm{~g} /$ day to achieve optimal health. ${ }^{24}$ In the case of hemodialysis patients, the intake of fiber is far below those recommendations. ${ }^{25,26}$ Dietary restrictions for potassium, phosphorus and the 
presence of malnutrition are the major contributions to this low intake of fiber among CKD patients. Studies of the dietary intake have consistently demonstrated that fiber intake is lower than the recommended for reducing the risk of cardiovascular disease in this population. ${ }^{25}$

In our cohort, $90 \%$ of the participants reported a total fiber intake lower than $25 \mathrm{~g} /$ day. Similarly, Koueiry et al. ${ }^{14}$ conducted a cross-sectional analysis of the diet of 70 hemodialysis patients using a food frequency questionnaire validated in dialysis patients. In this analysis, the main outcome variable was dietary fiber intake, but the authors also focus on energy and protein intake, soluble fiber and fats. Even tough, the analysis included a small sample size, it is remarkable that only two participants had a fiber intake of $25 \mathrm{~g} /$ day or above. This means that $97 \%$ of the entire cohort did not meet the current recommendations for an optimal cardiovascular health. ${ }^{14}$

It is very well-known that the renal diet is one of the most difficult to teach and to follow, and that it is very unpopular among patient with kidney disease. It consists of multiple nutrient restrictions to guarantee the control within normal limits of nutritionrelated labs, including phosphorous, potassium and calcium. The emotional and physiological burden of those restrictions may present an important contribution to the reported poor intake and low diet quality seen in this population. The intake of many food groups and nutrients, including fruits and fiber are found to be insufficient among dialysis patients. ${ }^{26}$ Our results are also in agreement with what has been reported by Luis et al. ${ }^{27}$ who after examining the diet of hemodialysis patients described that their diets were potentially atherogenic, very low in fiber and high in saturated fat. The study conducted by Wai et al. ${ }^{16}$ supports the idea about an atherogenic diet profile found in most dialysis 
patients. The authors found in this study that all-cause mortality had a significant association with adequate intake of fruits and vegetables (HR: $0.35 ; 95 \% \mathrm{CI}, 0.15-0.83$ ) in patients with CKD stage 3 or 4 .

The rationale linking fruit intake and mortality was proposed by Bermejo et al., ${ }^{28}$ who claimed that a high fruit intake is a vehicle for vitamin, minerals, phytochemicals and antioxidants consumption, which may reduce homocysteine levels and improve overall cardiovascular health. ${ }^{29}$ Previous research has discussed the physiological advantages of dietary fiber in the context of renal disease. In these conditions, fiber can bind with dietary phosphorous in the gut and be excreted in feces. ${ }^{30}$ High serum levels of phosphorus have been associated with adverse outcomes in maintenance HD patients. ${ }^{31}$ In our analysis of the relationship between inflammation and diet quality, we found that in our cohort, participants in the lowest quartile of inflammation had a better diet quality (greater AHEI scores) and scored higher in cereal-fiber subcomponent when compared to the rest of the patients. Our findings suggest a beneficial potential role of cereal-fiber and overall quality of the diet in modulating inflammation and decreasing mortality, which have been reported by previous researches..$^{24,32,33}$

In an attempt to explain the association of high dietary fiber intake with decreased inflammation, several mechanisms have been proposed. ${ }^{33-36}$ Dietary fiber may modulate inflammation by lowering the absorption of dietary carbohydrates. ${ }^{34}$ High-fiber diets are associated with higher plasma levels of functional substances produced by colonic bacteria such as indoles, phenols, and amines. These functional substances are thought to have a role in systemic inflammation. ${ }^{35}$ In addition to those effects, high-fiber diet 
decreases systemic concentrations of uremic toxins by potentially altering gut bacterial metabolism. ${ }^{36}$

Unfortunately, current Medical Nutrition Therapy (MNT) for hemodialysis patients dictates that patients shift their nutrition goals from standard dietary recommendations to limit intake in many foods high in fiber including fruits, vegetables, nuts, whole grains among many others. As a result of numerous restrictions, their diet departs from what is considered a healthy, balanced and adequate diet, ${ }^{14,15,27,32}$ which may further exacerbate health complications and facilitate the unset of comorbidities associated with ESRD, including cardiovascular disease. ${ }^{38}$

\section{Limitations}

The extrapolation of our findings and the potential practical applications to other hemodialysis populations are limited by a small sample size of participants from only one hemodialysis facility. Notwithstanding the validity of the aforementioned mechanisms of actions, the long-term consequences of a low quality diet and the nutritional deficiencies corresponding to low cereal-fiber and fruit intake remain unknow. Large scale observational studies have not been conducted to determine outcomes associated with the long-term individual deficiencies observed in renal diets, and clinical control trials concerning supplementations are needed. In addition, our cut-off value for NLR was similar to that used by others; however, studies are needed to answer which NLR cut-off values are optimal and clinically meaningful. 


\section{Conclusion}

Hemodialysis patients should be encouraged to use various food sources to meet their energy and protein requirements, as well as to satisfy at least two portions of fruits and 7 grams of cereal fiber per day to prevent cardiovascular mortality. Considering the socio-economic burden associated with HD treatment, efforts must be made to support a better diet quality and to increase patient dietary choices. The current MNT for dialysis should be re-considered and liberalized to allow a more relaxing and enjoyable approach to eating that facilitates greater intake and ultimately improves outcomes. 
Table 1. Cohort's demographics characteristics and 12 month-endpoints

\begin{tabular}{lc}
\hline Variable & Mean $\pm S D$ \\
\hline Age & $62.3 \pm 12.7$ \\
Female & $28.6 \%$ \\
Years-in-dialysis & $6.2 \pm 4.2$ \\
BMI & $27.2 \pm 5.5$ \\
Diabetic & $58.4 \%$ \\
Ethnicity & \\
Hispanic & \\
AA & $18.2 \%$ \\
Caucasian & $39.0 \%$ \\
West Indian & $31.2 \%$ \\
\multicolumn{1}{c}{12 month-endpoints } \\
\multicolumn{2}{l}{} \\
Hospitalized & $11.7 \%$ \\
Hospitalized PPY & $63.6 \%$ \\
Mortality & $1.1 \pm 0.2$ \\
Hospitalized PPY= Hospitalization per patient per year
\end{tabular}


Table 2. Comparing diet components between survivors versus non-survivors and hospitalized versus not hospitalized

\begin{tabular}{|c|c|c|c|c|c|c|}
\hline Variable & $\begin{array}{l}\text { Survivors } \\
N=67\end{array}$ & $\begin{array}{l}\text { Non } \\
\text { survivors } \\
\mathrm{N}=10\end{array}$ & $\begin{array}{l}\text { P- } \\
\text { value* }\end{array}$ & $\begin{array}{l}\text { Not- } \\
\text { Hospitalized } \\
\mathrm{N}=49\end{array}$ & $\begin{array}{l}\text { Hospitalized } \\
\mathrm{N}=28\end{array}$ & $\begin{array}{l}\text { P- } \\
\text { value* }\end{array}$ \\
\hline $\begin{array}{l}\text { Energy } \\
\text { (kcal) }\end{array}$ & $1917 \pm 400$ & $1615 \pm 321$ & 0.026 & $1937 \pm 351$ & $1844 \pm 428$ & 0.332 \\
\hline $\operatorname{Protein}(\mathrm{g})$ & $81 \pm 16$ & $66 \pm 11$ & 0.061 & $80 \pm 16$ & $77 \pm 16$ & 0.441 \\
\hline Fat(g) & $73.6 \pm 24.9$ & $76.1 \pm 42.9$ & 0.778 & $77.13 \pm 27.5$ & $71.9 \pm 27.6$ & 0.427 \\
\hline Sat & $23.1 \pm 10.7$ & $20.9 \pm 15.8$ & 0.580 & $24.0 \pm 10.7$ & $22.1 \pm 11.7$ & 0.480 \\
\hline Poly & $10.5 \pm 7.4$ & $12.9 \pm 5.5$ & 0.300 & $10.7 \pm 6.8$ & $10.9 \pm 7.4$ & 0.901 \\
\hline Trans & $0.9 \pm 1.1$ & $1.0 \pm 1.4$ & 0.810 & $0.9 \pm 1.1$ & $0.9 \pm 1.2$ & 0.831 \\
\hline $\begin{array}{l}\text { Total } \\
\text { Fiber(g) }\end{array}$ & $17.7 \pm 6.6$ & $16.45 \pm 7.7$ & 0.560 & $17.8 \pm 6.7$ & $17.4 \pm 6.7$ & 0.793 \\
\hline $\begin{array}{l}\text { Cereal } \\
\text { fiber }(\mathrm{g})\end{array}$ & $11.5 \pm 4.4$ & $7.4 \pm 4.4$ & 0.007 & $11.6 \pm 5.0$ & $10.7 \pm 4.4$ & 0.424 \\
\hline $\begin{array}{l}\text { Fruit } \\
\text { (serv.) }\end{array}$ & $2.38 \pm 0.99$ & $1.5 \pm 0.84$ & 0.009 & $2.60 \pm 1.1$ & $2.08 \pm 0.95$ & 0.029 \\
\hline $\begin{array}{l}\text { Veg. } \\
\text { (serv.) }\end{array}$ & $3.02 \pm 1.2$ & $2.3 \pm 0.94$ & 0.072 & $3.0 \pm 1.3$ & $2.89 \pm 1.19$ & 0.721 \\
\hline
\end{tabular}

Table 3. Multivariate Cox regression analysis analyzing Fruit intake for mortality and hospitalizations

\begin{tabular}{lllll}
\hline & Mortality & & Hospitalizations & \\
\hline Variable & $\begin{array}{c}\text { Hazard ratio } \\
\text { CI95\% }\end{array}$ & P-value & $\begin{array}{c}\text { Hazard ratio } \\
\text { CI95\% }\end{array}$ & P-value \\
& & & & \\
Gender & $1.23(0.253-5.97)$ & 0.789 & $0.905(0.481-1.70)$ & 0.757 \\
Age & $1.00(0.962-1.05)$ & 0.785 & $0.99(0.975-1.01)$ & 0.502 \\
Diabetic & $2.88(0.587-15.12)$ & 0.192 & $1.52(0.836-2.79)$ & 0.168 \\
Fruits $(\geq 2$ ser.) & $0.24(0.69-0.88)$ & 0.031 & $0.687(0.352-1.34)$ & 0.272 \\
\hline CI=Confidence interval, statistical significance $\mathrm{P}<0.05$ & & &
\end{tabular}


Table 4. Multivariable Cox regression analyzing Cereal-fiber intake for mortality and hospitalizations

\section{Mortality Hospitalizations}

\begin{tabular}{lllll}
\hline Variable & Hazard ratio & P-value & Hazard ratio & P-value \\
& CI 95\% & & CI 95\% & \\
Gender & $1.96(0.401-9.67)$ & 0.404 & $0.952(0.507-1.78)$ & 0.879 \\
Age & $1.02(0.975-1.074)$ & 0.347 & $0.995(0.977-1.01)$ & 0.625 \\
Diabetic & $1.94(0.386-9.88)$ & 0.420 & $1.467(0.783-2.74)$ & 0.231 \\
Cereal fiber $(\geq 7$ gr. $)$ & $0.187(0.05-0.69)$ & 0.012 & $0.946(0.512-1.752)$ & 0.859 \\
\hline
\end{tabular}

$\mathrm{CI}=$ Confidence interval, statistical significance $\mathrm{P}<0.05$

Table 5. Comparing AHEI total score and its components between hospitalized versus not-hospitalized and survivors versus non-survivors

\begin{tabular}{|c|c|c|c|c|c|c|}
\hline \multirow{2}{*}{$\begin{array}{l}\text { Variable } \\
(\text { mean } \pm \text { SD } \\
\text { scores) }\end{array}$} & Survivors & $\begin{array}{c}\text { Non } \\
\text { survivors }\end{array}$ & $\begin{array}{c}P- \\
\text { value* }\end{array}$ & $\begin{array}{c}\text { Not- } \\
\text { Hospitalized }\end{array}$ & Hospitalized & \multirow[t]{2}{*}{$\begin{array}{l}P- \\
\text { value* }\end{array}$} \\
\hline & $\mathrm{N}=66$ & $\mathrm{~N}=10$ & & $\mathrm{~N}=49$ & $\mathrm{~N}=28$ & \\
\hline AHEI & $45.8 \pm 9.8$ & $41.84 \pm 9.55$ & 0.229 & $45.74 \pm 0.60$ & $45.15 \pm 9.5$ & 0.820 \\
\hline poly-to- & $7.2 \pm 2.44$ & $5.2 \pm 3.02$ & 0.062 & $5.11 \pm 3.02$ & $5.7 \pm 3.3$ & 0.450 \\
\hline $\begin{array}{l}\text { transFat } \\
\% \text { energy }\end{array}$ & $9.49 \pm 1.15$ & $9.07 \pm 2.50$ & 0.374 & $9.48 \pm 1.03$ & $9.41 \pm 1.56$ & 0.840 \\
\hline $\begin{array}{l}\text { white-to- } \\
\text { red meat }\end{array}$ & $6.3 \pm 2.9$ & $6.0 \pm 3.68$ & 0.711 & $6.30 \pm 2.98$ & $6.34 \pm 3.0$ & 0.952 \\
\hline $\begin{array}{l}\text { cereal- } \\
\text { fiber }\end{array}$ & $6.02 \pm 2.2$ & $4.4 \pm 2.4$ & 0.035 & $5.94 \pm 2.2$ & $5.7 \pm 2.3$ & 0.690 \\
\hline nuts/soy & $4.89 \pm 2.2$ & $4.5 \pm 3.2$ & 0.626 & $4.5 \pm 2.3$ & $5.0 \pm 2.3$ & 0.339 \\
\hline fruit & $5.72 \pm 2.6$ & $3.4 \pm 2.4$ & 0.010 & $6.16 \pm 2.83$ & $5.0 \pm 2.2$ & 0.067 \\
\hline vegetable & $5.64 \pm 2.94$ & $4.7 \pm 2.4$ & 0.325 & $5.72 \pm 2.87$ & $5.4 \pm 2.91$ & 0.639 \\
\hline
\end{tabular}


Table 6. Total AHEI score, sub-scores and diet components by comparing participants grouped into NLR quartiles ${ }^{\mathrm{a}}$

\begin{tabular}{lccccl}
\hline Variable & quartile 1 & quartile 2 & quartile 3 & quartile 4 & $P$ - \\
(mean $\pm S D)$ & NLR & NLR & NLR & NLR & values* \\
& $(\leq 1.75)$ & $(1.76-2.6)$ & $(2.7-3.9)$ & $(\geq 4.0)$ & \\
& $\mathrm{N}=19$ & $\mathrm{~N}=21$ & $\mathrm{~N}=18$ & $\mathrm{~N}=19$ & \\
\hline
\end{tabular}

$\underline{\text { Diet quality index (scores) }}$

$\begin{array}{lrrrrr}\text { AHEI } & 49.2 \pm 9.6 & 43.3 \pm 7.1 & 43.3 \pm 11.1 & 45.5 \pm 10.9 & 0.20 \\ & & & & & \\ \quad \text { poly-to-sat } & 5.97 \pm 3.5 & 5.1 \pm 2.8 & 5.0 \pm 3.2 & 5.7 \pm 3.4 & 0.79 \\ \text { transFat\%enery } & 9.7 \pm 0.4 & 9.2 \pm 2.0 & 9.3 \pm 9.1 & 9.5 \pm 9.2 & 0.62 \\ \text { white-to-red meat } & 6.5 \pm 3.0 & 7.9 \pm 2.5 & 6.4 \pm 2.9 & 5.3 \pm 3.4 & 0.36 \\ \quad \text { cereal-fiber } & 6.9 \pm 2.0 & 5.0 \pm 2.0 & 5.3 \pm 2.3 & 5.8 \pm 2.4 & 0.06 \\ \text { nuts/soy } & 5.2 \pm 0.9 & 4.4 \pm 2.8 & 4.3 \pm 2.8 & 5.3 \pm 2.2 & 0.50 \\ \text { fruit } & 6 \pm 2.4 & 5 \pm 2.3 & 5.1 \pm 3.1 & 5.6 \pm 2.6 & 0.63 \\ \text { vegetable } & 6.3 \pm 2.7 & 4.9 \pm 2.6 & 5.1 \pm 2.9 & 5.6 \pm 3.2 & 0.45\end{array}$

Diet components (servings)

\begin{tabular}{lclccc} 
Energy (kcal) & $1902 \pm 412$ & $1925 \pm 451$ & $1779 \pm 141$ & $1896 \pm 313$ & 0.69 \\
Protein (g) & $86.6 \pm 16.9$ & $67.2 \pm 17$ & $66 \pm 16.6$ & $82.3 \pm 14$ & 0.64 \\
Fat (g) & $64.1 \pm 27.1$ & $66.8 \pm 20.2$ & $64.4 \pm 40.7$ & $69.5 \pm 20.3$ & 0.87 \\
$\quad$ Sat.(g) & $22.7 \pm 9.8$ & $24.3 \pm 12.9$ & $23.9 \pm 15.3$ & $20.1 \pm 5.7$ & 0.67 \\
$\quad$ Poly.(g) & $11.8 \pm 8.3$ & $10.0 \pm 5.3$ & $11.3 \pm 6.7$ & $10.3 \pm 7.6$ & 0.85 \\
$\quad$ Trans.(g) & $0.6 \pm 0.6$ & $1.0 \pm 1.3$ & $1.1 \pm 1.3$ & $0.9 \pm 1.6$ & 0.50 \\
Fiber (g) & $18.7 \pm 7.6$ & $16.5 \pm 6.0$ & $17.5 \pm 6.7$ & $17.7 \pm 6.6$ & 0.77 \\
$\begin{array}{l}\text { Cereal-fiber } \\
\text { (g) }\end{array}$ & $13.4 \pm 3.1$ & $9.4 \pm 4.2$ & $11.1 \pm 5.7$ & $10.2 \pm 4.5$ & 0.04 \\
Veg.(serv.) & $3.3 \pm 1.0$ & $2.5 \pm 1.0$ & & & \\
$\begin{array}{l}\text { Fruit (serv.) } \\
\text { White/Red }\end{array}$ & $2.4 \pm 0.9$ & $2.0 \pm 0.86$ & $2.7 \pm 1.3$ & $3.1 \pm 1.2$ & 0.14 \\
meat (serv.) & $3.1 \pm 1.2$ & $3.4 \pm 0.9$ & $2.1 \pm 1.2$ & $2.4 \pm 1.1$ & 0.50 \\
$\begin{array}{l}\text { Nuts\&soy } \\
\text { (serv.) }\end{array}$ & $0.5 \pm 0.1$ & $0.4 \pm 0.3$ & $2.7 \pm 1.2$ & $2.6 \pm 1.5$ & 0.18 \\
\hline${ }^{a}$ quartile 1 (NLR $\left.\leq 1.75\right)$, quartile 2 (NLR 1.76-2.6), quartile 3 (NLR 2.7-3.9) and quartile 4 (NLR $\left.\geq 4.0\right)$ & \\
*one-way ANOVA test, statistically significant P<0.05 & & & & \\
\end{tabular}


Table 7. Total AHEI score, sub-scores and diet components by comparing participants grouped in the lowest quartile of inflammation versus the rest

\begin{tabular}{lccc}
\hline $\begin{array}{l}\text { Variable } \\
(\text { mean } \pm S D)\end{array}$ & NLR $\leq 1.75$ & NLR $>1.75$ & $P$-value* \\
\hline
\end{tabular}

\section{Diet quality index scores}

$\begin{array}{lrrr}\text { AHEI } & 49.2 \pm 9.6 & 44.0 \pm 9.6 & 0.046 \\ & & & \\ \text { poly-to-Sat } & 5.9 \pm 3.5 & 5.3 \pm 3.1 & 0.453 \\ \text { transFat\%ener } & 9.7 \pm 0.4 & 9.3 \pm 1.5 & 0.264 \\ \text { white-to-red } & 6.5 \pm 3.0 & 6.2 \pm 3.0 & 0.714 \\ \text { meat } & & & \\ \text { cereal-fiber } & 6.9 \pm 2.0 & 5.4 \pm 2.2 & 0.014 \\ \text { nuts/soy } & 5.2 \pm 0.9 & 4.7 \pm 2.6 & 0.239 \\ \text { fruit } & 6.0 \pm 2.4 & 5.2 \pm 2.7 & 0.282 \\ \text { vegetable } & 6.3 \pm 2.7 & 5.2 \pm 2.8 & 0.144\end{array}$

Diet components (servings)

\begin{tabular}{lccc} 
Energy (kcal) & $1902 \pm 412$ & $1870 \pm 402$ & 0.768 \\
Protein (g) & $80.6 \pm 16.9$ & $78.5 \pm 15.9$ & 0.624 \\
Fat (g) & $74.1 \pm 27.1$ & $73.7 \pm 27.9$ & 0.955 \\
Sat.(g) & $22.7 \pm 9.8$ & $22.8 \pm 11.9$ & 0.979 \\
Poly.(g) & $11.8 \pm 8.3$ & $10.5 \pm 6.8$ & 0.491 \\
Trans.(g) & $0.6 \pm 0.6$ & $1.0 \pm 1.2$ & 0.064 \\
Fiber(g) & $18.7 \pm 7.6$ & $17.2 \pm 6.4$ & 0.381 \\
Cereal Fiber (g) & $13.4 \pm 3.1$ & $10.2 \pm 4.8$ & 0.008 \\
Veg(serv) & $3.3 \pm 1.0$ & $2.8 \pm 1.2$ & 0.110 \\
Fruit(serv) & $2.4 \pm 0.9$ & $2.2 \pm 1.0$ & 0.469 \\
White/R(serv) & $3.1 \pm 1.2$ & $3.0 \pm 1.2$ & 0.670 \\
Nut/soy(serv) & $0.5 \pm 0.1$ & $0.4 \pm 0.2$ & 0.372 \\
\hline NLR=Neutrophil-to-lymphocyte ratio & & \\
*Student T test, statistically significant $\mathrm{P}<0.05$ & &
\end{tabular}


References

1. Saran R, Li Y, Robinson et al. US Renal Data System 2014 Annual Data Report: Epidemiology of Kidney Disease in the United States. Am J Kidney Dis 2014;66(1):A7.

2. Bloembergen WE, Port FK, et all. Causes of death in dialysis patients: racial and gender differences. J Am Soc Nephrol 1994;5(5):1231-1242.

3. O'Seaghdha CM, Foley RN. Septicemia, access, cardiovascular disease, and death in dialysis patients. Perit Dial Int 2005;25:534.

4. Kopple JD, Berg R, Houser H, Steinman TI, Teschan P. Nutritional status of patients with different levels of chronic renal insufficiency. Kidney Int Suppl 989;2(27).

5. Bossola M, Tazza L, Giungi S, Luciani G. Anorexia in hemodialysis patients: an update. Kidney Int 2006;70(3):417-422.

6. Kalantar-Zadeh K, Block G, McAllister CJ, et al. Appetite and inflammation, nutrition, anemia, and clinical outcome in hemodialysis patients. Am J Clin Nutr 2004 Aug;80(2):299-307.

7. Fouque D, Guebre-Egziabher F. An update on nutrition in chronic kidney disease. Int Urol Nephrol 2007;39:239-246.

8. Kant AK. Dietary patterns and health outcomes. J Am Diet Assoc 2004;104:615635.

9. Kelly J, Palmer SC,Wai, Ruospo M, Carrero JJ. Healthy Dietary Patterns and Risk of Mortality and ESRD in CKD: A Meta-Analysis of Cohort Studies. Clin J Am Soc Nephrol 2017;12(2):272-279.

10. Orlich MJ, Singh PN, Sabate J, et al. Vegetarian dietary patterns and mortality in Adventist Health Study 2. JAMA Intern Med 2013;173:1230-1238.

11. Waijers PM, Feskens EJ, Ocke MC. A critical review of predefined diet quality scores. Br J Nutr 2007;97:219-231.

12. Williams CM, Lovegrove JA, Griffin BA. Dietary patterns and cardiovascular disease. Proc Nutr Soc 2013;72:407-411.

13. Smyth A, Griffin M, Yusuf S, et al. Diet and major renal outcomes: a prospective cohort study. The NIH-AARP diet and health study. J Ren Nutr 2016;26:288-298.

14. Khoueiry G, Waked A, Goldman M, et al. Dietary intake in hemodialysis patients does not reflect a heart healthy diet. J Ren Nutr 2011;21:438-447. 
15. Chiu YF, Chen YC, Wu PY, et al. Association between the hemodialysis eating index and risk factors of cardiovascular disease in hemodialysis patients. J Ren Nutr 2014;24:163-171.

16. Wai SN, Kelly JT, Johnson DW, Campbell KL. Dietary patterns and clinical outcomes in chronic kidney disease: the CKD. QLD nutrition study. J Ren Nuutr 2017;27(3):175-82.

17. Kim H, Lim H, Choue R. A better diet quality is attributable to adequate energy intake in hemodialysis patients. Clin Nutr Res 2015 Jan 1;4(1):46-55.

18. Janett Barbaresko, Manja Koch. Dietary pattern analysis and biomarkers of lowgrade inflammation: a systematic literature review. Nutr Rev 2013;71(8):511-27.

19. Colman S, Bross R, Benner D, et al. The Nutritional and Inflammatory Evaluation in Dialysis patients (NIED) study: overview of the NIED study and the role of dietitians. J Ren Nutr 2005;15:231-243.

20. Stephanie M. George, Rachel Ballard-Barbash,.Comparing Indices of Diet Quality With Chronic Disease Mortality Risk in Postmenopausal Women in the Women's Health Initiative Observational Study: Evidence to Inform National Dietary Guidance. Am J Epidemiol. 2014;180(6): 616-625.

21. McCullough ML, Feskanich D Stampfer, MJ Giovannucci et al. Diet quality and major chronic disease risk in men and women: moving toward improved dietary guidance. Am J Clin Nutr 2002;76:1261-1271.

22. Okyay GU, I_nal S, O“nec, K, et al. Neutrophil to lymphocyte ratio in evaluation of inflammation in patients with chronic kidney disease. Ren Fail 2013;35:29-36.

23. Malhotra R, Marcelli D, Von Gersdorff. Relationship of Neutrophil-toLymphocyte Ratio and Serum Albumin Levels with C - reactive protein in Hemodialysis Patients: Results from 2 International Cohort Studies. Nephron 2015;130:263-270.

24. Veronese N, Solmi M, Caruso MG, et al. Dietary fiber and health outcomes: an umbrella review of systematic reviews and meta-analyses. Am J Clin Nutr 2018;107:436-444.

25. Kelly JT, Rossi M, Johnson DW, Campbell KL. Beyond sodium, phosphate and potassium: potential dietary interventions in kidney disease. Semin Dial 2017; May 30(3):197-202.

26. Kovesdy CP, Shinaberger CS, Kalantar-Zadeh K. Epidemiology of dietary nutrient intake in ESRD. Semin Dial 2010; 23: 353-358. 
27. Luis D, Zlatkis K, Comenge B, et al. Dietary quality and adherence to dietary recommendations in patients undergoing hemodialysis. J Ren Nutr 2016;26:190195.

28. Bermejo L, Aparicio A, Andres P, Lopez-Sobaler AM, Ortega RM. The influence of fruits and vegetables intake on the nutritional status and plasma homocysteine levels of institutionalised elderly people. Public Health Nutr 2007;10:266-272.

29. Perna AF, Ingrosso D, Satta E, et al: Metabolic consequences of hyperhomocysteinemia in uremia. Am J Kidney Dis 2011;38:S85-S90.

30. Reinhold JG, Faradji B, Abadi P, Ismail-Beigi F. Decreased absorption of calcium, magnesium, zinc and phosphorus by humans due to increased fiber and phosphorus consumption as wheat bread. J Nutr Rev 1991;49:204-206.

31. Kalantar-Zadeh K, Kuwae N, Regidor DL, et al. Survival predictability of timevarying indicators of bone disease in maintenance hemodialysis patients. Kidney Int 2006;70(4):771-80.

32. Lou LM, Campos B, Gimeno JA, Caverní A., and Boned B. Nutrient intake and eating habits in hemodialysis patients: comparison with a model based on Mediterranean diet. Nefrologia 2007;27: 38-45.

33. Krishnamurthy VM, Wei G, Baird BC, Murtaugh M, Chonchol MB, et al. High dietary fiber intake is associated with decreased inflammation and all-cause mortality in patients with chronic kidney disease. Kidney Int 2012; 81: 300-306.

34. Liu S, Manson JE, Buring JE, et al. Relation between a diet with a high glycemic load and plasma concentrations of high-sensitivity C-reactive protein in middleaged women. Am J Clin Nutr 2002;75:492-498.

35. Qi L, Van Dam RM, Liu S, et al. Whole-grain, bran, and cereal fiber intakes and markers of systemic inflammation in diabetic women. Diabetes Care 2006;29:207-211.

36. Evenepoel P, Meijers BK, Bammens BR, et al. Uremic toxins originating from colonic microbial metabolism. Kidney Int Suppl 2009;76:S12-S19.

37. National Kidney Foundation. KDOQI clinical practice guidelines for nutrition in chronic renal failure. Am J Kidney Dis 2000;35(2):S1-S14.

38. Biruete A, Jeong JH, Barnes JL, Wilund KR. Modified nutritional recommendations to improve dietary patterns and outcomes in hemodialysis patients. J Ren Nutr 2017;27(1):62-70. 


\section{CHAPTER VI: SUMMARY OF CONCLUSIONS AND IMPACT ON PRACTICE}

This study investigated the impact of neutrophil-to-lymphocyte ratio (NLR), nutritional status and the diet quantity/quality of 77 hemodialysis (HD) participants on clinical outcomes, specifically on mortality and hospitalization over one year. The relationships between diet quantity and nutrition markers, and between diet quality and inflammation were also explored.

High hospitalization and mortality rates are reported in HD patients; ${ }^{1}$ these outcomes have been attributed, in part, to the high prevalence of malnutrition, ${ }^{2}$ inadequate nutrition intake ${ }^{3}$ and pro-inflammatory status in this renal condition. ${ }^{4}$ However, the extent of which each of these factors contributes individually or in combination to adverse outcomes is a persistent subject of current investigations and controversies. $^{5}$

Our findings support the use of neutrophil-to-lymphocyte ratio, an inexpensive and convenient inflammation marker, as strong predictor of outcomes in hemodialysis patients, as it was suggested by research in other cohorts of hemodialysis patients and those with other conditions. ${ }^{6,7}$ Our results provide preliminary data on the protective effect that a low neutrophil-to-lymphocyte ratio might have on the risk of hospitalizations in diabetic patients receiving hemodialysis and provided significant information regarding other risk factors for hospitalization. We demonstrated a paradoxical relationship between BMI $\mathrm{kg} / \mathrm{m}^{2}$ and the number of hospitalizations; as higher BMI was associated with lower number of hospitalizations in 12 months. This epidemiological paradox, in which high BMI is associated with improved survival, is found in patients with CKD and on those undergoing hemodialysis, and it has been previously reported. ${ }^{8}$ In 
our cohort, participants with higher BMI had 10\% lower risk for hospitalization, which suggested that, in hemodialysis patients with higher BMI, higher body fat and more years in dialysis, there is a protective effect on adverse events requiring hospitalizations.

Our results demonstrated an association of nutrition-inflammation status measured by the malnutrition-inflammation score (MIS) with energy intake, reduced hospitalization events and mortality risk among hemodialysis patients. Meeting energy recommendations was shown to have a positive impact on preventing hospitalization and lowering mortality rates. We also demonstrated that MIS was more sensitive to detect protein-energy malnutrition and a stronger predictor for disease outcomes than the Subjective Global Assessment (SGA), a result with implications for practice.

The examination of the average daily intake of energy and protein in our study cohort revealed that despite advice on improving adequacy of the renal diet from dietitians, nurses, doctors, and other health professionals, a large proportion of patients did not meet KDOQI for energy and protein recommendations. Approximately only half of our participants (53\%) met KDOQI energy recommendations, while 55\% met protein recommendations and only $21 \%$ met both energy and protein recommendations. These results are supported by prior reports on dietary energy and protein intakes (DEI and DPI) in dialysis patients that clearly demonstrated that most dialysis patients do not meet KDOQI recommendations, which in turn may increase their risk of developing proteinenergy wasting (PEW) and ultimately increase morbidity and mortality rates in this population. ${ }^{9-13}$ 
In our cohort, patients who died had significantly lower energy intake, ate less fruit servings per day and consumed lower daily amounts (gm) of cereal fiber. Almost $90 \%$ of the participants reported a total fiber intake lower than $25 \mathrm{~g} /$ day. We demonstrated that consuming at least two fruit servings per day decreased mortality risk by $75 \%$ and eating at least 7 grams of cereal fiber per day decreased mortality risk by $81 \%$; however, the impact of the diet quality index (measured by AHEI) was neither significant in preventing hospitalizations nor mortality.

In our analysis of the relationship between inflammation and diet quality, we found that in our cohort, participants in the lowest quartile of inflammation had a better diet quality (greater AHEI scores) and scored higher in the cereal-fiber subcomponent when compared to the rest of the participants. Based on these findings, we proposed that hemodialysis patients should be encouraged to use various food sources to meet their energy and protein requirements as well as to satisfy at least two portions of fruits and seven grams of cereal fiber per day to prevent cardiovascular mortality.

Our study provided observational evidence for nutrition interventions that aim at improving nutrition-inflammation status and promote adequate energy, protein and fiber intakes. Our findings suggest that there are benefits in consuming greater amounts of cereal-fiber and increasing the overall quality of the diet for modulating inflammation and decreasing mortality. Considering the socio-economic burden associated with hemodialysis therapy, efforts must be made to support improving dietary options. In view of our results, we recommend that the current medical nutrition therapy for HD patients be modified to afford patients greater food choices by frequently assessing their risks for 
malnutrition and inflammation using simple scoring tools, and by tailoring their diets to their specific nutritional needs to improve clinical outcomes.

\section{References}

1. U.S. Renal Data System, USRDS 2013 Annual Data Report: Atlas of End-Stage Renal Disease in the United States, National Institutes of Health, National Institute of Diabetes and Digestive and Kidney Diseases, Bethesda, MD, 2014.

2. Lopes AA, Bragg-Gresham J, Elder SJ et al. Independent and joint associations of nutritional status indicators with mortality risk among chronic hemodialysis patients in the Dialysis Outcomes and Practice Patterns Study (DOPPS). J Ren Nutr 2010 Jul; 20(4):224-234.

3. Kovesdy CP, Shinaberger CS, Kalantar-Zadeh K. Epidemiology of dietary nutrient intake in ESRD. Semin Dial Jul 2010; 23(4):353-358.

4. Ikizler TA. Nutrition, inflammation and chronic kidney disease. Curr Opin Nephrol Hypertens Mar. 2008;17(2):162-167.

5. Fouque D, Guebre-Egziabher F. An update on nutrition in chronic kidney disease. Int Urol Nephrol 2007;39(1):239-246.

6. Li H, Lu X, Xiong R, Wang, S. High neutrophil-to-lymphocyte ratio predicts cardiovascular mortality in chronic hemodialysis patients. Mediators Inflamm. $2017 ; 2017$.

7. Huang Y, Sun Y, Peng P, et at. Prognostic and clinicopathologic significance of neutrophil-to-lymphocyte ratio in esophageal squamous cell carcinoma: evidence from a meta-analysis. Onco Targets Ther 2017 Feb;10(23):1165-1172

8. Kalantar-Zadeh K, Fouque D, Kopple JD. Outcome research, nutrition, and reverse epidemiology in maintenance dialysis patients. J Ren Nutr 2004 Apr;14(2):64-71.

9. Lorenzo V, de Bonis E, Rufino M, et al. Caloric rather than protein deficiency predominates in stable chronic hemodialysis patients. Nephrol Dial Transplant. 1995 Oct;10(10):1885-1889.

10. Cooper $\mathrm{C}$ and Beaven S. Protein and energy content of diets of patients undergoing hemodialysis for treatment of chronic renal failure-a short report. $\mathrm{J}$ Hum Nutr Diet 1993;(6):521-523.

11. Araujo IC, Kamimura MA, Draibe SA, et al. Nutritional parameters and mortality in incident hemodialysis patients. J Ren Nutr. 2006 Jan;16(1):27-35. 
12. Burrowes JD, Larive B, Cockram DB, et al. Effects of dietary intake, appetite, and eating habits on dialysis and non-dialysis treatment days in hemodialysis patients: cross-sectional results from the HEMO study. J Ren Nutr 2003 Jul;13(3):191-198.

13. Wang AY, Sanderson J, Sea MM, et al. Important factors other than dialysis adequacy associated with inadequate dietary protein and energy intakes in patients receiving maintenance peritoneal dialysis. Am J Clin Nutr 2003 Apr;77(4):834841. 


\section{CHAPTER VII: STRENGTHS AND LIMITATIONS}

Our study demonstrated that nutritional assessment, using the well-recognized Subjective Global Assessment (SGA), the Malnutrition-Inflammation Score (MIS), and/or the widely available food questionnaires, requires minimal resources to be performed periodically and systematically, integrating these practices into frequent health professionals' clinical routines. These tools provide important information to identify early patients at risk and to prevent the high hospitalization and mortality rates afflicting hemodialysis patients. However, developing strategies to effectively tackle proteinenergy wasting (PEW) for improving the clinical outcomes of these patients demands well- designed intervention studies.

The strengths of this study consisted of capturing and analyzing longitudinal data and directly assessing dietary intake, instead of indirect measurements such as those described in most of the nutritional studies conducted in patients with CKD. In addition, the 24-hour recalls were collected by a registered dietitian, who was responsible for the routine care of the participants enrolled in this study and familiar with participants' dietary practices, which ensured high accuracy of the data. The results of this study could be translated into clinically relevant nutrition interventions for hemodialysis populations.

From a clinical standpoint, our results also increase awareness on the impact of inflammation, PEW and low diet quality on patient outcomes. Patients and their family should work closely with their health-care professionals to tailor patients' diets to incorporate general renal recommendations based on the patient's individual needs, but including a variety of foods within the context of preventing cardiovascular risk. Future studies should investigate the development of effective programs and innovative 
approaches to implement PEW screening and monitoring, and a systematical assessment of qualitative and quantitative dietary intakes in hemodialysis patients.

The limitations of this study were a relatively small sample size that was recruited from one dialysis center, which makes generalization to other HD populations difficult; however, several minorities were represented in this study as well as a variety of conditions and dietary needs. A larger sample size might have allowed for calculation of relevant cut-off points for the novel biomarkers. 


\section{CHAPTER VIII: FUTURE RESEARCH}

The results from this study demonstrated that adequate fiber intake could prevent cardiovascular death and inflammatory processes in patients receiving hemodialysis therapy. Thus, the relationship of adequate fiber intake with inflammation and cardiovascular events needs further study, specifically mortality from cardiovascular disease in this population. In addition, further clinical trials of potential early interventions are warranted to evaluate the effects of different amounts of fiber intake on inflammation and to better explain the mechanisms that sustain these effects on mortality. Cut-off values for inflammation measured by Neutrophil-to-Lymphocyte Ratio (NLR) and for Malnutrition-Inflammation Score (MIS) are also desperately needed, which will require much larger sample size than the one analyzed in this study. 
VITA

\title{
JANET DIAZ MARTINEZ
}

\author{
1990-1995 B.S Food Science \\ University of Havana \\ Havana, Cuba \\ 1995-1998 M.S Molecular Biology \\ Center of Genetic Engineering and Biotechnology \\ Havana, Cuba \\ 2011-2013 M.S Dietetics and Nutrition \\ Florida International University \\ Miami, Florida, USA \\ 2017-2019 PhD in Dietetics and Nutrition Dietetics and Nutrition \\ Florida International University \\ Miami, Florida, USA
}

\section{PUBLICATIONS AND PRESENTATIONS}

Diaz Martinez J, Campa A, Delgado-Enciso I, Hain D, George F, Huffman F, Baum M. The relationship of blood Neutrophil-to-Lymphocyte ratio with nutrition markers and health outcomes in hemodialysis patients. Int Urol Nephrol 2019.

https://doi.org/10.1007/s11255-019-02166-6.

Diaz-Martinez J, Delgado-Enciso I, Burrier V, Bouchard M, Campa A. Comparing hemodialysis (HD) access type on nutrition status, hospitalization and mortality in HD patients. NKF Spring Conference 2019. Boston, MT, May 8-12, 2019.

Diaz-Martinez J, Delgado-Enciso I, Huffman F, Baum M, George F, Campa A. Nutritional Status and Dietary Intake in Predicting Mortality Among Hemodialysis Patients. Journal of Renal Nutrition 2019, Volume 29, Issue 3: 261.

Diaz-Martinez J, Martinez-Motta P, Ivan Delgado-Enciso, Fatma Huffman, Marianna K. Baum, Florence George, Adriana Campa. Diet and mortality in hemodialysis patients. ASN Conference Baltimore, MD 2019.

Diaz-Martinez J, Martinez-Motta P, Delgado-Enciso I, Huffman F, Baum M, George F, Campa A. MIS and SGA as predictors of mortality and their relationship with nutrition parameters in hemodialysis patients. ASN conference Baltimore, MD, 2019.

Diaz-Martinez J, Tamargo J, Campa A, Baum M, Huffman F. Racial/Ethnic Differences in Dietary Protein Intake, Energy Intake and Diet Quality Index Among Hemodialysis Patients. Journal of the Academy of Nutrition and Dietetics, Volume 118, Issue 10, A132, 2018. 
Diaz Martinez J, Campa A, Baum MK, Gil N, Quintero J, Kotzker W. Novel Marker of Inflammation and its Association with Nutritional Status and Dietary Intake in Hemodialysis Patients. Journal of Renal Nutrition 2018, Volume 28, Issue 2, 14.

Diaz Martinez J, Campa A, Baum M, Huffman F, Bouchard M, Kotzker W. Quantity and Quality of Dietary Intake and its relationship to Nutrition-Inflammation Status among hemodialysis patients. Nutritional Epidemiology, Current Developments in Nutrition, Volume 2, Issue 11, 1 November 2018. https://doi.org/10.1093/cdn/nzy045.

Parsons M, Baum MK, Shin D-H, Martinez JD, Williams S, Greer P, Martinez SS, Campa A. GSTM1 null-allele polymorphism, oxidative stress and HIV disease progression in an HIV-infected population. FASEB. Experimental Biology. Boston, MA, April 20-24, 2013.

Baum MK, Sherman, KE, Martinez SS, Shin D-H, Jayaweera D, Greer P, Williams S, Parsons M, Martinez J, Campa A. Apoptosis and Oxidative Stress are Associated with Liver Disease Progression in HIV/HCV Co-Infection. 20th Conference on Retroviruses and Opportunistic Infections (CROI), Atlanta, GA, March 3-6, 2013.

Nutritionist designated by the legislature to co-write the ban on the sale of junk foods in public schools, which became law in 2008 and published in the Official Gazette of the Government of the State of Colima.

Manual "Traditional Mexican food. Healthy recipes for low income families". DIF Mexico, 2000.

Senior Thesis: "Folic acid supplementation in Cuban pregnant women" Cuba, 1996. 